\title{
Do Superstitious Traders Lose Money?
}

\author{
Utpal Bhattacharya ${ }^{1}$ \\ Wei-Yu Kuo ${ }^{2}$ \\ Tse-Chun Lin $^{3}$
}

Jing Zhao ${ }^{4}$

\begin{abstract}
$\underline{\text { Abstract }}$
Do superstitious traders lose money? We answer this question in the context of trading in the Taiwan Futures Exchange, where we exploit the Chinese superstition that the number " 8 " is lucky and the number "4" is unlucky. We find that individual investors, but not institutional investors, submit disproportionately more limit orders at " 8 " than at " 4 ." This imbalance, defined as "superstition index" for each investor, is positively correlated with trading losses. Superstitious investors lose money mainly because of their bad market timing and stale orders. Nevertheless, the reliance on number superstition for limit order submissions does decrease with trading experience.
\end{abstract}

Keywords: superstition, limit order clustering, investment performance, individual investors

JEL Classifications: D14, G02, G14, G15

We thank two anonymous referees and an AE for their insightful comments, and the Taiwan Futures Exchange for providing the data. Wei-Yu Kuo would like to express his gratitude to the Ministry of Science and Technology of Taiwan (project numbers MOST 103-2410-H-004-077-MY2) and E.SUN Commercial Bank for their financial support. Tse-Chun Lin gratefully acknowledges the research support from the Faculty of Business and Economics, the University of Hong Kong, and the Research Grants Council of the Hong Kong SAR government. We also thank Darwin Choi, Mark Grinblatt, Craig Holden, Stacey Jacobsen, Jay Ritter, Noah Stoffman, and seminar participants at Chinese University of Hong Kong, CKGSB, Indian Institute of Technology (Kharagpur), Peking University (both in Beijing and in Shenzhen), RSM Erasmus, University of Florida, Tsing Hua University, Southwestern University of Economics and Finance, Wuhan University, Zhongnan University of Economics and Law, Fudan University, National Chung Cheng University, Singapore Management University, Australasian Finance and Banking Conference (2014), China International Conference of Finance (2015) and Financial Management Association's Annual Meeting (2015) for their comments. Any remaining errors are ours.

${ }^{1}$ Corresponding author: Address: Hong Kong University of Science and Technology, Clear Water Bay, Kowloon, Hong Kong. Fax: 852-2358-1749. Tel: 852-2358-8498. Email:ubhattac@ust.hk.

${ }^{2}$ National Chengchi University. Tel.: +886-2-2939-8033. E-mail address: wkuo@nccu.edu.tw.

${ }^{3}$ University of Hong Kong. Tel.: +852-2857-8503. E-mail address: tsechunlin@ @ku.hk.

${ }^{4}$ Hong Kong Polytechnic University. Tel.: +852-2766-4539. E-mail address: jingzhao@ polyu.edu.hk. 


\title{
Do Superstitious Traders Lose Money?
}

\begin{abstract}
$\underline{\text { Abstract }}$
Do superstitious traders lose money? We answer this question in the context of trading in the Taiwan Futures Exchange, where we exploit the Chinese superstition that the number "8" is lucky and the number "4" is unlucky. We find that individual investors, but not institutional investors, submit disproportionately more limit orders at " 8 " than at " 4 ." This imbalance, defined as "superstition index" for each investor, is positively correlated with trading losses. Superstitious investors lose money mainly because of their bad market timing and stale orders. Nevertheless, the reliance on number superstition for limit order submissions does decrease with trading experience.
\end{abstract}

Keywords: superstition, limit order clustering, investment performance, individual investors

JEL Classifications: D14, G02, G14, G15 
Superstition, which is defined as a belief that is not based on reason, has been a part of the human condition since humans began. ${ }^{1}$ Michael Jordan, arguably the greatest basketball player of all time, wore his University of North Carolina shorts under his uniform every time he led the Chicago Bulls to their six NBA championships. ${ }^{2}$ The European governing body of Formula 1 auto racing, which is based in Paris and Geneva, bans the number " 13 " in its entry list for cars. ${ }^{3}$ India's Independence Day falls a day after Pakistan's because astrologers in India insisted that August 14, 1947, was an inauspicious day to become independent. ${ }^{4}$ The Games of the XXIX Summer Olympics opened in Beijing on August 8, 2008, at 8:08 p.m. because the number " 8 " is a lucky number in Chinese culture. In contrast, Chinese culture considers the number "4" to be unlucky. For instance, some buildings in China have no fourth floor (Kramer and Block, 2008), and there is an unwritten rule in the Taiwan Navy that the digits of a naval vessel's number should not add up to four (Tsang, 2004).

It is surprising, considering how pervasive superstition is globally, that there is no academic research, as far as we know, on the effect of superstition on individual trading decisions and investment performance. This paper is one such piece of research that aims to add to the emerging literature on the behavior of retail investors. Specifically, we investigate whether some investors carry their superstitious beliefs in numbers over to their trading, how this type of superstitious trading behavior affects their investment performance, and, lastly, whether learning by trading helps investors alleviate their reliance on their number superstition.

We answer these questions by examining limit order submissions in the Taiwan Futures Exchange (TAIFEX). In Mandarin, the official language of Taiwan, the pronunciation of the number " 4 " sounds like "death" and is regarded as inauspicious. On the contrary, the number " 8 " is considered auspicious as its pronunciation sounds like "good fortune." If Mandarin-speaking investors prefer the

\footnotetext{
${ }^{1}$ Miller and Taylor (1995) and Kramer and Block (2008) provide some theoretical underpinnings to explain the effect of superstitious beliefs on decision making.

${ }^{2} \mathrm{http} / / / \mathrm{www} . m e n s f i t n e s s . c o m /$ life/sports/10-most-superstitious-athletes

${ }^{3} \mathrm{https}$ ://joesaward.wordpress.com/2009/12/01/why-there-is-no-number-13-in-formula-1/

${ }^{4}$ http://mukto-mona.net/Articles/mehul/superstition_india271205.htm 
number " 8 " over the number "4," we might observe disproportionately more limit orders submitted at prices ending with the number " 8 " and disproportionately fewer limit orders submitted at prices ending with the number " $4 . " 5$

Taking advantage of the account-level trades and quotes records of index futures in TAIFEX, we show that individual investors are indeed affected by this number superstition when submitting limit orders. The submission ratio at " 8 ," calculated as the limit orders submitted at prices ending with " 8 " over all submitted limit orders, is $0.098 .^{6}$ This ratio is significantly higher than 0.063 , the submission ratio at prices ending with " 4 ." In contrast, the difference between the submission ratios at these two numbers is not significant for domestic institutional investors nor for Qualified Foreign Institutional Investors (QFIIs). In particular, for domestic institutional investors, the submission ratio at " 8 " is 0.103 , while the submission ratio at "4" is 0.100 . The submission ratios at "8" and "4" for QFIIs are 0.097 and 0.094 , respectively. These results indicate that individual investors use heuristics based on number superstition when making investment decisions, whereas institutional investors, domestic or foreign, do not.

Next, we investigate the association between investors' number superstition and their investment performance. To empirically test this association, we calculate the limit order submission ratios at prices ending at $0,1,2, \ldots 9$ as the number of limit orders submitted at that price point scaled by the total number of limit orders submitted at all price points. We then construct a superstition index for each

\footnotetext{
${ }^{5} \mathrm{We}$ focus on the last digit because the effect of superstitious beliefs is more likely to be present in this digit. In most trading days within our sample period, only the last two digits of the four-digit Taiwan futures index move, the last digit (right-most digit) moving the most. Therefore, it is reasonable to assume that investors mostly concentrate on the last digit when making their trading decisions. In this sense, our paper is distinct from the price barrier literature, such as Ley and Varian (1994), who show that prices behave differently when they approach round numbers like 100 and 1000 . They focus on the left-most digit while we focus on the right-most digit. Meanwhile, unlike the left-most digit, there is no evidence that the right-most digit of prices follows Benford's Law (Benford, 1938, and Ley, 1996). In our case, if investors are not superstitious, we would observe a uniform distribution of the last digit of limit order prices.

${ }^{6}$ We find that the limit orders submission ratios at prices ending with " 0 " and " 5 " of individual investors are 0.249 and 0.148 , respectively. This is consistent with the notion that individual investors' limit order tend to cluster at round numbers (Kuo, Lin, and Zhao, 2015).
} 
investor by calculating the difference between his limit order submission ratios at prices ending at "8" and at "4." 7 The higher the superstition index, the more superstitious an investor is.

After sorting individual investors into five groups according to their superstition indices in the current year, we find that individual investors with a higher degree of number superstition have significantly lower intraday, 1-day, and 5-day mark-to-market index returns of their executed limit orders in the subsequent year. The individuals within the top-quintile of the superstition index underperform their counterparts within the bottom-quintile of the superstition index by 1.7 basis points within a trading day. The underperformance deteriorates to 2.4 (6.3) basis points one (five) day(s) after the limit order executions. In addition, we also find underperformance of superstitious individual investors for their market orders and round-trip trades. Specifically, the underperformance of intraday market orders is 1.3 basis points, which is similar in magnitude as the underperformance of the intraday limit order returns.

The negative association between superstition index and subsequent investment performance remains significant after controlling for several factors that are known to be related to investment performance. These factors include the wealth (proxied by the average order size), cognitive limitation (proxied by the round-number limit order submission ratio used in Kuo, Lin, and Zhao, 2015), experience (proxied by the number of limit orders submitted in the previous year), the disposition effect, and the past performance. We also find similar results based on a two-stage regression. In particular, we first regress the superstition index on the concurrent control variables to extract the residual superstition index. We then regress the investment performance on the residual superstition index which, by construction, is orthogonal to the control variables. Both findings indicate that the number superstition captures a distinct aspect of investors' trading skill that is negatively related to their investment performance.

We then perform two sets of placebo tests to check the robustness of the negative link between superstition and trading performance. First, since we find that limit order submissions of institutional investors are not affected by lucky/unlucky numbers, we should not find the superstition index to be

\footnotetext{
${ }^{7}$ The superstition index is calculated using all submitted limit orders, while the investment performance is calculated only using the executed ones.
} 
associated with investment performance for these investors. Our results are in line with this intuition. Second, we construct a pseudo superstition index using the difference between submission ratios at "7" and "3." The numbers "7" and "3" are viewed as neither lucky nor unlucky in Chinese culture. We find that the pseudo superstition index is not correlated with investment performance, which lends further support to our main findings. ${ }^{8}$

We next explore why superstitious investors lose money. We find that superstitious individual investors have bad market timing as they buy less (more), compared with their non-superstitious counterparts, on trading days with high (low) market returns. This could be partly driven by the fact that their limit orders become stale in the absence of active monitoring after submission, and other traders take advantage of this by hitting their limit orders with a buy (sell) order immediately after good (bad) news. Our results indicate that the limit orders submitted by superstitious individual investors do have longer time-to-execution and time-to-cancellation for both buy and sell orders. We go on to show that institutional investors, both domestic and foreign, make money from the most superstitious traders.

Finally, we examine whether investor learning could mitigate the reliance on the number superstition for submitting limit orders. Seru, Shumway, and Stoffman (2010) find that some individual investors may become better at trading with experience. In our context, investors might become less affected by the superstitious number heuristics when they learn from past trading experience. To test this learning-by-trading hypothesis, we regress the difference of superstition index between two consecutive years on the number of limit orders submitted in the previous year. We use the difference in superstition index to control for the unobserved invariant investor characteristics. Our result shows that past trading frequency helps to reduce individual investors' propensity to submit superstitious limit orders. A onestandard-deviation (51 limit orders) increase in the number of limit orders submitted in the previous year

\footnotetext{
${ }^{8}$ We also consider two more pseudo superstition indices, the differences between submission ratios at "7" and " 2 " and those at "2" and " 3 ." We do not find a significant association between these two pseudo superstition indices and investment performance either. These results are not tabulated but, like all other successive untabulated results, are available from the authors on request.
} 
leads to a $0.74 \%$ more reduction of the superstition index in the current year. We further find that, though trading experience reduces superstition, this learning effect diminishes over time.

Alternatively, investors could learn in a naïve and reinforced way from their past performance. Chiang, Hirshleifer, Qian, and Sherman (2011) show that high returns in previous IPO auctions increase the likelihood of participating in future auctions, and both bidders' returns and their auction selection abilities deteriorate afterwards. However, we do not find supportive evidence for this reinforcement learning, as individual investors do not submit more limit orders at " 8 " when they observe higher returns of orders submitted at these lucky prices.

Our paper contributes to the literature on retail investor behavior, the field that deals with the psychological biases that affect individual trading decisions (biases like overconfidence or disposition effect) and the consequences of these biases on investment performance. ${ }^{9}$ Specifically, we explore one particular type of heuristics that some investors have when making trading decisions: reference points based on number superstition. Since the seminal work by Tversky and Kahneman (1974), there have been many studies exploring how people rely on reference points when making choices under uncertainty. For example, 52-week high stock prices have been shown to influence financial decisions among various market participants. ${ }^{10} \mathrm{~A}$ number of studies find that round number prices serve as reference points in financial decision making as well. ${ }^{11}$ Although there are few studies on lucky and unlucky numbers as reference points, we provide the first attempt to show that some retail investors use lucky and unlucky

\footnotetext{
${ }^{9}$ Barber and Odean (2013) provide an excellent survey of this field.

${ }^{10}$ The following have been influenced: corporate managers (Baker, Pan, and Wurgler, 2012), employees (Heath, Huddart, and Lang, 1999), options traders (Poteshman and Serbin, 2003; Driessen, Lin, and Van Hemert, 2013), stock traders (George and Hwang, 2004; Li and Yu, 2012), and analysts (Birru, 2015; Li, Lin, and Lin, 2015).

${ }^{11}$ See, for example, Neiderhoffer (1965, 1966); Ball, Torous, and Tschoegl (1985); Harris (1991); Curcio and Goodhart (1991); Donaldson and Kim (1993); Christie and Schultz (1994); Christie, Harris, and Schultz (1994); Ley and Varian (1994); Gwilym, Clare, and Thomas (1998a, 1998b); Booth, Kallunki, Lin, and Martikainen (2000); Palmon, Smith, and Sopranzetti (2004); Sonnemans (2005); and Bhattacharya, Holden and Jacobsen (2012).
} 
numbers to make their trading decisions, and their trading profits are related to the reliance on this heuristic. $^{12}$

The fact that superstitious individuals exist in the world may be obvious. However, it is not clear that they carry their superstition to trade important assets like a stock index futures. Further, as heuristics are often efficient thumb rules that govern decisions under uncertainty, it is not clear that all heuristics used in financial decision-making lead to losses. Superstitious investors may not lose money if their superstitious beliefs in numbers, though interesting in its own right, is irrelevant to their trading prowess. Thus, finding out why they lose money - bad market timing and stale orders - sheds more light on our understanding of the retail investor behavior.

Lastly, our paper also adds to the household finance literature, a literature Campbell (2006) succinctly motivates in his AFA presidential address: "The welfare benefits of financial markets depend in large part on how effectively households use these markets." Our results indicate that some retail investors use financial markets unwisely, and so there may be room for financial education to improve their welfare as we show that learning mitigates the reliance of retail investors on number superstition.

\section{Hypotheses Development from the Literature}

\section{A. Limit Orders Submitted at Prices Ending with Lucky and Unlucky Numbers}

The psychology literature documents that superstitious beliefs affect individuals' optimism (e.g., Darke and Freedman, 1997). Superstitious beliefs also affect the willingness to take financial risks. ${ }^{13}$ Recent studies on real estate prices show that housing prices are inflated when the floor number or the

\footnotetext{
${ }^{12}$ For example, Kolb and Rodriguez (1987) find that during the period from 1962 to 1985 , the mean CRSP index return for Friday the Thirteenth is significantly lower than that for other Fridays. However, Dyl and Maberly (1988) do not find the same result according to S\&P index return data from 1940 to 1987.

${ }^{13}$ Using cognitive priming experiments, Jiang, Cho, and Adaval (2009) find that Asian individuals, who are exposed to lucky numbers, give higher estimates of their chances of winning a lottery, are more willing to participate in a lottery or a risky promotional game, and express greater willingness to make risky financial investments.
} 
number in the address is a lucky one. ${ }^{14}$ In financial markets, there is limited evidence that numerical superstitious beliefs matter. ${ }^{15}$ Hirshleifer, Jian, and Zhang (2016) find that newly listed Chinese firms are more likely to have lucky numbers in their listing codes. The firms with lucky listing codes are traded at a premium and experience inferior post-IPO abnormal returns. Brown, Chua, and Mitchell (2002) and Brown and Mitchell (2008) show that the daily opening and closing prices cluster at the number " 8 " in Asian Pacific and Chinese stock markets.

IPO listing codes and transaction prices do not directly reflect the number preference of individual investors, as investors do not directly control listing codes or transaction prices. In contrast, individual investors directly choose the prices for their limit orders. The question is which digit of the four-digit TAIFEX index investors are most likely to focus on when they submit their limit orders. Although the price of index futures in TAIFEX ranges from 4,011 to 9,934 during our sample period, the average daily standard deviation and daily price range are only around 26 and 87 index points, respectively. On most trading days within our sample period, only the last two digits of the four-digit index fluctuate. Furthermore, since a tick size is one index point, and an investor can only observe the five best asks and bids in the limit order book, the effect of superstitious beliefs is most likely to appear in the last digit of the four-digit index. ${ }^{16}$

If investors are not affected by their superstitious beliefs, the last digit of limit order prices should be uniformly distributed. If, on the contrary, individual investors take lucky/unlucky numbers into account when submitting limit orders, it would lead to a disproportionately large (small) volume of limit orders submitted at prices ending with lucky (unlucky) numbers. This gives us our first hypothesis:

\footnotetext{
${ }^{14}$ See, for example, Agarwal, He, Liu, Png, Sing, and Wong (2014); Shum, Sun, and Ye (2014); and Fortin, Hill, and Huang (2014).

${ }^{15}$ Dichev and Janes (2003), Yuan, Zheng, and Zhu (2006), and Lepori (2009) show that the occurrence of negative superstitious events (i.e. eclipses) is associated with lower trading volumes and lower stock returns.

${ }^{16}$ Take the limit order book at 13:45 on September 12, 2014, for example. The best five bid prices are 9244, 9243, 9242, 9241, and 9240, while the best five ask prices are 9245, 9246, 9247, 9248, and 9249, respectively. The only difference among these best five bids and five asks is in the last digit.
} 
Hypothesis 1: Individual investors submit a disproportionately large volume of limit orders at prices ending with " 8 " and submit a disproportionately small volume of limit orders at prices ending at “4.” Moreover, institutional investors, particularly QFII, are not subject to this number superstition.

Domestic institutional investors may not be affected by number superstition if their order submissions hinge on their professional analyses. For the foreign institutional investors, as the number superstition originates from the Mandarin language, this type of superstition should be even more irrelevant to their financial decision making. ${ }^{17}$ We thus expect limit order submissions to be uniformly distributed in the last digit for institutional investors.

\section{B. Superstition and Investment Performance}

There exist two intimately related causes why the superstition index might be negatively related to the subsequent investment performance of an individual investor. First, superstition might reflect an investor's overall trading skills, and this leads to a negative correlation between superstition index and investment performance. This inferior trading skill could be due to lower abilities in information gathering and information processing. As the trading skill has been linked to other investor characteristics like wealth, experience, cognitive ability, and other behavioral biases like the disposition effect, it is important to show that the negative relation between our superstition index and investment performance remains significant even after controlling for these investor characteristics.

For example, Geng, Li, Subrahmanyam, and Yu (2014) find that the wealthy investors in China beat the performance of the market portfolio by a large margin. Seru, Shumway, and Stoffman (2010) show evidence that trading experience helps to improve investment decisions. Cognitive ability, proxied by an investor's IQ, is found to be associated with his wealth level, stock market participation, investment performance, and mutual fund choice (Grinblatt, Keloharju, and Linnainmaa, 2011, 2012; and Grinblatt, Ikäheimo, Keloharju, and Knüpfer, 2016). Similarly, Kuo, Lin, and Zhao (2015) employ the proportion of

\footnotetext{
${ }^{17}$ Institutional investors from China, who may be subject to the same numerical superstition, did not trade in the Taiwanese financial markets during our sample period.
} 
limit orders submitted at round number prices as a proxy for cognitive limitation and show a negative correlation between cognitive limitation and investment performance. Further, Odean (1998) finds that investors who are reluctant to realize their losses - the disposition effect - have lower subsequent returns. In our multivariate regressions, we incorporate these known characteristics as control variables. Our result is robust to controlling for this set of proxies for poor trading skills.

Second, even when an investor has average trading skills, his number preference originating from superstition might result in a suboptimal submission strategy of limit orders, which also leads to a negative relation between our superstition index and limit order performance. For example, when it is optimal to submit a limit order ending at "7" or "9," a superstitious investor might choose to submit at "8," which results in a lower performance at "8." For another example, when it is optimal to submit at “4," a superstitious investor might submit at " 3 ," "5," or any other number, which also leads to the underperformance for limit orders whose prices end with numbers other than " 4. "

We thus propose our second hypothesis as follows:

Hypothesis 2: An investor's superstition level is negatively associated with his subsequent investment performance.

To test our second hypothesis, we calculate a superstition index for each investor in the following way. We first calculate the limit order submission ratios at prices ending at $0,1,2, \ldots 9$ as the number of limit orders submitted at that price point scaled by the total number of limit orders submitted at all price points. A superstition index is then constructed for each investor by calculating the difference between his limit order submission ratios at prices ending at " 8 " and at " 4 ." The higher the index, the higher the number superstition of an investor. In the empirical section, we do find that superstitious investors underperform and exhibit some suboptimal limit order submission strategies like bad market timing or stale limit orders. They also lose money at all price points to institutional investors.

\section{Investor Learning}


The investor learning literature has shown that past trading experience has an impact on investment decisions. One line of literature focuses on learning by trading. Feng and Seasholes (2005) and Dhar and Zhu (2006) both find that investors' trading experience, measured as trading frequency, mitigates the reluctance to realize losses. Seru, Shumway, and Stoffman (2010) show that some individual investors become better at trading when they become more experienced, while others stop trading after realizing that they have poor trading skills. Their findings show a positive influence of investor learning on future investment performance.

Another line of investor learning literature argues that investors could learn in a naïve and overoptimistic way. For example, Choi, Laibson, Madrian, and Metrick (2009) find that individual investors over-extrapolate from their personal experience when making savings decisions in their 401(K) accounts. Chiang, Hirshleifer, Qian, and Sherman (2011) document that when a bidder had high returns in previous IPO auctions, he is more likely to participate in future auctions. Nevertheless, the returns and the auction selection ability deteriorate with his previous IPO auction returns. Their findings show that reinforcement learning based on past investment performance could negatively affect future performance.

It is important to note that the two lines of literature use different measures for learning; the former uses past trading experience (frequency) and the latter uses past returns. In our context, if investors learn from trading experience, we should observe that they become less superstitious when more trading experience is accumulated. If investors learn in a naïve way, they may submit more orders at " 8 " when their limit order returns at " 8 " are high, and less orders at " 4 " when limit order returns at "4" are low. We thus propose the following hypotheses:

Hypothesis 3.A (Learning by Trading): The change in an investor's superstition index between two years is negatively associated with the investor's trading frequency in the previous year.

Hypothesis 3.B (Reinforcement Learning): The change in an investor's superstition index between two years is positively (negatively) associated with investor's performance of limit orders submitted at "8” (“4”). 


\section{Data Description}

\section{A. The Taiwan Futures Exchange}

TAIFEX employs an Electronic Trading System (ETS) to process orders submitted by market participants from 8:45 a.m. to 1:45 p.m. The two major types of product traded in TAIFEX include the Taiwan Stock Exchange Index Futures (hereafter TXF) and the Mini-Taiwan Stock Exchange Index Futures (hereafter MXF). The TXF is based on all listed stocks on the Taiwan Stock Exchange and the MXF is a mini version of the TXF with a quarter of the margin and payoff for the TXF. The tick size of both contracts is one index point. One index point increase in the transaction price yields a profit of 200 (50) New Taiwanese Dollar (TWD) for one TXF (MXF) contract. ${ }^{18}$ Both types of index futures have five maturity months: the spot month, the next calendar month, and the next three quarterly months. Each type of index futures with a certain maturity month is traded as one unique product in TAIFEX. ${ }^{19}$

\section{B. Submitted and Executed Limit Orders}

We use all the limit order submission and execution records in TAIFEX during the period from January 2003 to September 2008. The data contain detailed information about investor account identity and investor type (individual investors, domestic proprietary investors, or Qualified Foreign Institutional Investors (QFIIs)). We are thus able to examine the superstitious behavior of different investor types.

Panel A of Table I shows that there are about 108 million limit orders submitted by market participants during the sample period. Among these orders, $61.87 \%$ are from individual investors, $34.17 \%$ from domestic proprietary investors, and 3.96\% from QFIIs. Panel B of Table I shows that there are about

\footnotetext{
${ }^{18}$ One US Dollar is around 30 TWD during our sample period.

${ }^{19}$ More institutional details for TAIFEX can be found in Liu, Tsai, Wang, and Zhu (2010), Li, Lin, Cheng, and Lai (2013), Kuo and Lin (2013), and Kuo, Lin, and Zhao (2015).
} 
143 million limit order contracts transacted during our sample period. ${ }^{20}$ Individual investors account for $73.20 \%$ of the transaction volume, while domestic institutional investors and QFIIs together account for the rest. Notice that one very important feature in TAIFEX is that individual investors, instead of institutional investors, are the major market participants. This market, therefore, provides us with an ideal environment to study the number superstition in trading among individual investors. Its second advantage is that index futures, unlike stocks, is a single product with a single large and liquid market, and so we do not have to control for various cross-sectional firm-specific stock characteristics.

\section{(INSERT TABLE I HERE)}

When investigating the link between number superstition and investment performance, we require that investors submit at least 10 limit orders in each of two consecutive years to generate a meaningful estimate of the superstition index. ${ }^{21}$ After applying this screen, we obtained 125 million trades and 156,171 investor-year observations.

\section{Limit Orders at Prices Ending with Lucky and Unlucky Numbers}

\section{A. Limit Order Submissions among Different Investor Types}

To identify number superstition, we focus on the last digit of limit order prices. For example, if the limit order price is 6,508 , we characterize the order as submitted at a price ending with the lucky number "8." Similarly, the limit order with a price of 6,504 is treated as an order submitted at a price ending with the unlucky number "4." The same logic is applied to other numbers in the last digit. We then calculate the limit order submission ratios at prices ending with a number " $\mathrm{X}$ " for the individual investors, domestic institutional investors, and QFIIs as follows:

$$
\text { SubRatio }_{X}=\frac{\text { Number of limit orders submitted at "X" }}{\text { Total number of submitted limit orders }}
$$

\footnotetext{
${ }^{20}$ Individual investors typically trade one or two contracts in one order, while institutional investors typically trade more contracts in one order. The overall execution ratio for submitted contracts is around 0.444 .

${ }^{21}$ The same data filter is adopted in Kuo, Lin, and Zhao (2015).
} 
The submission ratio measures the proportion of limit orders submitted at prices ending with " $\mathrm{X}$ " ( $\mathrm{X}$ is an integer ranging from 0 to 9). Theoretically, if investors trade index futures based on information or hedging needs, their limit orders should be equally likely to be submitted at prices ending with any integer ranging from 0 to 9 . So this ratio should be 0.1 for each of the $10 \mathrm{Xs}$. However, if investors are affected by the superstition heuristic, they would submit disproportionately more limit orders at prices ending with " 8 " (the lucky prices) and fewer limit orders at prices ending with " 4 " (the unlucky prices). ${ }^{22}$

Figure 1 shows the limit order submission ratio for each of the 10 last digits separately for individual investors, domestic institutions, and QFIIs. Figure 1.A shows that individual investors indeed submit more limit orders at " 8 " than those at "4." The submission ratio is 0.098 at " 8 ," which is much higher than the 0.063 at " 4 ." The statistical significance of the difference in these two submission ratios will be presented in the regression analysis in the next sub-section. Figure 1.A also shows that individual investors tend to submit more limit orders at round numbers " 0 " and " 5 ." This is consistent with the limit order clustering at round number prices documented in Kuo, Lin, and Zhao (2015). Figure 1.B shows a fairly uniform distribution of submission ratio for domestic institutions. In particular, the submission ratio at " 8 " is 0.103 , while the submission ratio at " 4 " is 0.100 . A similarly flat pattern for QFIIs is observed in Figure 1.C, where the submission ratios at " 8 " and "4" are 0.097 and 0.094 , respectively.

\section{B. Multivariate Regression Analyses}

In this sub-section, we test the statistical significance of the number superstition through multivariate regression analyses. For each limit order, we are able to determine if it is submitted by an

\footnotetext{
${ }^{22}$ In addition to the superstition for price, we also consider the superstition for date. We examine the proportion of limit orders submitted on each date of the month. The logic is that if investors prefer the number 8 over 4 , they might submit more limit orders on the $8^{\text {th }}$ of the month relative to the $4^{\text {th }}$ of the month. However, we do not find supportive evidence for date superstition. Figure A1.A in the Appendix shows that the submission ratio on the $8^{\text {th }}$ of the month is not significantly higher than that on the $4^{\text {th }}$ of the month for individual investors. The same is true for domestic institutions (Figure A1.B in the Appendix) and QFII (Figure A1.C in the Appendix).
} 
individual investor, a domestic institution, or a QFII, and if it is to trade the MXF or the TXF. We run the following regression:

$$
\begin{aligned}
& \text { SubRatio }_{X}-0.1 \\
& =\alpha+\beta_{1} D_{8}+\beta_{2} D_{4}+\beta_{3} D_{0}+\beta_{4} D_{5}+\left(\beta_{5} D_{8}+\beta_{6} D_{4}+\beta_{7} D_{0}+\beta_{8} D_{5}\right) \times D_{\text {indv }} \\
& +\left(\beta_{9} D_{8}+\beta_{10} D_{4}+\beta_{11} D_{0}+\beta_{12} D_{5}\right) \times D_{Q F I I}+\left(\beta_{13} D_{8}+\beta_{14} D_{4}+\beta_{15} D_{0}+\beta_{16} D_{5}\right) \\
& \times D_{M X F}+\left(\beta_{17} D_{8}+\beta_{18} D_{4}+\beta_{19} D_{0}+\beta_{20} D_{5}\right) \times D_{\text {indv }} \times D_{M X F} \\
& +\left(\beta_{21} D_{8}+\beta_{22} D_{4}+\beta_{23} D_{0}+\beta_{24} D_{5}\right) \times D_{Q F I I} \times D_{M X F}+\beta_{25} D_{i n d v}+\beta_{26} D_{Q F I I} \\
& +\beta_{27} D_{M X F}+\varepsilon_{X}
\end{aligned}
$$

The dependent variable is the deviation of the actual submission ratio at prices ending with " $\mathrm{X}$ " from its theoretical value, 0.1 , under the assumption that the last digit of the prices of submitted limit orders follows a uniform distribution. In each year, SubRatio ${ }_{X}$ is calculated separately for individual investors, domestic institutions, and QFIIs, and for MXF and TXF orders. $D_{8}, D_{4}, D_{0}$, and $D_{5}$ are dummy variables for $\mathrm{X}=8,4,0$, and 5, respectively. Controlling for the round numbers, 0 and 5, facilitates removing the round-number effect. $D_{\text {indv }}$ and $D_{Q F I I}$ are indicators for individual and QFII investors, respectively. $D_{M X F}$ equals 1 if the order is to trade $\mathrm{MXF}$, and 0 otherwise.

$\beta_{1}, \beta_{5}$, and $\beta_{9}$ measure the extent to which submission ratio is abnormal at prices ending at "8" for domestic institutions, individual investors, and QFIIs, respectively. Here "abnormal" means that it is different from the mean submission ratio at the six other price points, "1", "2", “3", "6", "7" and "9". Similarly, $\beta_{2}, \beta_{6}$, and $\beta_{10}$ measure whether or not the submission ratio is abnormal at prices ending at " 4 " among these three groups, respectively.

Model 2 of Table II provides supportive evidence that individual investors tend to submit more limit orders at " 8 " than at " 4 ". The proportion of limit orders submitted at " 8 " is 0.020 higher than the proportion of limit orders submitted at prices ending with a number other than "4," "0," and "5." The submission ratios at " 4 " is 0.013 lower than the proportion of limit orders submitted at prices ending with a number other than " 8, ," " 0 ," and " 5 ". The F-test shows that the difference between $\beta_{5}$ and $\beta_{6}$ is 
significant. ${ }^{23}$ For institutional investors, the submission ratios are not significantly higher or lower at " 8 " and "4." Model 5 of Table II shows that when we incorporate the triple-interaction terms, the insignificant coefficient $\beta_{17}(-0.001)$ suggests that individual investors do not have a preference for the lucky prices ending at " 8 " beliefs when submitting both MXF and TXF orders. In contrast, the significantly negative coefficient $\beta_{18}(-0.012)$ suggests that individual investors seem affected by their superstitious beliefs to avoid the unlucky prices ending at "4" when submitting both MXF than TXF orders.

\section{(INSERT TABLE II HERE)}

\section{Submissions of Buy and Sell Orders}

To take a closer look at the limit order submissions at the lucky and unlucky numbers, we report the submission ratios at the last one digit separately for buy and sell orders. This allows us to investigate if the number superstition varies among buy and sell limit orders. Figures A2 and A3 in the Appendix show that individual investors indeed submit more orders at " 8 " than at " 4 " both when they buy and when they sell. Similar to the previous results, such pattern is not evident for institutional investors.

In summary, individual investors exhibit a significant and economically meaningful superstition heuristic in lucky and unlucky numbers when submitting limit orders. This result is robust to the type of limit order, namely, buy orders versus sell orders. On the other hand, institutional investors, domestic or foreign, do not exhibit statistically discernible patterns in number superstition. Overall, these results are supportive of Hypothesis 1.

\section{Superstition and Investment Performance}

In this section, we construct an investor-level superstition index to measure the extent to which an investor's number superstition is revealed by his limit order submission. We then examine the association between the superstition index and investment performance.

\footnotetext{
${ }^{23} \mathrm{We}$ also perform an F-test to show that the difference between $\left(\beta_{1}+\beta_{5}\right)$ and $\left(\beta_{2}+\beta_{6}\right)$ is significant. For brevity, however, only differences between the coefficients of interaction terms are reported in Table II.
} 


\section{A. The Superstition Index}

In each year t, we calculate the superstition index for each investor i as the following:

$$
S I_{i, t}=\frac{\text { Number of limit orders submitted at "8"-Number of limit orders submitted at "4" }}{\text { Total number of limit orders submitted by investor } i}
$$

To ensure a meaningful calculation of the superstition index, we require that an investor submit at least 10 limit orders in each of two consecutive years. ${ }^{24}$ Table AI in the Appendix presents the descriptive statistics of the superstition index. Panel A of Table AI shows that individual investors exhibit the highest degree of number superstition, with the mean and median being significantly higher than zero. Besides, the mean and median of superstition index appear to be persistent as well. In particular, the mean superstition index of individual investors slightly increases from 0.0365 in 2003 to 0.0493 in 2008 . Moreover, the variation is large among these investors, with a high standard deviation around 0.091 in 2008. Panel B of Table A1 shows that domestic institutional investors seem to exhibit some degree of numerical superstition in general, while Panel C of Table A1 shows that QFIIs do not show much favor (disfavor) in submitting limit orders at prices ending with "8" ("4").

\section{B. Superstition Index and Other Individual Investor Traits}

We now report correlations between the superstition index and other individual investor traits documented in the literature. Table III shows that the superstition index persists over time. The correlation between the past year's superstition index and the current year's superstition index of an investor is 0.4205 . This implies that number superstition is likely to be an investor's innate trait.

Table III also shows that the superstition index is negatively related to the average order size, which is our measure for investor's wealth level. The Taiwan Futures Exchange (TAIFEX) adopts a pre-

\footnotetext{
${ }^{24} \mathrm{We}$ also tried to winsorize the superstition index at $1 \%$ level on both sides to check if our findings are driven by outliers. We find quite similar results before and after winsorization. Thus, in the main text, we simply report the results without any winsorization.
} 
margin system where an investor is required to deposit an initial margin in his margin account before he can actually trade. The more contracts an investor purchases or sells, the more the margin he needs to deposit. Thus, we employ the average number of contracts per order, i.e. the order size, as a proxy for investor's wealth. ${ }^{25}$ Our result indicates that wealthy investors tend to be less superstitious.

The correlation between superstition index and the limit order submission ratio at " 0 " and " 5 " is slightly negative, indicating that superstition index captures an investor's trading characteristic that is different from his preference for round numbers. Further, investors who exhibit more significant disposition effect tend to be more affected by their superstitious beliefs in numbers.

Collectively, the correlations in Table III show that superstition is related to other characteristics of investors that affect investment performance. The correlations, however, are not high in magnitude, implying that even though superstition is correlated with these investor characteristics, it is distinct from them. Thus, it is important to control for these investor traits when we perform the analysis on the relation between superstition and investment performance.

\section{(INSERT TABLE III HERE)}

\section{Superstition Index and Investment Performance of Individual Investors-Quintile Analysis}

We sort individual investors into quintiles by the superstition index in one year and look at their investment performance in the subsequent year. For the remainder of this paper, investors with higher (lower) superstition index are referred to as Q5 (Q1) investors. The performance metrics we use to

\footnotetext{
${ }^{25}$ For detailed margin requirement, please see the Internet Appendix in Kuo, Lin, and Zhao (2015) and the TAIFEX official website, http://www.taifex.com.tw/eng/eng2/TX.asp. We have also tried three other proxies for wealth. The first measure is the maximum order size, which is the largest order size that an investor submits within a year. The second and the third measures are the average open interest and the maximum open interest, respectively. Open interest is calculated as the maximum position that an investor is exposed to for one round-trip trade. The average open interest is the mean open interest of all round-trip trades in a year for an investor, while the maximum open interest is the maximum of an investor's open interest in all round trips in a year. Regression results of using these alternative wealth measures are quite similar, and are not tabulated in the paper. However, the results are available from the authors upon request.
} 
measure investment performance include the limit order returns, market order returns, as well as the performance of the round-trip trades. As the average round-trip duration for index futures in TAIFEX is about two days, we look at the mark-to-market returns at the horizon of intraday, one day, and five days after transactions.

The first return metric we examine is the mark-to-market return of executed limit orders that initiate a long or short position on the same day. We calculate the intraday returns based on the difference between the daily closing price and the initiated limit order's price, divided by the latter. This calculation assumes that the initiated limit orders are covered (closed-out) at the closing price of the trading day. For each investor-year observation, we first calculate the average intraday returns, and then average them with equal weights for all of the observations in each quintile. We also calculate 1-day and 5-day mark-tomarket returns with closing prices on days $t+1$ and $t+5$, respectively.

Panel A of Table IV presents the mark-to-market returns of executed limit orders. We notice that the Q5 individual investors significantly underperform their Q1 counterparts by 1.7 basis points within a trading day. The inferior performance of the Q5 investors continues to deteriorate, and the performance gap widens to 2.4 (6.3) basis points for the 1-day (5-day) mark-to-market returns.

Panel A of Table IV also indicates that individual investors in all quintiles experience negative mark-to-market returns for their limit orders. This is consistent with the findings in Barber and Odean (2000) and Barber, Lee, Liu, and Odean (2009) that individual investors lose money on their investments. $^{26}$

\section{(INSERT TABLE IV HERE)}

\footnotetext{
${ }^{26}$ The underperformance of superstitious individual investors, compared with their non-superstitious counterparts, exists not only for the limit orders submitted at prices ending with " 8 " but also for limit orders submitted at prices ending with other numbers. As discussed in Hypothesis 2, a preference of lucky number 8 and an avoidance of unlucky number 4 would distort the optimal limit order submission strategy for all numbers. This suboptimal limit order submission will ultimately lead to underperformance for limit orders ending at all numbers. We find this to be true. The results are reported in Tables AII, AIII, AIV, and Figure A4, all in the Appendix.
} 
The mark-to-market intraday return of a market order is calculated in the same way, i.e., assuming that the initiated market order is covered at the closing price of the trading day. For each investor-year observation, we first calculate the average intraday returns in the current year, and then average them with equal weights among all of the observations in each quintile. Results for mark-tomarket 1-day and 5-day returns are similarly calculated.

Panel B of Table IV shows that Q5 individual investors significantly underperform the Q1 individual investors by 1.3 basis points in their market orders within a trading day. The magnitude is similar to that of the intraday returns for limit orders. The underperformance deteriorates to 3.0 (5.6) basis points one day (five days) after the transactions.

We follow Jordan and Diltz (2003) and Feng and Seasholes (2005) to calculate the performance of round-trip trades. A round-trip trade is defined as a newly initiated position being covered. To adjust for the cross-sectional variation in the round-trip duration, and to facilitate the comparison with the markto-market returns of limit and market orders, we focus on the round-trip daily profit and daily index returns for the investors.

The round-trip profit is calculated as the number of index points earned or lost times 200 (50) TWD for the TXF (MXF) contracts. We calculate the round-trip index return as the profit divided by the average transaction price of all buy orders within a round-trip trade. ${ }^{27}$ The round-trip daily profit (index return) is thus determined by dividing the average round-trip profit (index return) by the average roundtrip duration. ${ }^{28}$ Similar to the mark-to-market returns, all items are first calculated for each investor and then averaged with equal weights for investors in each quintile.

Panel C of Table IV shows that the Q5 individual investors significantly underperform Q1 individual investors by 1,199 TWD for daily profits. The realized underperformance in terms of round-

\footnotetext{
${ }^{27}$ A round-trip trade may contain several buys and sells before the position is back to zero.

${ }^{28}$ As round-trip trades sometimes have very short durations, the extremely short durations may lead to extremely large daily profits and daily index returns if we calculate the daily performance on a per roundtrip basis. To mitigate this potential outlier issue, we first calculate the average round-trip duration and average profit for each investor, and then we calculate the investor's daily profit as average round-trip profit divided by average duration. Round-trip daily index returns are calculated in the same way.
} 
trip daily index return is about 10.5 basis points per trading day. To have a better picture of the economic losses, we estimate the total realized profit for each investor in each quintile per year (by multiplying rows 1, 3, and 4 in Panel C of Table IV). The Q5 individual investors lose 105,341 TWD (roughly 3,200 USD) more than their Q1 counterparts per year during our sample period. ${ }^{29}$ Such a loss is economically significant. It is also in line with our Hypothesis 2 that the investment performance of individual investors is negatively associated with their number superstition.

Panel C of Table IV also shows that the duration of losing round-trip trades is generally longer than that of winning ones for individual investors. This is consistent with the findings in Odean (1998) that individual investors are subject to the disposition effect when making their buying and selling decisions. Therefore, when we conduct the multivariate regression analysis, we control for the disposition effect to single out the effect of number superstition on investment performance.

\section{Superstition Index and Investment Performance of All Investors - Multivariate Regression Analysis}

We now perform the following multivariate cross-sectional regression:

$$
\begin{aligned}
\operatorname{Return}_{i, t}=\alpha & +\beta_{1} \text { SI }_{i, t-1}+\beta_{2} \text { OrderSize }_{i, t-1}+\beta_{3} \text { SubRatio }_{0 \text { and } 5, i, t-1}+\beta_{4} \operatorname{Ln}\left(N_{i, t-1}\right) \\
& +\beta_{5} \text { Disposition }_{i, t-1}+\beta_{6} \text { Return }_{i, t-1}+\varepsilon_{i, t}
\end{aligned}
$$

where $\operatorname{Return}_{i, t}$ and $\operatorname{Return}_{i, t-1}$ are the average mark-to-market returns or round-trip returns for investor $i$ in years $t$ and $t-1 . S I_{i, t-1}$ is investor $i$ 's superstition index in year $t-1$, calculated as the difference between limit order submission ratio at prices ending with " 8 " and that at prices ending with " 4 " in year $t-1$. The coefficient of particular interest is $\beta_{1}$, as it measures how the number superstition is associated with investment performance.

$\operatorname{OrderSize}_{i, t-1}$ is the average number of contracts per limit order submitted by investor $i$ in year $t-1$, which serves as a proxy for the wealth level of an investor. SubRatio 0 and $5, i, t-1$ is investor $i$ 's

\footnotetext{
${ }^{29}$ These incremental losses of Q5 individual investors are not driven by the excessive trading documented in Barber and Odean (2000) and Barber, Lee, Liu, and Odean (2009). In fact, though not tabulated, we find that Q5 investors trade less than their Q1 counterparts.
} 
submission ratio at prices ending with " 0 " and " 5 " in year $t-1$. Kuo, Lin, and Zhao (2015) use the limit order submission ratio at round number prices to proxy for an investor's cognitive limitation. $\operatorname{Ln}\left(N_{i, t-1}\right)$ is the log of number of limit orders submitted by investor $i$ in the previous year. Disposition $_{i, t-1}$ is the difference between the durations of losing and winning round-trip trades of investor $i$ in year $t$ - 1 , divided by their average. Controlling for these variables helps to single out the effect of superstition on investment performance. We also control for the past performance to account for the trading skill of the investor.

Table AV in the Appendix, which shows the results of the above multivariate regression, confirms the univariate results we documented in Table IV: superstitious investors lose money.

The first three columns of Panel A in Table AV show significantly negative coefficients of the superstition index for individual investors. The estimated $\beta_{1}$ for intraday limit order return equals -0.029 , implying that a one-standard-deviation (0.084) increase in the superstition index results in a 0.24 basis points decrease in the mark-to-market intraday returns for individual investors, after controlling for investors' wealth, the round number submission ratio, trading experience, disposition effect, and past returns. Similar results hold for the mark-to-market 1-day and 5-day returns. We find a similar negative association between the superstition index and the market order performance for individual investors in the middle three columns of Panel A in Table AV. The significantly negative coefficient for 5-day return equals -0.198 , implying that a one-standard-deviation (0.084) increase of the superstition index leads to a 1.66 basis points decrease in the mark-to-market 5-day return of market orders. The results are similar but less significant for the intraday and 1-day returns. The last two columns of Panel A present the multivariate regression results for the round-trip trades. The round-trip performance is negatively associated with the superstition index as well. A one-standard-deviation (0.084) increase in the superstition index leads to a lower (721 TWD) round-trip daily profit and a lower (5.84 basis points) daily index return. 
Notice that the negative association between the superstition and investment performance in Panel A of Table AV remains significant even after controlling for wealth, cognitive limitation, trading experience, disposition effect, and past performance. This indicates that our superstition measure captures a distinct individual investor characteristic. ${ }^{30}$ Furthermore, we find that Disposition $_{i, t-1}$ is negatively related to the investment performance of individual investors, suggesting that the more an investor exhibits the disposition effect, the lower are the returns of his investments. This is consistent with the findings in Odean (1998).

To summarize, both the main quintile analysis in Table IV and the subsequent regression exercises shown in Table AV in the Appendix provide evidence that the superstition index is negatively associated with the investment performance of individual investors. The more an investor is influenced by superstitious beliefs when deciding the limit order price, the poorer is his investment performance. This is true for individual investors, but not true for institutional investors as shown in Panels B and C of Table AV in the Appendix. Overall, the results provide compelling evidence to support Hypothesis 2.

\section{E. Two-Stage Regression Analysis}

To further support that superstition captures a unique dimension of trading skills, we perform a two-stage regression analysis. In the first stage, we regress superstition index on proxies for other aspects of trading skills.

$$
\begin{aligned}
S_{i, t-1}=\alpha+ & \beta_{1} \text { OrderSize }_{i, t-1}+\beta_{2} \text { SubRatio }_{0 \text { and } 5, i, t-1}+\beta_{3} \operatorname{Ln}\left(N_{i, t-1}\right)+\beta_{4} \text { Disposition }_{i, t-1} \\
& +\beta_{5} \text { Return }_{i, t-1}+\varepsilon_{i, t-1}
\end{aligned}
$$

where $\operatorname{OrderSize}_{i, t-1}$ is the average number of contracts per limit order submitted by investor $i$ in year $t$ 1, SubRatio and $5, i, t-1_{1}$ is investor $i$ 's submission ratio at prices ending with " 0 " and " 5 " in year $t-1$,

\footnotetext{
${ }^{30} \mathrm{We}$ also perform a double sorting analysis where we sort individual investors into quintiles by the superstition index and the submission ratio at the round number prices (the cognitive ability measure in Kuo, Lin, and Zhao, 2015). The result shows that the underperformance of the most superstitious (Q5) individual investors is larger for investors with lower submission ratio at round number prices. This indicates that our superstition index is different from the cognitive ability measure. These results are reported in Table AVI in the Appendix.
} 
$\operatorname{Ln}\left(N_{i, t-1}\right)$ is the log of number of limit orders submitted by investor $i$ in the previous year, and Disposition $_{i, t-1}$ is the difference between the durations of losing and winning round-trip trades of investor $i$ in yaer $t$ - 1 , divided by their average. Return $_{i, t-1}$ is the average mark-to-market returns or round-trip returns for investor $i$ in year $t-1$.

Panel A of Table AVII in the Appendix (first-stage regression) shows that superstition is significantly related to other aspects of trading skill. The wealthier and more experienced investors have lower superstition indices, while investors who are more affected by the disposition effect tend to be more superstitious.

We take the residuals from Eq. (5) and perform the following second stage regression. By doing so, we single out the effect of superstition from other aspects of trading skills.

$$
\begin{aligned}
\operatorname{Return}_{i, t}=\alpha & +\beta_{1} \text { Residual }_{\text {SI } i, t-1}+\beta_{2} \text { OrderSize }_{i, t-1}+\beta_{3} \text { SubRatio }_{0, i, t-1}+\beta_{4} \operatorname{Ln}\left(N_{i, t-1}\right) \\
& +\beta_{5} \text { Disposition }_{i, t-1}+\beta_{6} \text { Return }_{i, t-1}+\varepsilon_{i, t}
\end{aligned}
$$

Panel B of Table AVII in the Appendix (second-stage regression) presents the results of our second stage regression. They show that the residual superstition index, which is the portion of superstition that cannot be explained by other known trading characteristics, is still negatively associated with investment performance. In particular, the coefficients of limit order returns are all significantly negative. This implies that superstition does capture a unique dimension of trading skills that is related to investment performance.

\section{F. Placebo Tests}

To show that our negative association between superstition and investment performance is not a statistical fluke, we conduct two placebo tests in this subsection. The first and the natural one is to check the negative link between superstition and trading performance for institutional investors. Since the limit order submission of institutional investors is supposedly not affected by the lucky/unlucky numbers, the 
superstition index should not be associated with investment performance for these investors. This is exactly what we find in Panel B (domestic institutions) and Panel C (QFII) of Table AV in the Appendix.

For the second placebo test, we construct a pseudo superstition index based on the difference between the submission ratios at "7" and "3," and repeat the regression analysis of Eq. (4). The numbers "7" and "3" are deemed neither lucky nor unlucky in Chinese culture. Therefore, the pseudo superstition index should not capture the degree of superstition among investors, nor should it be linked to investment performance.

Table AVIII in the Appendix shows that the negative association does not exist between the pseudo superstition index and investment performance among individual investors. The parameter estimates of $\beta_{1}$ are not significant at the $10 \%$ level in any of the columns. We also consider two more pseudo superstition indices: the differences between submission ratios at "7" and "2" and at " 2 " and "3." We do not find significant association between these two pseudo superstition indices and investment performance either (results not tabulated). This further corroborates our Hypothesis 2 that superstitious individual investors, who tend to favor the number " 8 " and avoid the number " 4 ," incur worse investment performance than their non-superstitious counterparts.

\section{G. The Lucky vs. Unlucky Side of Superstition Index}

The superstition index consists of two parts: the submission ratio at " 8 " (the lucky number part) and the submission ratio at " 4 " (the unlucky number part). In this subsection, we examine if the association between superstition and investment performance is driven by a particular part. We consider the lucky part of the superstition index as the difference between the submission ratios at " 8 " and " 3 ," while the unlucky one as the difference between the submission ratios at " 3 " and "4." Number " 3 " is ideal to serve as a benchmark because it is a neutral number that is neither a round number nor adjacent to the round numbers like "0" and "5." We also use the number "2" as a benchmark, and find similar results (not reported). 
We repeat the regression analysis of Eq. (4) with these two proxies for the lucky and unlucky parts of the superstition index as our main variables of interest. Table AIX in the Appendix shows that the negative association between superstition and investment performance exists for both parts, though it is more significant for the lucky part. It indicates that the tendency of individual investors both to favor the number " 8 " and to avoid the number " 4 " is negatively related to their investment performance.

\section{Why do Superstitious Individual Investors Lose Money?}

In this section we explore the potential reasons why superstitious individual investors lose money. In financial markets, there are only two ways in which investors could lose by trading: picking the wrong investment and/or picking it at the wrong time. In our setting, the only investment is the index futures. So the only way for individual investors to lose money would be bad market timing. We first investigate whether superstitious investors exhibit poor market timing and then examine how it happens.

\section{A. Market Timing}

Following Seasholes and Zhu (2010), we calculate the Buy Ratio and Buy-Sell Ratio for individual investors with various superstition indices and under different market returns to gauge their market timing abilities. The Buy Ratio is defined as the number of buy contracts (taking long positions) scaled by total number of executed contracts. We calculate the Buy-Sell Ratio as the difference between the numbers of buy and sell contracts, divided by their average. Both open limit and market orders are included in the calculation of Buy Ratio and Buy-Sell Ratio. If superstitious investors are indeed poor market timers, we would expect them to have lower Buy Ratio and Buy-Sell Ratio, compared with their non-superstitious counterparts, on the trading days with high market returns.

We first sort individual investors into quintiles by the superstition index in one year. Investors in the superstitious index quintile 5 (Q5) are the most superstitious. We then sort the trading days of the next year into quintiles based on the daily market returns. Market returns on trading days in Quintile-5 (M5) 
are the highest. We then compute the average Buy Ratio and average Buy-Sell Ratio of each product (MXF or TXF orders with all available maturity dates) for the investors in each superstitious quintile and market return quintile.

The results are reported in Table V. The last row of Panel A in Table V shows that the difference between the Buy Ratios of M5 and M1 market returns is significantly negative (-0.122) for Q5 individual investors. The result indicates that Q5 individual investors (the most superstitious ones) tend to establish larger long positions on the trading days with lower market returns than on the trading days with higher market returns. In contrast, this difference is insignificant (-0.012) for Q1 individual investors (the least superstitious ones). This suggests that Q5 individual investors in general have poorer market timing ability than their Q1 counterparts. Furthermore, we can see that such a difference in marketing timing ability between Q5 and Q1 investors is mainly manifest on the trading days with low market returns. So Q5 investors buy more than Q1 investors in low market return days, but the difference is not significant in high market return days. Panel B of Table V shows similar results for Buy-Sell Ratio. This evidence suggests that indeed bad market timing is responsible for the underperformance of the most superstitious investors.

\section{(INSERT TABLE V HERE)}

We also conduct a placebo test to see if we can replicate the results of Table V based on a pseudo superstition index - the difference between the submission ratios at "7" and " 3 " - instead of the actual superstition index - the difference between the submission ratios at " 8 " and " 4 ". According to the results shown in Table AX in the Appendix, we notice no relation between the pseudo-superstition index and market timing ability.

\section{B. Stale Limit Orders}

Why are superstitious investors poor market timers? It could be the case that individual investors submit their limit orders without active monitoring, and then their orders become stale and eventually get 
picked off by active traders. Linnainmaa (2010) shows that stale limit orders can partly explain the poor performance of individual investors in Finland. In order to check if individual limit orders become stale after submission, we examine the time-to-execution and time-to-cancellation of the orders in this subsection.

Time-to-execution is the time elapsed between order submission and order execution for executed limit orders. Time-to-cancellation is the time elapsed between order submission and order cancellation for limit orders that are submitted and then deleted by individual investors. Both measures can serve as an indicator of how actively investors monitor their limit orders. We first sort individual investors into quintiles according to their superstition indices in one year, and plot the average time-to-execution (cancellation) of limit orders submitted at prices ending with " $\mathrm{X}$ " in the subsequent year. $\mathrm{X}$ is an integer ranging from 0 to 9. As usual, investors in Quintile-5 (Q5) are the most superstitious.

Figure 2.A shows that for the limit orders submitted at various prices, Q5 investors have longer time-to-execution than Q1 investors. Similarly, Figure 2.B shows that the time-to-cancellation is also longer for Q5 investors at all price points. The differences in time-to-execution (cancellation) of Q5 and Q1 investors are significant (results not tabulated). In sum, our results are consistent with the conjecture that the limit orders of the most superstitious individual investors are left unattended in the limit order book for a longer time such that they become stale and eventually get picked off, partially contributing to their underperformance.

\section{(INSERT FIGURE 2 HERE)}

We also perform a regression analysis to show that the time-to-execution and time-to-cancellation are indeed related to investment performance. Table AXI in the Appendix shows that investors who have stale limit orders, namely, investors with longer time-to-execution and longer time-to-cancellation, tend to incur poorer investment performance. This must be because someone is exploiting their predictable trades by, for example, picking off their stale limit orders. The question is: who are these investors? We show that institutional investors, both domestic and foreign, make money at all price points from the most 
superstitious traders. As shown in Figure A5 in the Appendix, both domestic and foreign intuitional investors earn more higher positive returns at all price points when they pick up the orders submitted by Q5 individual investors as compared to those submitted by Q1 individual investors. Our results indicate that the superstitious individual investors are losing to the more sophisticated institutional investors.

\section{Superstition and Learning by Trading}

In this section, we examine whether individual investors learn by trading to mitigate or reinforce their reliance on superstition in limit order submissions, as proposed by our Hypotheses 3.A and 3.B, respectively. Specifically, we perform the following regression:

$$
\begin{aligned}
S I_{i, t}-S I_{i, t-1}= & \alpha+\beta_{1} \operatorname{Ln}\left(N_{i, t-1}\right)+\beta_{2} \text { Return }_{8, i, t-1}+\beta_{3} \text { Return }_{4, i, t-1}+\beta_{4} \text { Return }_{\text {other }, i, t-1} \\
& +\beta_{5} \text { Return }_{\text {market }, i, t-1}+\beta_{6} \text { SI }_{i, t-1}+\beta_{7} \text { OrderSize }_{i, t-1}+\beta_{8} \text { SubRatio }_{0 \text { and } 5, i, t-1} \\
& +\beta_{9} \text { Disposition }_{i, t-1}+\varepsilon_{i, t}
\end{aligned}
$$

where $S I_{i, t}$ and $S I_{i, t-1}$ are the superstition indices of investor $i$ in years $t$ and $t-1$. We use the change in superstition index to control for unobserved time-invariant investor characteristics. $\operatorname{Ln}\left(N_{i, t-1}\right)$ is the $\log$ of the number of limit orders submitted by investor $i$ in year $t-1$. Return $n_{8, i, t-1}$ is the mark-to-market intraday return of limit orders submitted by investor $i$ at prices ending with " 8 " in year $t-1$. Return $4, i, t-1$ is the mark-to-market intraday return of limit orders submitted by investor $i$ at prices ending with " 4 " in year $t$-1. Return others,i,t-1 $_{\text {is the mark-to-market intraday return of limit orders submitted by investor } i \text { at }}$ prices ending with other numbers in year $t$-1. Return market,i,t-1 $_{\text {is }}$ the mark-to-market intraday return of market orders submitted by investor $i$ in year $t-1$. We also control for the past superstition index, wealth, disposition effect, and the round-number submission ratio. The superstition index is expressed in percentage to facilitate comparison of estimated coefficients. The coefficients of interest are $\beta_{1}, \beta_{2}, \beta_{3}, \beta_{4}$, and $\beta_{5}$, as they measure whether investors learn from past trading frequency and past performance, respectively. 
Table VI shows that the change in the superstition index is significantly negatively related to the number of limit orders submitted by individual investor in the previous year. According to the estimated $\beta_{1}$ in Model 6, a one-standard-deviation (51 limit orders) increase in the number of submitted limit orders in the previous year will lead to $0.74 \%$ more reduction of the superstition index in the subsequent year. This indicates that individual investors learn from their past trading frequency and rely less on superstitious heuristics in their limit order submission.

The significantly negative coefficients of Return $_{\text {other }, i, t-1}$ suggest that individual investors with better performance of non-superstitious limit orders are able to learn to become less superstitious. In contrast, the coefficients of $\operatorname{Return}_{8, i, t-1}$ and $\operatorname{Return}_{4, i, t-1}$ are statistically insignificant, indicating that individual investors do not learn in a reinforcement way. This result is not surprising as we have shown in Tables AII, AIII, AIV, and Figure A4 that superstitious individual investors perform poorly at all numbers. For the most superstitious investors, there seems to be no particularly high return at " 8 " or a particularly low return on " 4 ," compared with other numbers; so it is likely that that these investors do not learn from performance of limit orders submitted at these lucky/unlucky numbers. In sum, our results are consistent with Hypothesis 3.A that individual investors learn by trading to alleviate their number superstition in limit order submissions.

\section{(INSERT TABLE VI HERE)}

Does the effect of trading experience diminish over time? We reproduce Table VI by replacing $\operatorname{Ln}\left(N_{i, t-1}\right)$ with $\operatorname{Ln}\left(N_{i, t-2}\right)$ and $\operatorname{Ln}\left(N_{i, t-3}\right)$, respectively. Doing so allows us to examine the relative importance of the past trading experience accumulated two or three years before. Table AXII in the Appendix shows that the $\beta_{1}$ of $\operatorname{Ln}\left(N_{i, t-2}\right)$ is less negative than that of $\operatorname{Ln}\left(N_{i, t-1}\right)$, and the $\beta_{1}$ of $\operatorname{Ln}\left(N_{i, t-3}\right)$ is insignificant. Our results suggest that the impact of the past trading frequency is diminishing over time.

\section{Conclusion}

This paper documents that individual investors exhibit number superstition when submitting limit orders. The limit order submission ratio at the lucky number " 8 " is 0.098 , which is significantly higher 
than 0.063 , the submission ratio at the unlucky number " 4 ." We also find that there exist both persistence and cross-sectional heterogeneity in the degree that investors are affected by their superstitious beliefs.

We construct an investor-level superstition index based on the limit order submission ratios at lucky and unlucky numbers and show that this index is negatively related to investment performance. Specifically, we find that more superstitious individual investors incur significantly lower intraday, 1-day, and 5-day mark-to-market index returns of their limit orders. In addition, we find similar underperformance of superstitious individual investors for their market orders and round-trip trades. The negative association between superstition index and subsequent investment performance remains significant even after controlling for known investor characteristics that have been shown in the literature to be related to investment performance. Thus, our findings show that the number superstition captures a distinct aspect of investors' trading skills.

Finally, we find that superstitious individual investors underperform because they have bad market timing (mostly because they buy on days when the market return are low) and have stale limit orders which get picked off by smarter traders. The good news is that individual investors can learn from their trading experience and become less superstitious. 


\section{References}

Agarwal, Sumit, Jia He, Haoming Liu, Ivan P.L. Png, Tien F. Sing, and Wei K. Wong, "Superstition and Asset Markets: Evidence from Singapore Housing,” Working paper, 2014.

Baker, Malcolm, Xin Pan, and Jeffrey Wurgler, "The Effect of Reference Point Prices on Mergers and Acquisitions," Journal of Financial Economics 106 (2012), 49-71.

Ball, Clifford, Walter Torous, and Adrian. Tschoegl, "The Degree of Price Resolution: The Case of the Gold Market,” Journal of Futures Markets 5 (1985), 29-43.

Barber, Brad M. and Terrance Odean, "Trading is Hazardous to your Wealth: The Common Stock Investment Performance of Individual Investors,” Journal of Finance 55 (2000), 773-806.

Barber, Brad and Terrance Odean, "The Behavior of Individual Investors.” In: Constantinides, Geroge, Milton Harris, and Rene Stulz (Eds.), Handbook of the Economics of Finance (2013), Volume 2, Elsevier, 1533-1570.

Barber, Brad M., Yi T. Lee, Yu J. Liu, and Terrance Odean, "Just How Much do Individual Investors Lose by Trading?" Review of Financial Studies 22 (2009), 609-632.

Benford, Frank, "The Law of Anomalous Numbers", Proceedings of the American Philosophical Society 78 (1938), 551-572.

Bhattacharya, Utpal, Craig W. Holden, and Stacy Jacobsen, "Penny Wise, Dollar Foolish: Buy-sell Imbalances on and around Round Numbers," Management Science 58 (2012), 413-431.

Birru, Justin, "Psychological Barriers, Expectational Errors, and Underreaction to News," Working Paper, 2015.

Booth, Geoffrey, Juha-Pekka Kallunki, Ji-Chai Lin, and Teppo Martikainen, "Internalization and Stock Price Clustering: Finish Evidence,” Journal of International Money and Finance 19 (2000), 737-751.

Brown, Philip, Angeline Chua, and Jason Mitchell, "The Influence of Cultural Factors on Price Clustering: Evidence from Asia-Pacific Stock Markets,” Pacific-Basin Finance Journal 10 (2002), 307-332. 
Brown, Philip and Jason Mitchell, “Culture and Stock Price Clustering: Evidence from The Peoples' Republic of China," Pacific-Basin Finance Journal 16 (2008), 95-120.

Campbell, John Y., “Household Finance,” Journal of Finance 61 (2006), 1553-1604.

Chiang, Yao M., David Hirshleifer, Yiming Qian, and Ann E. Sherman, "Do Investors Learn from Experience? Evidence from Frequent IPO Investors,” Review of Financial Studies 24 (2011), 15601589.

Choi, James, David Laibson, Brigitte Madrian, and Andrew Metrick, "Reinforcement Learning and Savings Behavior," Journal of Finance 64 (2009), 2515-2534.

Christie, William, and Paul Schultz, "Why do NASDAQ Market Makers Avoid Odd-eighth Quotes?" Journal of Finance 49 (1994), 1813-1840.

Christie, William, Jeffrey Harris, and Paul Schultz, "Why did NASDAQ Market Makers Stop Avoiding Odd-eighth Quotes?” Journal of Finance 49 (1994), 1841-1860.

Curcio, Riccardo and Charles Goodhart, "The Clustering of Bid/Ask Prices and the Spread in the Foreign Exchange Market,” FMG Discussion Paper 110, Financial Markets Group, London, 1991.

Darke, Peter R., and Johnathan L. Freedman, “The Belief in Good Luck Scale,” Journal of Research in Personality 31 (1997), 486-511.

Dhar, Ravi and Ning Zhu, "Up Close and Personal: An Individual Level Analysis of the Disposition Effect," Management Science 52 (2006), 726-740.

Dichev, Ilia and Troy Janes, "Lunar Cycle Effects in Stock Returns," Journal of Private Equity 6 (2003), 8-29.

Donaldson, Glen and Harold Kim, "Price Barriers in the Dow Jones Industrial Average," Journal of Finance and Quantitative Analysis, 28 (1993), 313-330.

Driessen, Joost, Tse-Chun Lin, and Otto van Hemert, "How the 52-week High and Low Affect OptionImplied Volatilities and Stock Return Moments,” Review of Finance 17 (2013), 369-401. 
Dyl, Edward A. and Edwin D. Maberly, “The Anomaly That Isn't There: A Comment on Friday the Thirteenth," Journal of Finance 43 (1988), 1285-1286.

Feng, Lei, and Mark Seasholes, "Do Investor Sophistication and Trading Experience Eliminate Behavioral Biases in Financial Markets?” Review of Finance 9 (2005), 305-351.

Fortin, Nicole M., Andrew J. Hill and Jeff Huang, "Superstition in Housing Market," Economic Inquiry 52 (2014), 974-993.

Geng, Zhiyang, Xindan Li, Avanidhar Subrahmanyam, and Honghai Yu, "Do the Rich Have an Informational Advantage? Evidence Based on Account Classifications of Individual Investors," Working Paper, 2014.

George, Thomas J., and Chuan-Yang Hwang, “The 52-week High and Momentum Investing,” Journal of Finance 59 (2004), 2145-2176.

Grinblatt, Mark, Matti Keloharju, and Juhani Linnainmaa, "IQ and Stock Market Participation,” Journal of Finance 66 (2011), 2121-2164.

Grinblatt, Mark, Matti Keloharju, and Juhani Linnainmaa, "IQ, Trading Behavior, and Performance," Journal of Financial Economics 104 (2012), 339-362.

Grinblatt, Mark, Seppo Ikäheimo, Matti Keloharju, and Samuli Knüpfer, “IQ and Mutual Fund Choice,” Management Science 62 (2016), 924-944.

Gwilym, Owain, Andrew Clare, and Stephen Thomas, "Price Clustering and Bid-ask Spreads in International Bond Futures," Journal of International Financial Markets Institutions and Money, 8 (1998a), 379-394.

Gwilym, Owain, Andrew Clare, and Stephen Thomas, "Extreme Price Clustering in the London Equity Index Futures and Options Markets,” Journal of Banking and Finance 22 (1998b), 1193-1206.

Harris, Lawrence, “Stock Price Clustering and Discreteness," Review of Financial Studies 4 (1991), 389415. 
Heath, Chip, Steven Huddart, and Mark Lang, "Psychological Factors and Stock Option Exercise," Quarterly Journal of Economics 114 (1999), 601-627.

Hirshleifer, David, Ming Jian, and Huai Zhang, "Superstition and Financial Decision Making," Management Science (2016), forthcoming.

Jiang, Yuwei, Angela Cho, and Rashmi Adaval, "The Unique Consequences of Feeling Lucky: Implications for Consumer Behavior,” Journal of Consumer Psychology 19 (2009), 171-184.

Jordan, Douglas J. and David Diltz, "The Profitability of Day Traders," Financial Analysts Journal 59 (2003), 85-95.

Kolb, Robert W. and Ricardo J. Rodriguez, "Friday the Thirteenth: 'Part VII'-A Note.” Journal of Finance 42 (1987), 1385-1387.

Kramer, Thomas and Lauren Block, "Conscious and Non-conscious Components of Superstitious Beliefs in Judgment and Decision Making," Journal of Consumer Research 34 (2008), 783-793.

Kuo, Wei Y. and Tse C. Lin, "Overconfident Individual Day Traders: Evidence from Taiwan Futures Market,” Journal of Banking and Finance 37 (2013), 3548-3561.

Kuo, Wei Y., Tse C. Lin, and Jing Zhao, “Cognitive Limitation and Investment Performance: Evidence from Limit Order Clustering,” Review of Financial Studies 28 (2015), 838-875.

Lepori, Gabriele M., "Dark Omens in the Sky: Do Superstitious Beliefs Affect Investment Decisions?" Working Paper, 2009.

Ley, Eduardo and Hal R. Varian, “Are There Psychological Barriers in the Dow-Jones Index?” Applied Financial Economics 4 (1994), 217-114.

Ley, Eduardo, "On the Peculiar Distribution of the U.S. Stock Indices Digits", The American Statistician, 50 (1996), 1-313.

Li, Fengfei, Chen Lin, and Tse C. Lin, "Does Anchoring Heuristic Affect Analyst Recommendation Revisions?” Working Paper, 2015. 
Li, Jun, and Jianfeng Yu, "Investor Attention, Psychological Anchors, and Stock Return Predictability," Journal of Financial Economics 104 (2012), 401-419.

Li, Hung C., Chao H. Lin, Teng Y. Cheng, and Syouching Lai, "How Different Types of Traders Behave in the Taiwan Futures Market?” Journal of Futures Markets 33 (2013), 1097-1117.

Linnainmaa, Juhani, 2010, Do Limit Orders Alter Inferences about Investor Performance and Behavior? Journal of Finance 65(4), 1473-1506.

Liu, Yu J., Chih L. Tsai, Ming C. Wang, and Ning Zhu, "Prior Consequences and Subsequent Risk Taking: New Field Evidence from the Taiwan Futures Exchange,” Management Science 56 (2010), 606-620.

Miller, Dale T., and Brian R. Taylor, "Counterfactual Thought, Regret, and Superstition: How to Avoid Kicking Yourself," Heuristics and Biases: The Psychology of Intuitive Judgment (1995), 367-378.

Neiderhoffer, Victor, “Clustering of Stock Prices,” Operations Research 13 (1965), 258-265.

Neiderhoffer, Victor, “A New Look at Clustering of Stock Prices,” Journal of Business 39 (1966), 390413.

Odean, Terrance, “Are Investors Reluctant to Realizes their Losses?” Journal of Finance 53 (1998), $1775-1798$.

Palmon, Oded, Barton Smith, and Ben Sopranzetti., "Clustering in Real Estate Prices: Determinants and Consequences," Journal of Real Estate Research 26 (2004), 115-136.

Poteshman, Allen M., and Vitaly Serbin, "Clearly Irrational Financial Market Behavior: Evidence from the Early Exercise of Exchange Traded Stock Options," Journal of Finance 58 (2003), 37-70.

Seasholes, Mark and Ning Zhu, Individual investors and local bias. Journal of Finance 65 (2010), 19872010.

Seru, Amit, Tyler Shumway, and Noah Stoffman, "Learning by Trading," Review of Financial Studies 23 (2010), 705-729. 
Shum, Matthew, Wei Sun, and Guangliang Ye, “Superstition and 'Lucky' Apartments: Evidence from Transection Level Data,” Journal of Comparative Economics 42 (2014), 109-117.

Sonnemans, Joep, "Price Clustering and Natural Resistance points in the Dutch Stock Market: A Nature Experiment," European Economic Review 50 (2005), 1937-1950.

Tsang, Eric .W.K., "Superstition and Decision-making: Contradiction or Complement?" Academy of Management Executive 18 (2004), 92-104.

Tversky, Amos and Daniel Kahneman, “Judgment under Uncertainty: Heuristics and Biases,” Science (1974), 1124-1131.

Yuan, Kathy, Lu Zheng, and Qiaoqiao Zhu, “Are Investors Moonstruck? Lunar Phases and Stock Returns," Journal of Empirical Finance 13 (2006), 1-23. 


\section{Table I. Descriptive Statistics of Limit Order Quotes and Trades}

This table reports the summary statistics of the limit orders quotes and trades for two major Taiwan index futures in the Taiwan Futures Exchange from January 2003 to September 2008. In 2008, we only have orders and trades data from January to September. The number of submitted limit orders and the number of executed limit order contracts are reported in Panels A and B, respectively. The number of limit orders (contracts) is reported separately for individual investors, domestic institutions, and Qualified Foreign Institutional Investors (QFII) and for Taiwan Stock Exchange Futures (TXF) and Mini-Taiwan Stock Exchange Futures (MXF).

Panel A: Number of Limit Orders Submitted

\begin{tabular}{|c|c|c|c|c|c|c|}
\hline \multirow[t]{2}{*}{ Year } & \multirow[t]{2}{*}{ Total } & \multicolumn{3}{|c|}{ Investor type } & \multicolumn{2}{|c|}{ Product type } \\
\hline & & Individual & $\begin{array}{c}\text { Domestic } \\
\text { Institutions }\end{array}$ & QFII & TXF & MXF \\
\hline 2003 & $8,391,970$ & $7,874,288$ & 450,329 & 67,353 & $5,931,492$ & $2,460,478$ \\
\hline 2004 & $11,756,902$ & $10,436,137$ & $1,181,927$ & 138,838 & $7,935,143$ & $3,821,759$ \\
\hline 2005 & $9,336,187$ & $7,171,025$ & $1,866,537$ & 298,625 & $6,853,377$ & $2,482,810$ \\
\hline 2006 & $16,080,187$ & $10,088,540$ & $5,160,370$ & 831,277 & $11,136,616$ & $4,943,571$ \\
\hline 2007 & $26,218,095$ & $13,297,493$ & $11,732,794$ & $1,187,808$ & $15,728,641$ & $10,489,454$ \\
\hline 2008 & $36,699,943$ & $18,251,513$ & $16,677,852$ & $1,770,578$ & $21,843,993$ & $14,855,950$ \\
\hline Total & $108,483,284$ & $67,118,996$ & $37,069,809$ & $4,294,479$ & $69,429,262$ & $39,054,022$ \\
\hline Ratio & $100 \%$ & $61.87 \%$ & $34.17 \%$ & $3.96 \%$ & $64.00 \%$ & $36.00 \%$ \\
\hline \multicolumn{7}{|c|}{ Panel B: Number of Limit Order Contracts Executed } \\
\hline \multirow[t]{2}{*}{ Year } & \multirow[t]{2}{*}{ Total } & \multicolumn{3}{|c|}{ Investor type } & \multicolumn{2}{|c|}{ Product type } \\
\hline & & Individual & $\begin{array}{c}\text { Domestic } \\
\text { Institutions }\end{array}$ & QFII & MXF & TXF \\
\hline 2003 & $15,662,806$ & $13,369,496$ & $1,960,223$ & 333,087 & $13,029,382$ & $2,633,424$ \\
\hline 2004 & $21,609,094$ & $17,067,248$ & $3,667,074$ & 874,772 & $17,722,556$ & $3,886,538$ \\
\hline 2005 & $16,011,798$ & $11,495,469$ & $3,445,196$ & $1,071,133$ & $13,834,750$ & $2,177,048$ \\
\hline 2006 & $23,351,164$ & $16,690,861$ & $5,288,886$ & $1,371,417$ & $19,829,998$ & $3,521,166$ \\
\hline 2007 & $29,554,384$ & $20,294,809$ & $6,882,178$ & $2,377,397$ & $23,626,300$ & $5,928,084$ \\
\hline 2008 & $36,963,929$ & $25,873,811$ & $8,470,446$ & $2,619,672$ & $25,871,823$ & $11,092,106$ \\
\hline Total & $143,153,175$ & $104,791,694$ & $29,714,003$ & $8,647,478$ & $113,914,809$ & $29,238,366$ \\
\hline Ratio & $100 \%$ & $73.20 \%$ & $20.76 \%$ & $6.04 \%$ & $79.58 \%$ & $20.42 \%$ \\
\hline
\end{tabular}




\section{Table II. Submission Ratio at Prices Ending with "X"}

This table reports the parameter estimates of the following regression:

$$
\begin{aligned}
\text { SubRatio }_{X}-0.1 & =\alpha+\beta_{1} D_{8}+\beta_{2} D_{4}+\beta_{3} D_{0}+\beta_{4} D_{5}+\left(\beta_{5} D_{8}+\beta_{6} D_{4}+\beta_{7} D_{0}+\beta_{8} D_{5}\right) \times D_{\text {indv }} \\
& +\left(\beta_{9} D_{8}+\beta_{10} D_{4}+\beta_{11} D_{0}+\beta_{12} D_{5}\right) \times D_{Q F I I}+\left(\beta_{13} D_{8}+\beta_{14} D_{4}+\beta_{15} D_{0}+\beta_{16} D_{5}\right) \times D_{M X F} \\
& +\left(\beta_{17} D_{8}+\beta_{18} D_{4}+\beta_{19} D_{0}+\beta_{20} D_{5}\right) \times D_{\text {indv }} \times D_{M X F}+\left(\beta_{21} D_{8}+\beta_{22} D_{4}+\beta_{23} D_{0}+\beta_{24} D_{5}\right) \\
& \times D_{Q F I I} \times D_{M X F}+\beta_{25} D_{\text {indv }}+\beta_{26} D_{Q F I I}+\beta_{27} D_{M X F}+\varepsilon_{X}
\end{aligned}
$$

SubRatio $_{X}$ is the submission ratio at " $\mathrm{X}$ ", which is calculated as the number of limit orders submitted at prices ending with " $\mathrm{X}$ " divided by total number of limit orders submitted at all prices (X is an integer ranging from 0 to 9). The dependent variable is the deviation of the actual submission ratio at " $\mathrm{X}$ " from its theoretical value assuming uniform distribution of the limit order prices. Each year, the submission ratio at " $\mathrm{X}$ " is calculated separately for individual investors, domestic institutions, and QFII investors, and for MXF and TXF orders. $D_{8}, D_{4}, D_{0}$, and $D_{5}$ are dummy variables for $\mathrm{X}=8,4,0$, and 5 , respectively. $D_{\text {indv }}$ and $D_{Q F I I}$ are indicators for individual and QFII investors. $D_{M X F}$ is equal to 1 if the order is to trade

\begin{tabular}{|c|c|c|c|c|c|}
\hline Independent Variables & Model 1 & Model 2 & Model 3 & Model 4 & Model 5 \\
\hline$D_{8}$ & $\begin{array}{c}0.013 * * * \\
(0.000)\end{array}$ & $\begin{array}{c}0.004 \\
(0.134)\end{array}$ & $\begin{array}{c}0.011 * * * \\
(0.000)\end{array}$ & $\begin{array}{c}0.002 \\
(0.479)\end{array}$ & $\begin{array}{c}0.002 \\
(0.544)\end{array}$ \\
\hline$D_{4}$ & $\begin{array}{l}-0.004 \\
(0.243)\end{array}$ & $\begin{array}{c}0.002 \\
(0.456)\end{array}$ & $\begin{array}{c}-0.003 \\
(0.359)\end{array}$ & $\begin{array}{c}0.003 \\
(0.418)\end{array}$ & $\begin{array}{c}-0.002 \\
(0.503)\end{array}$ \\
\hline$D_{0}$ & $\begin{array}{c}0.111 \text { *** } \\
(0.000)\end{array}$ & $\begin{array}{c}0.041^{* * * *} \\
(0.000)\end{array}$ & $\begin{array}{c}0.086 * * * \\
(0.000)\end{array}$ & $\begin{array}{c}0.016 \\
(0.182)\end{array}$ & $\begin{array}{c}0.037 * * * \\
(0.000)\end{array}$ \\
\hline$D_{5}$ & $\begin{array}{c}0.045^{* * * *} \\
(0.000)\end{array}$ & $\begin{array}{c}0.009 * * * \\
(0.008)\end{array}$ & $\begin{array}{c}0.035^{* * * *} \\
(0.000)\end{array}$ & $\begin{array}{l}-0.001 \\
(0.810)\end{array}$ & $\begin{array}{c}0.008 * * \\
(0.021)\end{array}$ \\
\hline \multicolumn{6}{|l|}{ Double Interactions } \\
\hline$D_{8} \times D_{\text {indv }}$ & & $\begin{array}{c}0.020^{* * * *} \\
(0.000)\end{array}$ & & $\begin{array}{c}0.020 * * * \\
(0.000)\end{array}$ & $\begin{array}{c}0.021 * * * \\
(0.000)\end{array}$ \\
\hline$D_{4} \times D_{\text {indv }}$ & & $\begin{array}{c}-0.013 * * * \\
(0.001)\end{array}$ & & $\begin{array}{c}-0.013 * * * \\
(0.001)\end{array}$ & $\begin{array}{c}-0.007 * \\
(0.067)\end{array}$ \\
\hline$D_{0} \times D_{\text {indv }}$ & & $\begin{array}{c}0.142 * * * \\
(0.000)\end{array}$ & & $\begin{array}{c}0.142 * * * \\
(0.000)\end{array}$ & $\begin{array}{c}0.124 * * * \\
(0.000)\end{array}$ \\
\hline$D_{5} \times D_{\text {indv }}$ & & $\begin{array}{c}0.069 * * * * \\
(0.000)\end{array}$ & & $\begin{array}{c}0.069 * * * \\
(0.000)\end{array}$ & $\begin{array}{c}0.060 * * * * \\
(0.000)\end{array}$ \\
\hline$D_{8} \times D_{Q F I I}$ & & $\begin{array}{c}0.005 \\
(0.382)\end{array}$ & & $\begin{array}{c}0.005 \\
(0.372)\end{array}$ & $\begin{array}{c}0.006 \\
(0.225)\end{array}$ \\
\hline$D_{4} \times D_{Q F I I}$ & & $\begin{array}{c}-0.007 \\
(0.394)\end{array}$ & & $\begin{array}{l}-0.006 \\
(0.399)\end{array}$ & $\begin{array}{c}0.003 \\
(0.572)\end{array}$ \\
\hline$D_{0} \times D_{Q F I I}$ & & $\begin{array}{c}0.068 * * * \\
(0.006)\end{array}$ & & $\begin{array}{c}0.068 * * * \\
(0.003)\end{array}$ & $\begin{array}{l}0.024^{*} \\
(0.099)\end{array}$ \\
\hline$D_{5} \times D_{Q F I I}$ & & $\begin{array}{c}0.039 * * * \\
(0.000)\end{array}$ & & $\begin{array}{c}0.039 * * * \\
(0.000)\end{array}$ & $\begin{array}{c}0.018 * * \\
(0.033)\end{array}$ \\
\hline$D_{8} \times D_{M X F}$ & & & $\begin{array}{c}0.004 \\
(0.277)\end{array}$ & $\begin{array}{c}0.004 \\
(0.264)\end{array}$ & $\begin{array}{c}0.005 \\
(0.412)\end{array}$ \\
\hline
\end{tabular}
MXF, and 0 if it is to trade TXF. In the last three rows we report the F-tests for the equality of coefficients. Standard errors are adjusted for heteroskedasticity. *, **, and *** indicate significance levels of $0.1,0.5$ and 0.01 , respectively. 


\begin{tabular}{|c|c|c|c|c|c|}
\hline$D_{4} \times D_{M X F}$ & & & $\begin{array}{c}-0.002 \\
(0.801)\end{array}$ & $\begin{array}{c}-0.002 \\
(0.720)\end{array}$ & $\begin{array}{c}0.009 \\
(0.149)\end{array}$ \\
\hline$D_{0} \times D_{M X F}$ & & & $\begin{array}{c}0.050 * * \\
(0.030)\end{array}$ & $\begin{array}{c}0.050 * * * \\
(0.002)\end{array}$ & $\begin{array}{c}0.008 \\
(0.672)\end{array}$ \\
\hline$D_{5} \times D_{M X F}$ & & & $\begin{array}{c}0.021 * * \\
(0.028)\end{array}$ & $\begin{array}{c}0.021 * * * \\
(0.003)\end{array}$ & $\begin{array}{c}0.002 \\
(0.793)\end{array}$ \\
\hline Triple Interactions & & & & & \\
\hline$D_{8} \times D_{\text {indv }} \times D_{M X F}$ & & & & & $\begin{array}{l}-0.001 \\
(0.927)\end{array}$ \\
\hline$D_{4} \times D_{i n d v} \times D_{M X F}$ & & & & & $\begin{array}{c}-0.012^{* *} * \\
(0.042)\end{array}$ \\
\hline$D_{0} \times D_{i n d v} \times D_{M X F}$ & & & & & $\begin{array}{l}0.036^{*} \\
(0.091)\end{array}$ \\
\hline$D_{5} \times D_{\text {indv }} \times D_{M X F}$ & & & & & $\begin{array}{c}0.017 * * \\
(0.032)\end{array}$ \\
\hline$D_{8} \times D_{Q F I I} \times D_{M X F}$ & & & & & $\begin{array}{l}-0.001 \\
(0.903)\end{array}$ \\
\hline$D_{4} \times D_{Q F I I} \times D_{M X F}$ & & & & & $\begin{array}{l}-0.019 \\
(0.134)\end{array}$ \\
\hline$D_{0} \times D_{Q F I I} \times D_{M X F}$ & & & & & $\begin{array}{c}0.089 * * \\
(0.034)\end{array}$ \\
\hline$D_{5} \times D_{Q F I I} \times D_{M X F}$ & & & & & $\begin{array}{c}0.042 * * \\
(0.019)\end{array}$ \\
\hline$D_{\text {indv }}$ & & $\begin{array}{c}-0.022 * * * \\
(0.000)\end{array}$ & & $\begin{array}{c}-0.022 * * * \\
(0.000)\end{array}$ & $\begin{array}{c}-0.022 * * * \\
(0.000)\end{array}$ \\
\hline$D_{Q F I I}$ & & $\begin{array}{c}-0.008 * * \\
(0.015)\end{array}$ & & $\begin{array}{c}-0.008 * * \\
(0.015)\end{array}$ & $\begin{array}{c}-0.008 * * \\
(0.016)\end{array}$ \\
\hline$D_{M X F}$ & & & $\begin{array}{c}-0.006 * * \\
(0.025)\end{array}$ & $\begin{array}{c}-0.006^{* *} \\
(0.014)\end{array}$ & $\begin{array}{c}-0.006^{* * *} \\
(0.015)\end{array}$ \\
\hline Constant & $\begin{array}{c}-0.012 * * * \\
(0.008)\end{array}$ & $\begin{array}{c}-0.002 \\
(0.613)\end{array}$ & $\begin{array}{c}-0.009 * * \\
(0.023)\end{array}$ & $\begin{array}{c}0.001 \\
(0.806)\end{array}$ & $\begin{array}{c}0.001 \\
(0.821)\end{array}$ \\
\hline Year fixed effect & Yes & Yes & Yes & Yes & Yes \\
\hline Number of obs. & 357 & 357 & 357 & 357 & 357 \\
\hline Adjusted $\mathrm{R}^{2}$ & 0.581 & 0.751 & 0.606 & 0.779 & 0.797 \\
\hline$F$-test & & & & & \\
\hline$D_{8}-D_{4}$ & $\begin{array}{l}0.017 * * * \\
(0.000)\end{array}$ & $\begin{array}{l}0.002 \\
(0.578)\end{array}$ & $\begin{array}{l}0.014 * * * \\
(0.000)\end{array}$ & $\begin{array}{l}-0.001 \\
(0.833)\end{array}$ & $\begin{array}{l}0.004 \\
(0.305)\end{array}$ \\
\hline$D_{8} \times D_{i n d v}-D_{4} \times D_{i n d v}$ & & $\begin{array}{l}0.033 \text { *** } \\
(0.000)\end{array}$ & & $\begin{array}{l}0.033 * * * \\
(0.000)\end{array}$ & $\begin{array}{l}0.028 * * * \\
(0.000)\end{array}$ \\
\hline$D_{8} \times D_{Q F I I}-D_{4} \times D_{Q F I I}$ & & $\begin{array}{l}0.012 \\
(0.161)\end{array}$ & & $\begin{array}{l}0.011 \\
(0.157)\end{array}$ & $\begin{array}{l}0.003 \\
(0.685)\end{array}$ \\
\hline$D_{8} \times D_{M X F}-D_{4} \times D_{M X F}$ & & & $\begin{array}{l}0.006 \\
(0.394)\end{array}$ & $\begin{array}{l}0.006 \\
(0.260)\end{array}$ & $\begin{array}{l}-0.004 \\
(0.624)\end{array}$ \\
\hline$D_{8} \times D_{\text {indv }} \times D_{M X F}-D_{4} \times D_{i n d v} \times D_{M X F}$ & & & & & $\begin{array}{l}0.011 \\
(0.169)\end{array}$ \\
\hline$D_{8} \times D_{i n d v} \times D_{M X F}-D_{4} \times D_{i n d v} \times D_{M X F}$ & & & & & $\begin{array}{l}0.018 \\
(0.247)\end{array}$ \\
\hline
\end{tabular}




\section{Table III. Superstition Index and Related Individual Investor Traits}

In this table we report the correlations between the superstition index and other individual investor traits. $S I_{i, t-1}$ and $S I_{i, t}$ are investor $i$ 's superstition indices in two consecutive years $t-1$ and $t$, calculated as the difference between limit order submission ratios at " 8 " and " $4 . "$ In each year, we calculate the investor's submission ratio at " 8 " as the number of limit orders submitted at prices ending with " 8 " divided by the total number of limit orders submitted at all prices. The submission ratio at "4" is calculated in a similar fashion. OrderSize $e_{i, t}$ is the average number of contracts per limit order submitted by investor $i$ in year $t$. SubRatio ${ }_{0}$ and $5, i, t$ is investor $i$ 's submission ratio in year $t$ at prices ending with " 0 " and "5." $\operatorname{Ln}\left(N_{i, t}\right)$ is the $\log$ of number of limit orders submitted by investor $i$ within year $t$. Disposition $i, t$ is the difference between the durations of losing and winning round-trip trades of investor $i$ in year $t$, divided by their average. To ensure a reasonable magnitude of the superstition index, we require that investors submit at least 10 limit orders in each of two consecutive years. The p-values are reported in parentheses. *, **, and $* * *$ indicate significance levels of $0.1,0.05$, and 0.01 , respectively.

\begin{tabular}{|c|c|c|c|c|c|c|}
\hline Correlations & $S I_{i, t}$ & $S I_{i, t-1}$ & OrderSize $_{i, t}$ & SubRatio $_{0}$ and $5, i, t$ & $\operatorname{Ln}\left(N_{i, t}\right)$ & Disposition $_{i, t}$ \\
\hline$S I_{i, t}$ & 1.0000 & & & & & \\
\hline$S I_{i, t-1}$ & $\begin{array}{c}0.4205^{* * *} * \\
(0.000)\end{array}$ & 1.0000 & & & & \\
\hline OrderSize $_{i, t}$ & $\begin{array}{c}-0.0229 * * * \\
(0.000)\end{array}$ & $\begin{array}{c}-0.0223 * * * \\
(0.000)\end{array}$ & 1.0000 & & & \\
\hline SubRatio $_{0}$ and $5, i, t$ & $\begin{array}{c}-0.0821 * * * \\
(0.000)\end{array}$ & $\begin{array}{c}-0.1134 * * * \\
(0.000)\end{array}$ & $\begin{array}{c}-0.0409 * * * \\
(0.000)\end{array}$ & 1.0000 & & \\
\hline $\operatorname{Ln}\left(N_{i, t}\right)$ & $\begin{array}{c}0.0043 * * * \\
(0.0936)\end{array}$ & $\begin{array}{c}-0.0037 \\
(0.1474)\end{array}$ & $\begin{array}{c}0.0894 * * * \\
(0.000)\end{array}$ & $\begin{array}{c}-0.1915 * * * \\
(0.000)\end{array}$ & 1.0000 & \\
\hline Disposition $_{i, t}$ & $\begin{array}{c}0.0475^{* * *} * \\
(0.000)\end{array}$ & $\begin{array}{c}0.0421 * * * \\
(0.000)\end{array}$ & $\begin{array}{c}-0.0322 * * * \\
(0.000)\end{array}$ & $\begin{array}{c}-0.0185^{* * *} * \\
(0.000)\end{array}$ & $\begin{array}{c}0.0790 * * * \\
(0.000)\end{array}$ & 1.0000 \\
\hline
\end{tabular}




\section{Table IV. Superstition Index and Investment Performance of Individual Investors - Quintile Analysis}

In this table, we sort individual investors into quintiles by the superstition index in one year, and report their returns in the subsequent year. Panel A shows the mark-to-market returns of limit orders. Panel B shows the mark-to-market returns of market orders. Mark-to-market intraday return is the difference between the trade price and the daily closing price divided by the trade price. Mark-to-market 1-day and 5-day returns are calculated in a similar fashion. Panel C shows the performance of round-trip trades. Round-trip duration is the number of trading days between the initiating and closing positions of a round-trip trade. For each investor, we calculate the round-trip daily profit and daily index return as the average roundtrip profit or index return divided by the average round-trip duration. In all panels, Quintile-5 (Q5) investors are more superstitious. In each year, we calculate the superstition index for each investor as the difference between limit order submission ratios at " 8 " and "4." We calculate the investor's submission ratio at " 8 " as the number of limit orders submitted at prices ending with " 8 " divided by the total number of limit orders submitted at all prices. The submission ratio at " 4 " is calculated in a similar fashion. All items are first calculated for each investor-year observation and then averaged for each quintile with equal weights. To ensure a reasonable magnitude of superstition index, we require that investors submit at least 10 limit orders in each of two consecutive years. The Satterthwaite p-value assumes unequal variances of investor performance in quintiles 1 and $5 . * * *$, and $* * *$ indicate significance levels of $0.1,0.05$, and 0.01 , respectively.

Panel A: Mark-To-Market Returns of Limit Orders

\begin{tabular}{|c|c|c|c|c|c|c|c|}
\hline Quintile Ranks & Q1 & Q2 & Q3 & $\mathrm{Q} 4$ & Q5 & Diff (Q5-Q1) & p-value \\
\hline Intraday $(\%)$ & -0.078 & -0.088 & -0.087 & -0.086 & -0.095 & $-0.017 * * *$ & 0.000 \\
\hline 1-day $(\%)$ & -0.111 & -0.136 & -0.126 & -0.128 & -0.135 & $-0.024 * * *$ & 0.000 \\
\hline 5-day $(\%)$ & -0.179 & -0.240 & -0.219 & -0.211 & -0.242 & $-0.063 * * *$ & 0.000 \\
\hline \multicolumn{8}{|c|}{ Panel B: Mark-To-Market Returns of Market Orders } \\
\hline Quintile Ranks & Q1 & Q2 & Q3 & Q4 & Q5 & Diff (Q5-Q1) & p-value \\
\hline Intraday $(\%)$ & -0.039 & -0.055 & -0.048 & -0.055 & -0.052 & $-0.013 * *$ & 0.015 \\
\hline 1-day $(\%)$ & -0.070 & -0.097 & -0.101 & -0.099 & -0.099 & $-0.030 * *$ & 0.011 \\
\hline 5-day $(\%)$ & -0.146 & -0.11 & -0.192 & -0.195 & -0.203 & $-0.056 * *$ & 0.015 \\
\hline \multicolumn{8}{|l|}{ Panel C: Round-Trip Performance } \\
\hline Quintile Ranks & Q1 & Q2 & Q3 & Q4 & Q5 & Diff (Q5-Q1) & $\mathrm{p}$-value \\
\hline Round-trip daily profit (TWD) & $-1,002$ & $-1,690$ & $-1,526$ & $-2,322$ & $-2,201$ & $-1,199 *$ & 0.096 \\
\hline Round-trip daily index return $(\%)$ & -0.076 & -0.135 & -0.134 & -0.195 & -0.181 & $-0.105^{*}$ & 0.065 \\
\hline Number of round-trip trades & 61 & 58 & 67 & 54 & 43 & $-18 * * *$ & 0.000 \\
\hline Round-trip duration (day) & 2.256 & 2.555 & 2.273 & 2.293 & 2.570 & $0.314 * * *$ & 0.000 \\
\hline Duration of winning round-trips (day) & 1.922 & 2.130 & 1.908 & 1.875 & 2.086 & $0.164 * * *$ & 0.000 \\
\hline Duration of losing round-trips (day) & 3.010 & 3.456 & 3.109 & 3.204 & 3.619 & $0.609 * * *$ & 0.000 \\
\hline
\end{tabular}


Table V. Individual Investors' Superstition Index, Market Return, and the Buy Ratio and Buy-sell Ratio - Quintile Analysis

In this table we report the Buy Ratio and Buy-sell Ratio for individual investors with various superstition indices and under different market returns. We first sort individual investors into quintiles by the superstition index in one year. Investors in quantile 5 (Q\%) of the superstitious index are the most superstitious. We then sort the trading days of the next year into quintiles based on the daily market returns. Market returns on trading days in Quintile-5 (M5) are the highest. We then compute the average Buy Ratio and average Buy-Sell Ratio of each product (MXF or TXF orders that expire in one month, two months, three months, six months, nine months, or one year) for the investors in each superstitious quintile and market return quintile. We define $S I_{i, t-1}$ as the difference between limit order submission ratios at " 8 " and " 4 " for investor $i$ in year $t$ 1. We calculate the investor's submission ratio at " 8 " as the number of limit orders submitted at prices ending with "8" divided by the total number of limit orders submitted at all prices. The submission ratio at "4" is calculated in a similar fashion. The Buy Ratio is calculated as the number of buy contracts (taking long positions) scaled by total number of executed contracts. We calculate the Buy-sell Ratio as the difference between the numbers of buy and sell contracts, divided by their average. Both limit and market orders are included in the calculation of Buy Ratio and Buy-sell Ratio. To ensure a reasonable magnitude of superstition index, we require that investors submit at least 10 limit orders in each of two consecutive years. The Satterthwaite $\mathrm{p}$-value assumes unequal variances of investor performance in quintiles 1 and $5 . *$, **, and *** indicate significance levels of $0.1,0.05$, and 0.01 , respectively.

Panel A: Buy Ratio

\begin{tabular}{lcccccc} 
Quintile Ranks of & \multicolumn{3}{c}{ Quintile Ranks of $S I_{i, t-1}$} & $\mathrm{Q} 4$ & $\mathrm{Q} 5$ & Diff $(\mathrm{Q} 5-\mathrm{Q} 1)$ \\
\cline { 2 - 6 } Market Return & $\mathrm{Q} 1$ & $\mathrm{Q} 2$ & $\mathrm{Q} 3$ & 0.678 & 0.723 & $0.098^{* * *}$ \\
M1 & 0.625 & 0.667 & 0.633 & 0.635 & 0.659 & $0.073^{* * *}$ \\
M2 & 0.587 & 0.618 & 0.613 & 0.000 & 0.000 \\
M3 & 0.595 & 0.608 & 0.613 & 0.623 & 0.640 & $0.045^{* * *}$ \\
M4 & 0.625 & 0.605 & 0.611 & 0.614 & 0.630 & 0.000 \\
M5 & 0.614 & 0.583 & 0.604 & 0.603 & 0.601 & -0.013 \\
& & & & & 0.593 \\
Diff (M5-M1) & -0.012 & $-0.084^{* * *}$ & $-0.029^{* * *}$ & $-0.076^{* * *}$ & $-0.122^{* * *}$ & \\
p-value & 0.157 & 0.000 & 0.000 & 0.000 & 0.000 & \\
\hline
\end{tabular}


Panel B: Buy-Sell Ratio

\begin{tabular}{lcccccc} 
Quintile Ranks of & \multicolumn{3}{c}{ Quintile Ranks of $S I_{i, t-1}$} & $\mathrm{Q} 4$ & $\mathrm{Q} 5$ & Diff (Q5-Q1) \\
\cline { 2 - 6 } Market Return & $\mathrm{Q} 1$ & $\mathrm{Q} 2$ & $\mathrm{Q} 3$ & 0.713 & 0.893 & $0.391^{* * *}$ \\
M1 & 0.502 & 0.668 & 0.533 & 0.000 & $0.290^{* * *}$ \\
M2 & 0.346 & 0.473 & 0.450 & 0.540 & 0.636 & 0.000 \\
M3 & 0.380 & 0.433 & 0.451 & 0.490 & 0.559 & $0.178^{* * *}$ \\
M4 & 0.502 & 0.419 & 0.446 & 0.457 & 0.519 & 0.017 \\
M5 & 0.455 & 0.333 & 0.415 & 0.411 & 0.403 & -0.052 \\
& & & & & 0.593 \\
Diff (M5-M1) & -0.047 & $-0.335^{* * *}$ & $-0.118^{* * *}$ & $-0.302^{* * *}$ & $-0.490^{* * *}$ & \\
p-value & 0.157 & 0.000 & 0.000 & 0.000 & 0.000 & \\
\hline
\end{tabular}




\section{Table VI. Investors' Learning and Superstition}

In this table we report the parameter estimates from the following regression for individual investors:

$$
\begin{aligned}
S I_{i, t}-S I_{i, t-1}=\alpha & +\beta_{1} \operatorname{Ln}_{\left(N_{i, t-1}\right)+\beta_{2} \text { Return }_{8, i, t-1}+\beta_{3} \text { Return }_{4, i, t-1}+\beta_{4} \text { Return }_{\text {other }, i, t-1}} \\
& +\beta_{5} \text { Return }_{\text {market }, i, t-1}+\beta_{6} \text { SI }_{i, t-1}+\beta_{7} \text { OrderSize }_{i, t-1}+\beta_{8} \text { SubRatio }_{0 \text { and } 5, i, t-1} \\
& +\beta_{9} \text { Disposition }_{i, t-1}+\varepsilon_{X}
\end{aligned}
$$

where $S I_{i, t}$ and $S I_{i, t-1}$ are the superstition indices in year $t$ and $t-1$, and they are calculated as the difference between limit order submission ratios at " 8 " and " 4 " in each year. We calculate the investor's submission ratio at " 8 " as the number of limit orders submitted at prices ending with " 8 " divided by the total number of limit orders submitted at all prices. The submission ratio at " 4 " is calculated in a similar fashion. $\operatorname{Ln}\left(N_{i, t-1}\right)$ is the $\log$ of the number of limit orders submitted at year $t-1$. Return $n_{8, i, t-1}$ is the mark-to-market intraday return of limit orders submitted at prices ending with " 8 " at year $t-1$. Return $_{4, i, t-1}$ is the mark-to-market intraday return of limit orders submitted at prices ending with " 4 " at year $t$-1. Return others,i,t-1 $_{\text {is }}$ is mark-to-market intraday return of limit orders submitted at prices ending with other numbers at year $t-1$. Return market $, i, t-1_{\text {is }}$ is the mark-to-market intraday return of market orders at year $t$-1. OrderSize Ort $_{-1}$ is the average number of contracts per limit order at year $t-1$. SubRatio $_{0 \text { and } 5, i, t-1}$ is the sum of investor $i$ 's submission ratios at prices ending with " 0 " and " 5 " at year $t$-1. Disposition ${ }_{i, t-1}$ is the disposition effect, which is calculated as the difference between winning and losing round-trip trades, divided by the average of the two at year $t-1$. We require that investors must

\begin{tabular}{|c|c|c|c|c|c|c|}
\hline \multirow{2}{*}{$\begin{array}{l}\text { Independent } \\
\text { Variables }\end{array}$} & \multicolumn{6}{|c|}{$S I_{i, t}-S I_{i, t-1}(\%)$} \\
\hline & Model 1 & Model 2 & Model 3 & Model 4 & Model 5 & Model 6 \\
\hline $\operatorname{Ln}\left(N_{i, t-1}\right)$ & $\begin{array}{c}-0.096 * * * \\
(0.000)\end{array}$ & & & & & $\begin{array}{c}-0.188 * * * \\
(0.000)\end{array}$ \\
\hline $\operatorname{Return}_{8, i, t-1}(\%)$ & & $\begin{array}{l}-0.053 \\
(0.449)\end{array}$ & & & & $\begin{array}{l}-0.103 \\
(0.343)\end{array}$ \\
\hline Return $_{4, i, t-1}(\%)$ & & & $\begin{array}{l}-0.040 \\
(0.581)\end{array}$ & & & $\begin{array}{l}-0.052 \\
(0.602)\end{array}$ \\
\hline $\begin{array}{l}\text { Return }_{\text {other }, i, t-1} \\
(\%)\end{array}$ & & & & $\begin{array}{c}-0.354 * * \\
(0.031)\end{array}$ & & $\begin{array}{c}-0.767 * * \\
(0.018)\end{array}$ \\
\hline $\begin{array}{l}\text { Return }_{\text {market }, i, t-1} \\
(\%)\end{array}$ & & & & & $\begin{array}{c}0.036 \\
(0.709)\end{array}$ & $\begin{array}{c}0.032 \\
(0.772)\end{array}$ \\
\hline$S I_{i, t-1}(\%)$ & $\begin{array}{c}-0.434 * * * \\
(0.000)\end{array}$ & $\begin{array}{c}-0.368 * * * \\
(0.000)\end{array}$ & $\begin{array}{c}-0.414 * * * \\
(0.000)\end{array}$ & $\begin{array}{c}-0.434 * * * \\
(0.000)\end{array}$ & $\begin{array}{c}-0.421 * * * \\
(0.000)\end{array}$ & $\begin{array}{c}-0.333 * * * \\
(0.000)\end{array}$ \\
\hline OrderSize $_{i, t-1}$ & $\begin{array}{c}-0.047 * * * \\
(0.000)\end{array}$ & $\begin{array}{c}-0.031 * * \\
(0.015)\end{array}$ & $\begin{array}{c}-0.054 * * * \\
(0.000)\end{array}$ & $\begin{array}{c}-0.050 * * * \\
(0.000)\end{array}$ & $\begin{array}{c}-0.040 * * * \\
(0.001)\end{array}$ & $\begin{array}{l}-0.013 \\
(0.293)\end{array}$ \\
\hline SubRatio $_{0}$ and $5, i, t-1$ & $\begin{array}{c}-0.932 * * * \\
(0.000)\end{array}$ & $\begin{array}{c}-0.855^{* * *} \\
(0.000)\end{array}$ & $\begin{array}{c}0.255 \\
(0.127)\end{array}$ & $\begin{array}{c}-0.823 * * * \\
(0.000)\end{array}$ & $\begin{array}{c}-0.539 * * * \\
(0.001)\end{array}$ & $\begin{array}{l}-0.017 \\
(0.940)\end{array}$ \\
\hline Disposition $_{i, t-1}$ & $\begin{array}{c}0.279 * * * \\
(0.000)\end{array}$ & $\begin{array}{c}0.294 * * * \\
(0.000)\end{array}$ & $\begin{array}{c}0.258 * * * \\
(0.000)\end{array}$ & $\begin{array}{c}0.265 * * * \\
(0.000)\end{array}$ & $\begin{array}{c}0.188 * * * \\
(0.002)\end{array}$ & $\begin{array}{c}0.207 * * * \\
(0.003)\end{array}$ \\
\hline Constant & $\begin{array}{c}2.785 * * * \\
(0.000)\end{array}$ & $\begin{array}{c}1.653 * * * \\
(0.000)\end{array}$ & $\begin{array}{c}1.767 * * * \\
(0.000)\end{array}$ & $\begin{array}{c}2.243 * * * \\
(0.000)\end{array}$ & $\begin{array}{c}2.059 * * * \\
(0.000)\end{array}$ & $\begin{array}{c}2.274 * * * \\
(0.000)\end{array}$ \\
\hline Year fixed effect & Yes & Yes & Yes & Yes & Yes & Yes \\
\hline Number of obs. & 56,260 & 47,462 & 40,029 & 56,169 & 32,890 & 22,298 \\
\hline Adjusted $\mathrm{R}^{2}$ & 0.168 & 0.128 & 0.140 & 0.167 & 0.150 & 0.090 \\
\hline
\end{tabular}
submit at least 10 limit orders in each of the two consecutive years, and we express the superstition index in percentage. $*, * *$, and $* * *$ indicate significance levels of $0.1,0.05$, and 0.01 , respectively. 


\section{Figure 1. Limit Order Submission Ratios at Various Prices}

In this figure, we report the limit order submission ratios at prices ending with " $\mathrm{X}$ " ( $\mathrm{X}$ is an integer ranging from 0 to 9). The submission ratio at " $X$ " is calculated as the number of limit orders submitted at "X" divided by the total number of submitted limit orders. We report the figures separately for individual investors, domestic institutions, and Qualified Foreign Institutional Investors (QFIIs.)

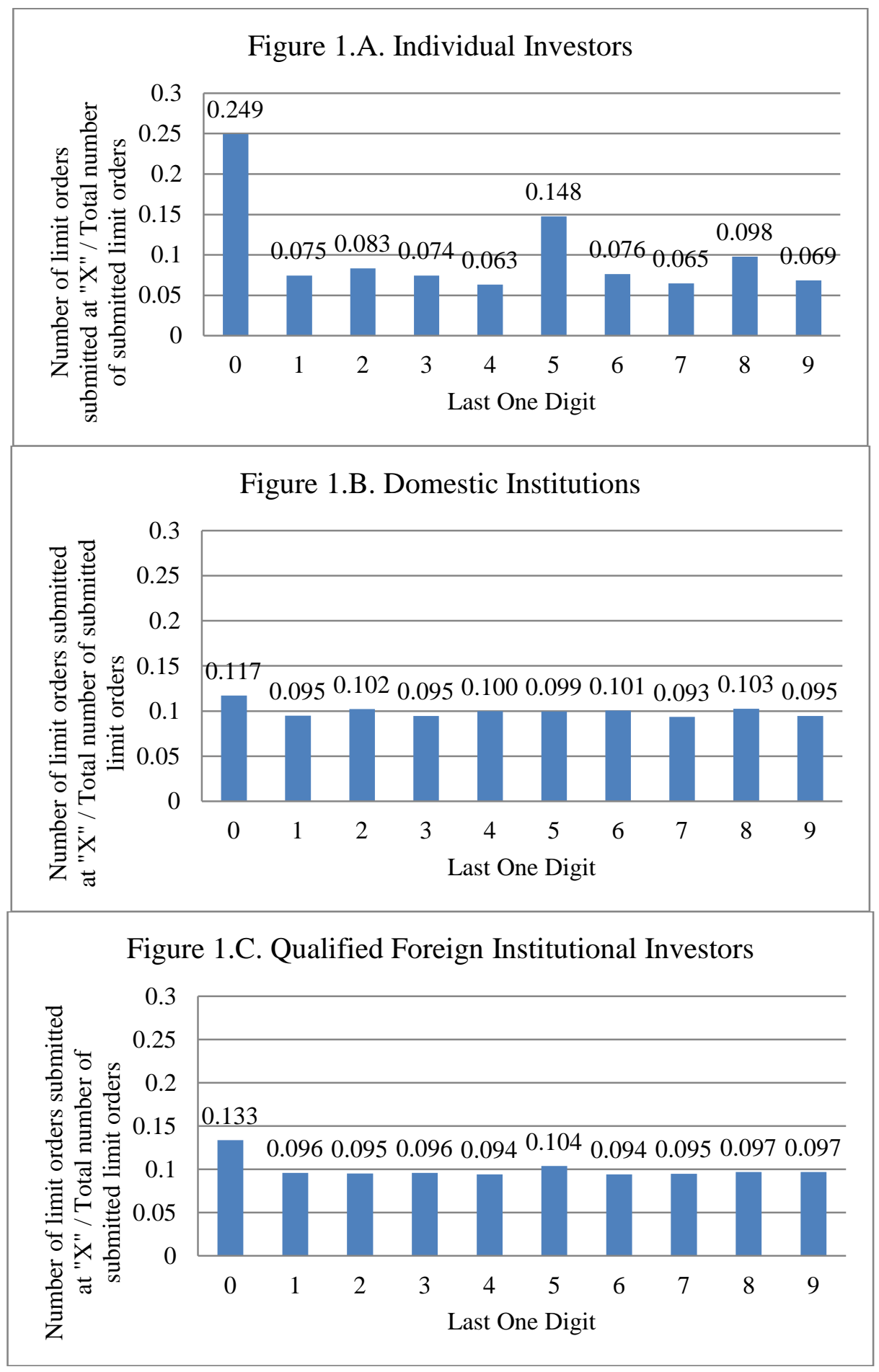




\section{Figure 2. Time-to-execution and Time-to-cancellation of Individual Investors' Limit Orders}

In this table we sort individual investors into quintiles by the superstition index in one year, and plot the time-to-execution and time-to-cancellation of limit orders submitted at prices ending with " $X$ " in the subsequent year. (X is an integer ranging from 0 to 9). Quintile-5 (Q5) investors are most superstitious. In each year, we calculate the superstition index for each investor as the difference between limit order submission ratios at " 8 " and " 4 ." The submission ratio at " 8 " is calculated as the number of limit orders submitted at prices ending with " 8 " divided by the total number of limit orders submitted at all prices. The submission ratio at " 4 " is calculated in a similar fashion. Time-to-execution is the interval from order submission to execution for executed limit orders. Time-to-cancellation is the interval from submission to cancellation for orders that are submitted and then deleted by individual investors.
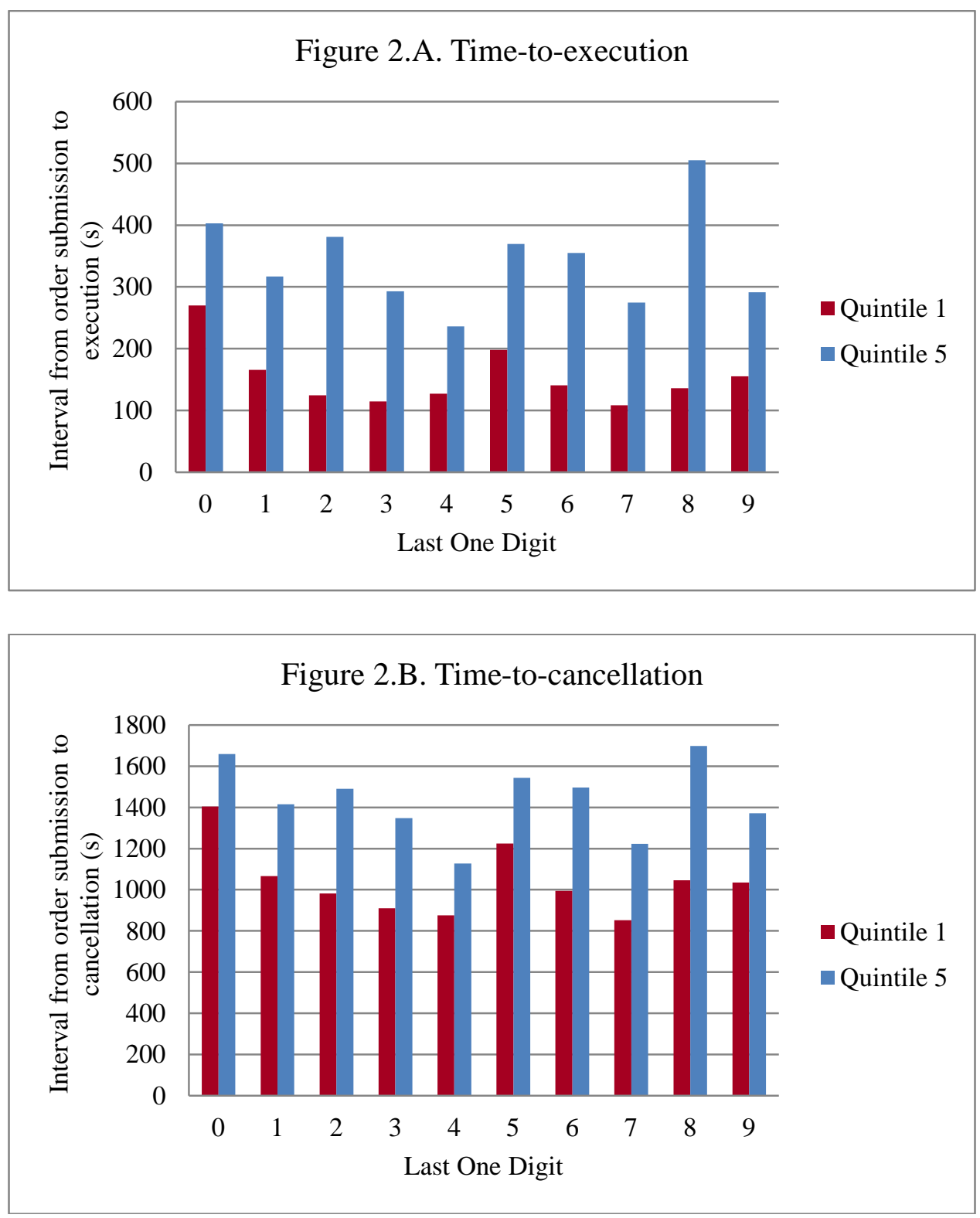
Do Superstitious Traders Lose Money?

\section{The APPENDIX}

\section{Utpal Bhattacharya}

Wei-Yu Kuo

Tse-Chun Lin

Jing Zhao 
Table AI. Descriptive Statistics of the Superstition Index

In this table, we report the summary statistics of the investor-level superstition index. In each year, we calculate the superstition index for each investor as the difference between limit order submission ratios at " 8 " and " 4 ." The submission ratio at " 8 " of an investor is calculated as the number of limit orders submitted at prices ending with " 8 " divided by the total number of limit orders submitted at all prices within a year. The submission ratio at " 4 " is calculated in a similar fashion. To ensure a reasonable magnitude of the superstition index, we require that investors submit at least 10 limit orders in each of two consecutive years. In 2008, we only have data for the first nine months.

Panel A: Individual Investors

\begin{tabular}{cccccccc}
\hline Year & Mean & Median & Standard Deviation & 20th Percentile & 40th Percentile & 60th Percentile & 80th Percentile \\
\hline 2003 & 0.0365 & 0.0292 & 0.0764 & 0.0000 & 0.0152 & 0.0435 & 0.0805 \\
2004 & 0.0408 & 0.0323 & 0.0799 & 0.0000 & 0.0185 & 0.0462 & 0.0833 \\
2005 & 0.0413 & 0.0323 & 0.0848 & 0.0000 & 0.0172 & 0.0476 & 0.0889 \\
2006 & 0.0425 & 0.0324 & 0.0836 & 0.0000 & 0.0189 & 0.0465 & 0.0857 \\
2007 & 0.0424 & 0.0303 & 0.0855 & 0.0000 & 0.0175 & 0.0439 & 0.0833 \\
2008 & 0.0493 & 0.0333 & 0.0909 & 0.0000 & 0.0213 & 0.0474 & 0.0882 \\
\hline
\end{tabular}

Panel B: Domestic Institutions

\begin{tabular}{|c|c|c|c|c|c|c|c|}
\hline Year & Mean & Median & Standard Deviation & 20th Percentile & 40th Percentile & 60th Percentile & 80th Percentile \\
\hline 2003 & 0.0273 & 0.0158 & 0.0820 & -0.0187 & 0.0000 & 0.0321 & 0.0690 \\
\hline 2004 & 0.0359 & 0.0241 & 0.0828 & -0.0083 & 0.0124 & 0.0364 & 0.0667 \\
\hline 2005 & 0.0285 & 0.0223 & 0.0733 & -0.0098 & 0.0114 & 0.0364 & 0.0684 \\
\hline 2006 & 0.0186 & 0.0132 & 0.0660 & -0.0114 & 0.0040 & 0.0270 & 0.0588 \\
\hline 2007 & 0.0221 & 0.0146 & 0.0613 & -0.0144 & 0.0000 & 0.0258 & 0.0601 \\
\hline 2008 & 0.0328 & 0.0192 & 0.0712 & -0.0065 & 0.0088 & 0.0313 & 0.0696 \\
\hline
\end{tabular}

Panel C: Qualified Foreign Institutional Investors

\begin{tabular}{|c|c|c|c|c|c|c|c|}
\hline Year & Mean & Median & Standard Deviation & 20th Percentile & 40th Percentile & 60th Percentile & 80th Percentile \\
\hline 2003 & 0.0005 & 0.0063 & 0.0356 & -0.0258 & 0.0048 & 0.0157 & 0.0232 \\
\hline 2004 & 0.0084 & 0.0124 & 0.0223 & 0.0037 & 0.0055 & 0.0140 & 0.0204 \\
\hline 2005 & -0.0087 & -0.0037 & 0.0447 & -0.0134 & -0.0055 & 0.0000 & 0.0198 \\
\hline 2006 & 0.0172 & 0.0063 & 0.0334 & -0.0010 & 0.0034 & 0.0098 & 0.0335 \\
\hline 2007 & 0.0150 & 0.0099 & 0.0347 & -0.0131 & 0.0044 & 0.0176 & 0.0336 \\
\hline 2008 & 0.0227 & 0.0131 & 0.0488 & -0.0003 & 0.0077 & 0.0233 & 0.0549 \\
\hline
\end{tabular}




\section{Table AII. Individual Investors' Superstition and Mark-to-market Returns of Limit Orders at "8," "4," "0," and other Numbers - Quintile Analysis}

In this table, we sort individual investors into quintiles by the superstition index in one year, and report the subsequent year's mark-to-market return of limit orders submitted at prices ending with " 8, , " 4, ," "0," and other numbers. Quintile-5 (Q5) investors are more superstitious. In each year, we calculate the superstition index for each investor as the difference between limit order submission ratios at "8" and "4." The submission ratio at " 8 " of an investor is calculated as the number of limit orders submitted at prices ending with " 8 " divided by the total number of limit orders submitted at all prices within a year. The submission ratio at "4" is calculated in a similar fashion. Mark-to-market intraday return is the difference between the trade price and the daily closing price divided by the trade price. Mark-to-market 1-day and 5-day returns are calculated in a similar fashion. All items are first calculated for each investor-year observation and then averaged for each quintile with equal weights. To ensure a reasonable magnitude of superstition index, we require that investors submit at least 10 limit orders in each of two consecutive years. The Satterthwaite p-value assumes unequal variances of investor performance in quintiles 1 and 5. *,**, and *** indicate significance levels of 0.1 , 0.05 , and 0.01 , respectively.

\begin{tabular}{|c|c|c|c|c|c|c|c|}
\hline Quintile Ranks & Q1 & Q2 & Q3 & Q4 & Q5 & Diff (Q5-Q1) & $\mathrm{p}$-value \\
\hline \multicolumn{8}{|c|}{ Mark-to-market returns of limit orders submitted at prices ending with "8" } \\
\hline Intraday (\%) & -0.056 & -0.056 & -0.055 & -0.068 & -0.073 & $-0.017 * * *$ & 0.002 \\
\hline 1-day $(\%)$ & -0.076 & -0.102 & -0.084 & -0.109 & -0.110 & $-0.034 * * *$ & 0.002 \\
\hline 5-day $(\%)$ & -0.063 & -0.153 & -0.117 & -0.134 & -0.166 & $-0.103 * * *$ & 0.000 \\
\hline \multicolumn{8}{|c|}{ Mark-to-market returns of limit orders submitted at prices ending with "4" } \\
\hline Intraday (\%) & -0.054 & -0.061 & -0.059 & -0.061 & -0.065 & $-0.011 *$ & 0.099 \\
\hline 1-day $(\%)$ & -0.081 & -0.103 & -0.097 & -0.095 & -0.089 & -0.008 & 0.535 \\
\hline 5-day $(\%)$ & -0.148 & -0.176 & -0.172 & -0.175 & -0.154 & -0.006 & 0.821 \\
\hline \multicolumn{8}{|c|}{ Mark-to-market returns of limit orders submitted at prices ending with "O" } \\
\hline Intraday $(\%)$ & -0.074 & -0.089 & -0.089 & -0.084 & -0.094 & $-0.020 * * *$ & 0.000 \\
\hline 1-day $(\%)$ & -0.111 & -0.128 & -0.126 & -0.119 & -0.131 & $-0.021 * *$ & 0.016 \\
\hline 5-day $(\%)$ & -0.185 & -0.241 & -0.208 & -0.183 & -0.221 & $-0.036 * *$ & 0.042 \\
\hline \multicolumn{8}{|c|}{ Mark-to-market returns of limit orders submitted at other prices } \\
\hline Intraday $(\%)$ & -0.076 & -0.086 & -0.085 & -0.084 & -0.097 & $-0.021 * * *$ & 0.000 \\
\hline 1-day (\%) & -0.110 & -0.132 & -0.123 & -0.128 & -0.138 & $-0.027 * * *$ & 0.000 \\
\hline 5-day (\%) & -0.179 & -0.223 & -0.216 & -0.217 & -0.243 & $-0.065 * * *$ & 0.000 \\
\hline
\end{tabular}




\section{Table AIII. Individual Investors' Superstition and Mark-to-market Returns of Limit Orders at Prices Ending with "X" - Regression Analysis}

In this table, we report the parameter estimates from the following regression:

$$
\begin{aligned}
\text { Return }_{X, i, t}=\alpha & +\beta_{1} \text { SI }_{i, t-1}+\left(\beta_{2} D_{8}+\beta_{3} D_{4}+\beta_{4} D_{0}\right) \times S_{i, t-1}+\beta_{5} D_{8}+\beta_{6} D_{4}+\beta_{7} D_{0} \\
& +\beta_{8} \text { OrderSize }_{i, t-1}+\beta_{9} \text { SubRatio }_{0} \text { and } 5, i, t-1 \\
& +\beta_{10} \operatorname{Ln}\left(N_{i, t-1}\right)+\beta_{11} \text { Disposition }_{i, t-1} \\
& \beta_{12} \text { Return }_{i, t-1}+\varepsilon_{X, i, t}
\end{aligned}
$$

where $\operatorname{Return}_{X, i, t}$ is the performance of individual limit orders submitted at prices ending with " $\mathrm{X}$ " for investor $i$ in year $t$ (X is an integer ranging from 0 to 9). $D_{8}, D_{4}$, and $D_{0}$ are dummy variables for $\mathrm{X}=8,4$, and 0 , respectively. Mark-to-market intraday return is the difference between the trade price and the daily closing price divided by the trade price. Mark-to-market 1-day and 5-day returns are calculated in a similar fashion. $S I_{i, t-1}$ is the superstition index of investor $i$ in year $t-1$, and it is calculated as the difference between limit order submission ratios at " 8 " and " 4 ." The submission ratio at " 8 " of an investor is calculated as the number of limit orders submitted at prices ending with " 8 " divided by the total number of limit orders submitted at all prices within a year. The submission ratio at "4" is calculated in a similar fashion. OrderSize $e_{i, t-1}$ is the average number of contracts per limit order submitted by investor $i$ in year t-1. SubRatio 0 and $5, i, t-1$ is the sum of investor $i$ 's submission ratios at prices ending with " 0 " and " 5 " in year $t-1 . \operatorname{Ln}\left(N_{i, t-1}\right)$ is the $\log$ of the number of limit orders submitted by investor $i$ in year $t-1$. Disposition $_{i, t-1}$ is the disposition effect, which is calculated as the difference between the durations of losing and winning round-trip trades of investor $i$ in year $t-1$, divided by their average. Return $_{i, t-1}$ is the average intraday, 1-day, or 5-day mark-to-market return for investor $i$ in year $t$-1. To ensure a reasonable

\begin{tabular}{|c|c|c|c|}
\hline \multirow{2}{*}{$\begin{array}{l}\text { Independent } \\
\text { Variable }\end{array}$} & \multicolumn{3}{|c|}{ Mark-to-market Return of Limit Orders (\%) } \\
\hline & Intraday & 1-day & 5-day \\
\hline \multirow[t]{2}{*}{$S I_{i, t-1}$} & $-0.072 * * *$ & $-0.094 *$ & $-0.220 * *$ \\
\hline & $(0.000)$ & $(0.054)$ & \\
\hline \multirow{2}{*}{$S I_{i, t-1} \times D_{8}$} & -0.016 & 0.046 & 0.028 \\
\hline & $(0.666)$ & $(0.555)$ & $(0.858)$ \\
\hline \multirow[t]{2}{*}{$S I_{i, t-1} \times D_{4}$} & -0.050 & -0.162 & 0.125 \\
\hline & $(0.381)$ & $(0.177)$ & $(0.596)$ \\
\hline \multirow{2}{*}{$S I_{i, t-1} \times D_{0}$} & -0.003 & -0.082 & -0.084 \\
\hline & $(0.947)$ & $(0.311)$ & $(0.599)$ \\
\hline \multirow[t]{2}{*}{$D_{8}$} & $0.011 * * *$ & 0.002 & 0.010 \\
\hline & $(0.002)$ & $(0.772)$ & $(0.491)$ \\
\hline \multirow[t]{2}{*}{$D_{4}$} & $0.022 * * *$ & $0.025 * * *$ & $0.032 *$ \\
\hline & $(0.000)$ & $(0.002)$ & $(0.055)$ \\
\hline \multirow[t]{2}{*}{$D_{0}$} & 0.002 & $0.016^{* * *}$ & $0.026^{* *}$ \\
\hline & $(0.406)$ & $(0.004)$ & $(0.028)$ \\
\hline \multirow[t]{2}{*}{ OrderSize $_{i, t-1}$} & $0.002 * * *$ & 0.000 & -0.002 \\
\hline & $(0.000)$ & $(0.624)$ & $(0.230)$ \\
\hline \multirow[t]{2}{*}{ SubRatio $_{0}$ and $5, i, t-1$} & $-0.039 * * *$ & $-0.084 * * *$ & $-0.151 * * *$ \\
\hline & $(0.000)$ & $(0.000)$ & $(0.000)$ \\
\hline \multirow[t]{2}{*}{$\operatorname{Ln}\left(N_{i, t-1}\right)$} & $0.010 * * *$ & $0.013 * * *$ & $0.010 * * *$ \\
\hline & $(0.000)$ & $(0.000)$ & $(0.008)$ \\
\hline
\end{tabular}
magnitude of the superstition index, we require that investors submit at least 10 limit orders in each of two consecutive years. ${ }^{*}, * *$, and $* * *$ indicate significance levels of $0.1,0.05$, and 0.01 , respectively. 


\begin{tabular}{lccc} 
Disposition $_{i, t-1}$ & $-0.027 * * *$ & $-0.035 * * *$ & $-0.027 * * *$ \\
& $(0.000)$ & $(0.000)$ & $(0.000)$ \\
Return $_{i, t-1}$ & $0.015^{* * *}$ & 0.005 & $0.008 * *$ \\
& $(0.000)$ & $(0.185)$ & $(0.026)$ \\
Constant & $-0.052^{* * *}$ & $-0.083 * * *$ & $-0.071 * * *$ \\
& $(0.000)$ & $(0.000)$ & $(0.005)$ \\
Year fixed effect & Yes & Yes & Yes \\
Number of obs. & 176,888 & 176,622 & 172,041 \\
Adjusted R & 0.008 & 0.003 & 0.005 \\
\hline
\end{tabular}




\section{Table AIV. Number of "X"s Where Superstitious Individual Investors Underperform}

In this table, we sort individual investors into quintiles by the superstition index in one year, and examine the performance of limit orders submitted at prices ending with " $\mathrm{X}$ " in the subsequent year ( $\mathrm{X}$ is an integer ranging from 0 to 9). We report the number of " $X$ "s where Quintile-5 investors (significantly) underperform Quintile-1 investors. Quintile-5 (Q5) investors are more superstitious. In each year, we calculate the superstition index for each investor as the difference between limit order submission ratios at " 8 " and "4." The submission ratio at " 8 " of an investor is calculated as the number of limit orders submitted at prices ending with " 8 " divided by the total number of limit orders submitted at all prices within a year. The submission ratio at " 4 " is calculated in a similar fashion. The underperformance is determined based on the intraday, 1-day, as well as 5-day mark-to-market returns of limit orders. Mark-tomarket intraday return is the difference between the trade price and the daily closing price divided by the trade price. Mark-to-market 1-day and 5-day returns are calculated in a similar fashion. To ensure a reasonable magnitude of superstition index, we require that investors submit at least 10 limit orders in each of two consecutive years. The Satterthwaite p-value assumes unequal variances of investor performance in quintiles 1 and 5. *,**, and *** indicate significance levels of $0.1,0.05$, and 0.01 , respectively.

\begin{tabular}{cccc}
\hline Significance & Number of "X"s where Q-5 individual investors underperform Q-1 investors \\
\cline { 2 - 4 } Level & Intraday & 1-day & 5-day \\
\hline $\mathrm{p}<1$ & 10 & 10 & 10 \\
$\mathrm{p}<0.1$ & 10 & 10 & 10 \\
$\mathrm{p}<0.05$ & 10 & 10 & 10 \\
$\mathrm{p}<0.01$ & 10 & 10 & 10 \\
\hline
\end{tabular}




\section{Table AV. Superstition Index and Investment Performance of All Investors - Regression Analysis}

In this table we report the parameter estimates for the following panel regression:

$\operatorname{Return}_{i, t}=\alpha+\beta_{1}$ SI I $_{i, t-1}+\beta_{2}$ OrderSize $_{i, t-1}+\beta_{3}$ SubRatio $_{0 \text { and } 5, i, t-1}+\beta_{4} \operatorname{Ln}\left(N_{i, t-1}\right)+\beta_{5}$ Disposition $_{i, t-1}+\beta_{6}$ Return $_{i, t-1}+\varepsilon_{i, t}$

where Return $_{i, t}$ and Return $_{i, t-1}$ are the average mark-to-market returns or round-trip performance for investor $i$ in year $t$ and year $t-1$. $S I_{i, t-1}$ is investor $i$ 's superstition index in year $t-1$, calculated as the difference between limit order submission ratios at " 8 " and " 4 ." In each year, we calculate the investor's submission ratio at " 8 " as the number of limit orders submitted at prices ending with " 8 " divided by the total number of limit orders submitted at all prices. The submission ratio at "4" is calculated in a similar fashion. OrderSize $e_{i, t-1}$ is the average number of contracts per limit order submitted by investor $i$ in year $t-1$. SubRatio ${ }_{0}$ and $5, i, t-1$ is the sum of investor $i$ 's submission ratios at prices ending with " 0 " and " 5 " in year $t-1 . \operatorname{Ln}\left(N_{i, t-1}\right)$ is the log of number of limit orders submitted by investor $i$ in the previous year. Disposition ${ }_{i, t-1}$ is the difference between the durations of losing and winning round-trip trades of investor $i$ in year $t-1$, divided by their average. Mark-to-market return of limit (market) orders is the return under the assumption that the initiating limit (market) orders are covered at the closing price of a trading day. The round-trip daily profit and daily index return are calculated as the average round-trip profit or index return divided by the average round-trip duration for each investor. Results for individual (Panel A) and institutional investors (Panels B and C) are reported separately. Standard errors are adjusted for heteroskedasticity. To ensure a reasonable magnitude of the superstition index, we require that investors submit at least 10 limit orders in each of two consecutive years. $* * *$, and $* * *$ indicate significance levels of $0.1,0.05$, and 0.01 , respectively. 
Panel A: Individual Investors

\begin{tabular}{|c|c|c|c|c|c|c|c|c|}
\hline \multirow{2}{*}{$\begin{array}{l}\text { Independent } \\
\text { Variable }\end{array}$} & \multicolumn{3}{|c|}{$\begin{array}{c}\text { Mark-to-market Return of Limit } \\
\text { Orders }(\%)\end{array}$} & \multicolumn{3}{|c|}{$\begin{array}{c}\text { Mark-to-market Return of Market } \\
\text { Orders }(\%)\end{array}$} & \multicolumn{2}{|c|}{ Round-trip Performance } \\
\hline & Intraday & 1-day & 5-day & Intraday & 1-day & 5-day & $\begin{array}{l}\text { Daily profit } \\
\text { (TWD) }\end{array}$ & $\begin{array}{l}\text { Daily index return } \\
(\%)\end{array}$ \\
\hline$S I_{i, t-1}$ & $\begin{array}{c}-0.029 * * * \\
(0.003)\end{array}$ & $\begin{array}{l}-0.035^{*} \\
(0.094)\end{array}$ & $\begin{array}{c}-0.090 * * \\
(0.045)\end{array}$ & $\begin{array}{l}-0.014 \\
(0.627)\end{array}$ & $\begin{array}{l}-0.092 \\
(0.120)\end{array}$ & $\begin{array}{l}-0.198 * \\
(0.090)\end{array}$ & $\begin{array}{l}-8,589.073 * \\
\quad(0.065)\end{array}$ & $\begin{array}{l}-0.696 * \\
(0.064)\end{array}$ \\
\hline OrderSize $_{i, t-1}$ & $\begin{array}{c}0.001 * * * \\
(0.001)\end{array}$ & $\begin{array}{l}-0.000 \\
(0.745)\end{array}$ & $\begin{array}{l}-0.001 \\
(0.425)\end{array}$ & $\begin{array}{c}0.000 \\
(0.672)\end{array}$ & $\begin{array}{l}-0.000 \\
(0.861)\end{array}$ & $\begin{array}{l}-0.005 \\
(0.169)\end{array}$ & $\begin{array}{c}-345.576 \\
(0.556)\end{array}$ & $\begin{array}{l}-0.022 \\
(0.632)\end{array}$ \\
\hline SubRatio $_{0}$ and $5, i, t-1$ & $\begin{array}{c}-0.023 * * * \\
(0.000)\end{array}$ & $\begin{array}{c}-0.050 * * * \\
(0.000)\end{array}$ & $\begin{array}{c}-0.096 * * * \\
(0.000)\end{array}$ & $\begin{array}{l}-0.017 * \\
(0.052)\end{array}$ & $\begin{array}{c}-0.050 * * * \\
(0.009)\end{array}$ & $\begin{array}{c}-0.076 * \\
(0.053)\end{array}$ & $\begin{array}{c}14,317.476 \\
(0.341)\end{array}$ & $\begin{array}{c}1.171 \\
(0.337)\end{array}$ \\
\hline $\operatorname{Ln}\left(N_{i, t-1}\right)$ & $\begin{array}{c}0.005^{* * * *} \\
(0.000)\end{array}$ & $\begin{array}{c}0.006 * * * \\
(0.000)\end{array}$ & $\begin{array}{c}0.004 \\
(0.189)\end{array}$ & $\begin{array}{c}0.008 * * * \\
(0.000)\end{array}$ & $\begin{array}{c}0.009 * * \\
(0.012)\end{array}$ & $\begin{array}{c}0.006 \\
(0.427)\end{array}$ & $\begin{array}{c}2,450.266 \\
(0.209)\end{array}$ & $\begin{array}{c}0.200 \\
(0.205)\end{array}$ \\
\hline Disposition $_{i, t-1}$ & $\begin{array}{c}-0.009 * * * \\
(0.000)\end{array}$ & $\begin{array}{c}-0.016 * * * \\
(0.000)\end{array}$ & $\begin{array}{c}-0.011 * * \\
(0.017)\end{array}$ & $\begin{array}{c}-0.012 * * * \\
(0.000)\end{array}$ & $\begin{array}{c}-0.015 * * \\
(0.019)\end{array}$ & $\begin{array}{c}-0.003 \\
(0.798)\end{array}$ & $\begin{array}{c}4,354.670 \\
(0.375)\end{array}$ & $\begin{array}{c}0.352 \\
(0.377)\end{array}$ \\
\hline $\operatorname{Return}_{i, t-1}$ & $\begin{array}{c}0.022 * * * \\
(0.000)\end{array}$ & $\begin{array}{c}0.010 * * * \\
(0.002)\end{array}$ & $\begin{array}{c}0.007 * * \\
(0.021)\end{array}$ & $\begin{array}{c}0.003 \\
(0.525)\end{array}$ & $\begin{array}{l}-0.001 \\
(0.825)\end{array}$ & $\begin{array}{c}0.001 \\
(0.878)\end{array}$ & $\begin{array}{c}0.057 * * \\
(0.033)\end{array}$ & $\begin{array}{c}0.056 * * \\
(0.050)\end{array}$ \\
\hline Constant & $\begin{array}{c}-0.101 * * * \\
(0.000)\end{array}$ & $\begin{array}{c}-0.132 * * * \\
(0.000)\end{array}$ & $\begin{array}{c}-0.269 * * * \\
(0.000)\end{array}$ & $\begin{array}{c}-0.048 * * * \\
(0.000)\end{array}$ & $\begin{array}{c}-0.077 * * * \\
(0.001)\end{array}$ & $\begin{array}{c}-0.144 * * * \\
(0.003)\end{array}$ & $\begin{array}{c}-22,735.463 \\
(0.190)\end{array}$ & $\begin{array}{l}-1.848 \\
(0.188)\end{array}$ \\
\hline Year fixed effect & Yes & Yes & Yes & Yes & Yes & Yes & Yes & Yes \\
\hline Number of obs. & 140,724 & 140,700 & 140,180 & 53,412 & 53,260 & 51,247 & 140,608 & 140,608 \\
\hline Adjusted $\mathrm{R}^{2}$ & 0.012 & 0.004 & 0.008 & 0.003 & 0.002 & 0.002 & -0.000 & -0.000 \\
\hline
\end{tabular}


Panel B: Domestic Institutions

\begin{tabular}{|c|c|c|c|c|c|c|c|c|}
\hline \multirow{2}{*}{$\begin{array}{l}\text { Independent } \\
\text { Variable }\end{array}$} & \multicolumn{3}{|c|}{$\begin{array}{c}\text { Mark-to-market Return of Limit } \\
\text { Orders }(\%)\end{array}$} & \multicolumn{3}{|c|}{$\begin{array}{c}\text { Mark-to-market Return of Market } \\
\text { Orders }(\%)\end{array}$} & \multicolumn{2}{|c|}{ Round-trip Performance } \\
\hline & Intraday & 1-day & 5-day & Intraday & 1-day & 5-day & $\begin{array}{l}\text { Daily profit } \\
\text { (TWD) }\end{array}$ & $\begin{array}{c}\text { Daily index return } \\
(\%)\end{array}$ \\
\hline$S I_{i, t-1}$ & $\begin{array}{l}-0.210 \\
(0.250)\end{array}$ & $\begin{array}{l}-0.630 \\
(0.164)\end{array}$ & $\begin{array}{l}-1.731 \\
(0.136)\end{array}$ & $\begin{array}{l}1.067^{*} \\
(0.090)\end{array}$ & $\begin{array}{l}1.603 \\
(0.108)\end{array}$ & $\begin{array}{c}0.909 \\
(0.697)\end{array}$ & $\begin{array}{l}-30,441.496 \\
(0.852)\end{array}$ & $\begin{array}{l}-2.953 \\
(0.804)\end{array}$ \\
\hline OrderSize $_{i, t-1}$ & $\begin{array}{c}0.001 \\
(0.626)\end{array}$ & $\begin{array}{l}0.005 \\
(0.149)\end{array}$ & $\begin{array}{c}0.009 \\
(0.292)\end{array}$ & $\begin{array}{l}0.003 \\
(0.516)\end{array}$ & $\begin{array}{c}0.008 \\
(0.473)\end{array}$ & $\begin{array}{c}0.006 \\
(0.882)\end{array}$ & $\begin{array}{c}-2,702.743 \\
(0.625)\end{array}$ & $\begin{array}{l}-0.152 \\
(0.684)\end{array}$ \\
\hline SubRatio $_{0}$ and $5, i, t-1$ & $\begin{array}{l}-0.094 \\
(0.154)\end{array}$ & $\begin{array}{r}-0.298^{*} \\
(0.070)\end{array}$ & $\begin{array}{l}-0.067 \\
(0.822)\end{array}$ & $\begin{array}{l}-0.239 \\
(0.234)\end{array}$ & $\begin{array}{l}-0.239 \\
(0.577)\end{array}$ & $\begin{array}{c}0.781 \\
(0.329)\end{array}$ & $\begin{array}{c}-109,654.930 * * \\
(0.038)\end{array}$ & $\begin{array}{l}-4.246 \\
(0.271)\end{array}$ \\
\hline $\operatorname{Ln}\left(N_{i, t-1}\right)$ & $\begin{array}{l}-0.002 \\
(0.720)\end{array}$ & $\begin{array}{l}-0.015 \\
(0.337)\end{array}$ & $\begin{array}{l}-0.002 \\
(0.951)\end{array}$ & $\begin{array}{l}-0.003 \\
(0.860)\end{array}$ & $\begin{array}{l}-0.029 \\
(0.381)\end{array}$ & $\begin{array}{c}0.021 \\
(0.765)\end{array}$ & $\begin{array}{l}-43,337.750 * * * \\
(0.006)\end{array}$ & $\begin{array}{l}-1.131 \\
(0.332)\end{array}$ \\
\hline Disposition $_{i, t-1}$ & $\begin{array}{c}-0.050 * * * \\
(0.002)\end{array}$ & $\begin{array}{c}-0.143 * * * \\
(0.000)\end{array}$ & $\begin{array}{c}-0.255^{* * *} * \\
(0.001)\end{array}$ & $\begin{array}{c}0.051 \\
(0.322)\end{array}$ & $\begin{array}{l}0.155 \\
(0.111)\end{array}$ & $\begin{array}{c}0.020 \\
(0.919)\end{array}$ & $\begin{array}{c}-80,629.523 * * * \\
(0.001)\end{array}$ & $\begin{array}{c}-5.759 * * * \\
(0.002)\end{array}$ \\
\hline $\operatorname{Return}_{i, t-1}$ & $\begin{array}{c}0.100 \\
(0.140)\end{array}$ & $\begin{array}{l}-0.033 \\
(0.645)\end{array}$ & $\begin{array}{c}0.034 \\
(0.480)\end{array}$ & $\begin{array}{l}-0.107 \\
(0.340)\end{array}$ & $\begin{array}{l}-0.247 \\
(0.129)\end{array}$ & $\begin{array}{l}-0.205 \\
(0.110)\end{array}$ & $\begin{array}{c}0.043 \\
(0.817)\end{array}$ & $\begin{array}{c}0.008 \\
(0.965)\end{array}$ \\
\hline Constant & $\begin{array}{c}0.045 \\
(0.449)\end{array}$ & $\begin{array}{c}0.214 \\
(0.109)\end{array}$ & $\begin{array}{c}0.181 \\
(0.492)\end{array}$ & $\begin{array}{c}0.091 \\
(0.424)\end{array}$ & $\begin{array}{c}0.256 \\
(0.393)\end{array}$ & $\begin{array}{l}-0.351 \\
(0.588)\end{array}$ & $\begin{array}{c}297,375.906 * * * \\
(0.002)\end{array}$ & $\begin{array}{l}8.687 \\
(0.218)\end{array}$ \\
\hline $\begin{array}{l}\text { Year fixed effect } \\
\text { Number of obs. } \\
\text { Adjusted } R^{2}\end{array}$ & $\begin{array}{c}\text { Yes } \\
563 \\
0.024\end{array}$ & $\begin{array}{c}\text { Yes } \\
563 \\
0.034\end{array}$ & $\begin{array}{c}\text { Yes } \\
561 \\
0.036\end{array}$ & $\begin{array}{l}\text { Yes } \\
259 \\
-0.005\end{array}$ & $\begin{array}{c}\text { Yes } \\
256 \\
0.033\end{array}$ & $\begin{array}{c}\text { Yes } \\
244 \\
-0.015\end{array}$ & $\begin{array}{c}\text { Yes } \\
554 \\
0.063\end{array}$ & $\begin{array}{c}\text { Yes } \\
554 \\
0.035\end{array}$ \\
\hline
\end{tabular}


Panel C: Qualified Foreign Institutional Investors

\begin{tabular}{|c|c|c|c|c|c|c|c|c|}
\hline \multirow{2}{*}{$\begin{array}{l}\text { Independent } \\
\text { Variable }\end{array}$} & \multicolumn{3}{|c|}{$\begin{array}{c}\text { Mark-to-market Return of Limit } \\
\text { Orders }(\%)\end{array}$} & \multicolumn{3}{|c|}{$\begin{array}{c}\text { Mark-to-market Return of Market } \\
\text { Orders }(\%)\end{array}$} & \multicolumn{2}{|c|}{ Round-trip Performance } \\
\hline & Intraday & 1-day & 5-day & Intraday & 1-day & 5-day & $\begin{array}{l}\text { Daily profit } \\
\text { (TWD) }\end{array}$ & $\begin{array}{l}\text { Daily index return } \\
(\%)\end{array}$ \\
\hline \multirow{2}{*}{$S I_{i, t-1}$} & -0.491 & -0.558 & 0.947 & $3.355^{*}$ & -2.177 & 8.292 & -3740699.500 & -193.907 \\
\hline & $(0.441)$ & $(0.750)$ & $(0.763)$ & $(0.083)$ & $(0.619)$ & $(0.162)$ & $(0.190)$ & $(0.314)$ \\
\hline \multirow[t]{2}{*}{ OrderSize $_{i, t-1}$} & -0.003 & 0.009 & 0.008 & -0.012 & 0.037 & 0.105 & $26,424.318$ & 1.699 \\
\hline & $(0.416)$ & $(0.348)$ & $(0.689)$ & $(0.279)$ & $(0.203)$ & $(0.195)$ & $(0.432)$ & $(0.484)$ \\
\hline \multirow{2}{*}{ SubRatio $_{0}$ and $5, i, t-1$} & -0.021 & $-0.686 * *$ & $-1.127 * *$ & 0.211 & -0.237 & 1.224 & $-100,800.758$ & -2.970 \\
\hline & $(0.860)$ & $(0.034)$ & $(0.022)$ & $(0.594)$ & $(0.760)$ & $(0.370)$ & $(0.842)$ & $(0.926)$ \\
\hline \multirow{2}{*}{$\operatorname{Ln}\left(N_{i, t-1}\right)$} & 0.007 & -0.008 & $0.081^{*}$ & 0.017 & 0.000 & -0.077 & $81,184.500$ & $7.761 * *$ \\
\hline & $(0.447)$ & $(0.799)$ & $(0.092)$ & $(0.648)$ & (0.999) & $(0.698)$ & $(0.107)$ & $(0.030)$ \\
\hline \multirow[t]{2}{*}{ Disposition $_{i, t-1}$} & -0.031 & -0.008 & 0.091 & -0.004 & 0.044 & 0.173 & $-43,563.090$ & -1.666 \\
\hline & $(0.270)$ & $(0.859)$ & $(0.533)$ & $(0.946)$ & $(0.789)$ & $(0.680)$ & $(0.838)$ & $(0.914)$ \\
\hline \multirow{2}{*}{ Return $_{i, t-1}$} & 0.138 & 0.024 & 0.044 & 0.060 & 0.282 & -0.159 & -0.017 & -0.047 \\
\hline & $(0.195)$ & $(0.829)$ & $(0.734)$ & $(0.713)$ & $(0.132)$ & $(0.453)$ & $(0.864)$ & $(0.597)$ \\
\hline \multirow[t]{2}{*}{ Constant } & 0.005 & 0.627 & 0.448 & -0.053 & -0.196 & -1.158 & 1348741.250 & 104.336 \\
\hline & $(0.967)$ & $(0.140)$ & $(0.433)$ & $(0.894)$ & $(0.837)$ & $(0.645)$ & $(0.302)$ & $(0.299)$ \\
\hline Year fixed effect & Yes & Yes & Yes & Yes & Yes & Yes & Yes & Yes \\
\hline Number of obs. & 166 & 165 & 165 & 65 & 64 & 60 & 153 & 153 \\
\hline Adjusted $\mathrm{R}^{2}$ & -0.012 & 0.016 & 0.043 & -0.084 & -0.052 & -0.100 & 0.060 & 0.093 \\
\hline
\end{tabular}


Table AVI. Superstition, Cognitive Limitation, and Intraday Mark-to-market Returns of Limit Orders of Individual Investors

In this table we double sort individual investors into quintiles by the superstition index and the submission ratio at " 0 " in year $t-1$, and report the intraday mark-to-market return of limit orders in year $t$. Quintile-5 (Q5) investors are more superstitious or have higher submission ratios at round number prices. In each year, we calculate the superstition index for each investor as the difference between limit order submission ratios at " 8 " and "4." The submission ratio at " 8 " of an investor is calculated as the number of limit orders submitted at prices ending with " 8 " divided by the total number of limit orders submitted at all prices within a year. The submission ratio at " 4 " and " 0 " are calculated in a similar fashion. Mark-to-market intraday return is expressed in percentage, and is the difference between the trade price and the daily closing price divided by the trade price. All items are first calculated for each investor-year observation and then averaged for each quintile with equal weights. To ensure a reasonable magnitude of superstition index, we require that investors submit at least 10 limit orders in each of two consecutive years. The Satterthwaite pvalue assumes unequal variances of investor performance in quintiles 1 and $5 . *, *$, and $* * *$ indicate significance levels of $0.1,0.05$, and 0.01 , respectively.

\begin{tabular}{|c|c|c|c|c|c|c|c|}
\hline \multirow{2}{*}{$\begin{array}{l}\text { Quintile Ranks of } \\
\text { SubRatio }_{0, t-1}\end{array}$} & \multicolumn{5}{|c|}{ Quintile Ranks of $S I_{t-1}$} & \multirow[b]{2}{*}{ Diff (Q5-Q1) } & \multirow[b]{2}{*}{ p-value } \\
\hline & Q1 & $\mathrm{Q} 2$ & Q3 & $\mathrm{Q} 4$ & Q5 & & \\
\hline Q1 & -0.057 & -0.058 & -0.059 & -0.074 & -0.088 & $-0.032 * * *$ & 0.000 \\
\hline Q2 & -0.077 & -0.069 & -0.070 & -0.075 & -0.092 & $-0.014 * * *$ & 0.003 \\
\hline Q3 & -0.082 & -0.074 & -0.090 & -0.079 & -0.098 & $-0.015 * * *$ & 0.004 \\
\hline Q4 & -0.092 & -0.100 & -0.095 & -0.096 & -0.103 & $-0.012 *$ & 0.051 \\
\hline Q5 & -0.102 & -0.109 & -0.110 & -0.106 & -0.102 & -0.000 & 0.990 \\
\hline Diff (Q5-Q1) & $-0.045 * * *$ & $-0.050 * * *$ & $-0.051 * * *$ & $-0.032 * * *$ & $-0.014 *$ & & \\
\hline $\mathrm{p}$-value & 0.000 & 0.000 & 0.000 & 0.000 & 0.051 & & \\
\hline
\end{tabular}




\section{Table AVII. Individual Investors' Superstition Index and Investment Performance - Two-Stage Regression}

In this table, we report the parameter estimates of a two-stage panel regression for individual investors. In the first stage, we perform the following regression for each of the eight return measures separately:

$S_{i, t-1}=\alpha+\beta_{1}$ OrderSize $_{i, t-1}+\beta_{2}$ SubRatio $_{0 \text { and } 5, i, t-1}+\beta_{3} \operatorname{Ln}\left(N_{i, t-1}\right)+\beta_{4}$ Disposition $_{i, t-1}+\beta_{5}$ Return $_{i, t-1}+\varepsilon_{i, t-1}$

We take Residual_SI $I_{i, t-1}$, the residual superstition index, from the first stage regression and perform the following regression in the second stage:

Return $_{i, t}=\alpha+\beta_{1}$ Residual_SI $_{i, t-1}+\beta_{2}$ OrderSize $_{i, t-1}+\beta_{3}$ SubRatio $_{0 \text { and } 5, i, t-1}+\beta_{4} \operatorname{Ln}\left(N_{i, t-1}\right)+\beta_{5}$ Disposition $_{i, t-1}+\beta_{6}$ Return $_{i, t-1}+\varepsilon_{i, t}$

where Return $_{i, t}$ and $\operatorname{Return}_{i, t-1}$ are the average mark-to-market returns or round-trip performance for investor $i$ in year $t$ and year $t-1 . S I_{i, t-1}$ is investor $i$ 's superstition index in year $t-1$, which is calculated as the difference between limit order submission ratios at " 8 " and " 4 ." The submission ratio at " 8 " of an investor is calculated as the number of limit orders submitted at prices ending with " 8 " divided by the total number of limit orders submitted at all prices within a year. The submission ratio at "4" is calculated in a similar fashion. OrderSize $i, t-1$ is the average number of contracts per limit order submitted by investor $i$ in year $t-1$. SubRatio $o_{0 \text { and } 5, i, t-1}$ is the sum of investor $i$ 's submission ratios at prices ending with " 0 " and " 5 " in year $t-1 . \operatorname{Ln}\left(N_{i, t-1}\right)$ is the $\log$ of number of limit orders submitted by investor $i$ in the previous year. Disposition $_{i, t-1}$ is the difference between the durations of losing and winning round-trip trades of investor $i$ in year $t$ - 1 , divided by their average. Mark-to-market return of limit (market) orders is the return under the assumption that the initiating limit (market) orders are covered at the closing price of a trading day. The round-trip daily profit and daily index return are calculated as the average round-trip profit or index return divided by the average round-trip duration for each investor. Results for the first and second stage regressions are separately reported in Panel A and Panel B. Standard errors are adjusted for heteroskedasticity. To ensure a reasonable magnitude of the superstition index, we require that investors submit at least 10 limit orders in each of two consecutive years. *, **, and *** indicate significance levels of $0.1,0.05$, and 0.01 , respectively. 
Panel A (First Stage Regression): Regressing Superstition Index on Other Aspects of Investor Trading Skills

\begin{tabular}{|c|c|c|c|c|c|c|c|c|}
\hline \multirow{2}{*}{$\begin{array}{l}\text { Independent } \\
\text { Variable }\end{array}$} & \multicolumn{3}{|c|}{$\begin{array}{c}\text { Mark-to-market Return of Limit } \\
\text { Orders }(\%)\end{array}$} & \multicolumn{3}{|c|}{$\begin{array}{c}\text { Mark-to-market Return of Market } \\
\text { Orders }(\%)\end{array}$} & \multicolumn{2}{|c|}{ Round-trip Performance } \\
\hline & Intraday & 1-day & 5-day & Intraday & 1-day & 5-day & $\begin{array}{l}\text { Daily profit } \\
\text { (TWD) }\end{array}$ & $\begin{array}{l}\text { Daily index return } \\
(\%)\end{array}$ \\
\hline OrderSize $_{i, t-1}$ & $\begin{array}{c}-0.001 * * * \\
(0.000)\end{array}$ & $\begin{array}{c}-0.001 * * * \\
(0.000)\end{array}$ & $\begin{array}{c}-0.001 * * * \\
(0.000)\end{array}$ & $\begin{array}{c}-0.001 * * * \\
(0.000)\end{array}$ & $\begin{array}{c}-0.001 * * * \\
(0.000)\end{array}$ & $\begin{array}{c}-0.001 * * * \\
(0.000)\end{array}$ & $\begin{array}{c}-0.001 * * * \\
(0.000)\end{array}$ & $\begin{array}{c}-0.001 * * * \\
(0.000)\end{array}$ \\
\hline SubRatio $_{0}$ and $5, i, t-1$ & $\begin{array}{c}-0.040 * * * \\
(0.000)\end{array}$ & $\begin{array}{c}-0.040 * * * \\
(0.000)\end{array}$ & $\begin{array}{c}-0.039 * * * \\
(0.000)\end{array}$ & $\begin{array}{c}-0.034 * * * \\
(0.000)\end{array}$ & $\begin{array}{c}-0.034 * * * \\
(0.000)\end{array}$ & $\begin{array}{c}-0.034 * * * \\
(0.000)\end{array}$ & $\begin{array}{c}-0.039 * * * \\
(0.000)\end{array}$ & $\begin{array}{c}-0.039 * * * \\
(0.000)\end{array}$ \\
\hline $\operatorname{Ln}\left(N_{i, t-1}\right)$ & $\begin{array}{c}-0.002 * * * \\
(0.000)\end{array}$ & $\begin{array}{c}-0.002 * * * \\
(0.000)\end{array}$ & $\begin{array}{c}-0.002 * * * \\
(0.000)\end{array}$ & $\begin{array}{c}-0.002 * * * \\
(0.000)\end{array}$ & $\begin{array}{c}-0.002 * * * \\
(0.000)\end{array}$ & $\begin{array}{c}-0.002 * * * \\
(0.000)\end{array}$ & $\begin{array}{c}-0.002 * * * \\
(0.000)\end{array}$ & $\begin{array}{c}-0.002 * * * \\
(0.000)\end{array}$ \\
\hline Disposition $_{i, t-1}$ & $\begin{array}{c}0.005 * * * \\
(0.000)\end{array}$ & $\begin{array}{c}0.005^{*} * * \\
(0.000)\end{array}$ & $\begin{array}{c}0.006 * * * \\
(0.000)\end{array}$ & $\begin{array}{c}0.006 * * * \\
(0.000)\end{array}$ & $\begin{array}{c}0.006^{* * * *} \\
(0.000)\end{array}$ & $\begin{array}{c}0.006 * * * \\
(0.000)\end{array}$ & $\begin{array}{c}0.005 * * * \\
(0.000)\end{array}$ & $\begin{array}{c}0.005^{* * * *} \\
(0.000)\end{array}$ \\
\hline $\operatorname{Return}_{i, t-1}$ & $\begin{array}{c}-0.010 * * * \\
(0.000)\end{array}$ & $\begin{array}{c}-0.002 * * * \\
(0.008)\end{array}$ & $\begin{array}{c}0.001 \\
(0.158)\end{array}$ & $\begin{array}{l}-0.000 \\
(0.748)\end{array}$ & $\begin{array}{l}-0.000 \\
(0.709)\end{array}$ & $\begin{array}{c}0.000 \\
(0.144)\end{array}$ & $\begin{array}{c}-0.000 * * \\
(0.031)\end{array}$ & $\begin{array}{c}-0.000 * * \\
(0.026)\end{array}$ \\
\hline Constant & $\begin{array}{c}0.069 * * * \\
(0.000)\end{array}$ & $\begin{array}{c}0.070 * * * \\
(0.000)\end{array}$ & $\begin{array}{c}0.071 * * * \\
(0.000)\end{array}$ & $\begin{array}{c}0.065^{* * * *} \\
(0.000)\end{array}$ & $\begin{array}{c}0.065 * * * \\
(0.000)\end{array}$ & $\begin{array}{c}0.065 * * * \\
(0.000)\end{array}$ & $\begin{array}{c}0.070 * * * \\
(0.000)\end{array}$ & $\begin{array}{c}0.070 * * * \\
(0.000)\end{array}$ \\
\hline Year fixed effect & Yes & Yes & Yes & Yes & Yes & Yes & Yes & Yes \\
\hline Number of obs. & 57,217 & 57,215 & 57,189 & 33,585 & 33,545 & 32,942 & 57,263 & 57,263 \\
\hline Adjusted $\mathrm{R}^{2}$ & 0.017 & 0.017 & 0.017 & 0.015 & 0.015 & 0.015 & 0.016 & 0.016 \\
\hline
\end{tabular}


Panel B (Second Stage Regression): Regressing Investment Performance on Residual Superstition Index

\begin{tabular}{|c|c|c|c|c|c|c|c|c|}
\hline \multirow{2}{*}{$\begin{array}{l}\text { Independent } \\
\text { Variable }\end{array}$} & \multicolumn{3}{|c|}{$\begin{array}{c}\text { Mark-to-market Return of Limit } \\
\text { Orders }(\%)\end{array}$} & \multicolumn{3}{|c|}{$\begin{array}{c}\text { Mark-to-market Return of Market } \\
\text { Orders }(\%)\end{array}$} & \multicolumn{2}{|c|}{ Round-trip Performance } \\
\hline & Intraday & 1-day & 5-day & Intraday & 1-day & 5-day & $\begin{array}{l}\text { Daily profit } \\
\text { (TWD) }\end{array}$ & $\begin{array}{l}\text { Daily index return } \\
(\%)\end{array}$ \\
\hline Residual_SI $I_{i, t-1}$ & $\begin{array}{c}-0.068 * * * \\
(0.000)\end{array}$ & $\begin{array}{c}-0.103 * * * \\
(0.001)\end{array}$ & $\begin{array}{c}-0.269 * * * \\
(0.000)\end{array}$ & $\begin{array}{l}-0.046 \\
(0.232)\end{array}$ & $\begin{array}{c}-0.176 * * \\
(0.026)\end{array}$ & $\begin{array}{l}-0.206 \\
(0.195)\end{array}$ & $\begin{array}{l}-15,849.138 \\
\quad(0.145)\end{array}$ & $\begin{array}{l}-1.270 \\
(0.147)\end{array}$ \\
\hline OrderSize $_{i, t-1}$ & $\begin{array}{c}0.002 * * * \\
(0.007)\end{array}$ & $\begin{array}{c}0.001 \\
(0.565)\end{array}$ & $\begin{array}{l}-0.001 \\
(0.518)\end{array}$ & $\begin{array}{c}0.002 \\
(0.124)\end{array}$ & $\begin{array}{c}0.002 \\
(0.331)\end{array}$ & $\begin{array}{l}-0.001 \\
(0.774)\end{array}$ & $\begin{array}{l}-1,650.379 \\
(0.187)\end{array}$ & $\begin{array}{l}-0.114 \\
(0.241)\end{array}$ \\
\hline SubRatio $_{0}$ and $5, i, t-1$ & $\begin{array}{c}-0.038 * * * \\
(0.000)\end{array}$ & $\begin{array}{c}-0.077 * * * \\
(0.000)\end{array}$ & $\begin{array}{c}-0.162 * * * \\
(0.000)\end{array}$ & $\begin{array}{c}-0.047 * * * \\
(0.000)\end{array}$ & $\begin{array}{c}-0.107 * * * \\
(0.000)\end{array}$ & $\begin{array}{c}-0.133 * * * \\
(0.010)\end{array}$ & $\begin{array}{c}37,803.789 \\
(0.328)\end{array}$ & $\begin{array}{c}3.085 \\
(0.325)\end{array}$ \\
\hline $\operatorname{Ln}\left(N_{i, t-1}\right)$ & $\begin{array}{c}0.010 * * * \\
(0.000)\end{array}$ & $\begin{array}{c}0.013 * * * \\
(0.000)\end{array}$ & $\begin{array}{l}0.007 * \\
(0.080)\end{array}$ & $\begin{array}{c}0.012 * * * \\
(0.000)\end{array}$ & $\begin{array}{c}0.017 * * * \\
(0.000)\end{array}$ & $\begin{array}{c}0.011 \\
(0.270)\end{array}$ & $\begin{array}{c}3,592.455 \\
(0.295)\end{array}$ & $\begin{array}{c}0.293 \\
(0.288)\end{array}$ \\
\hline Disposition $_{i, t-1}$ & $\begin{array}{c}-0.024 * * * \\
(0.000)\end{array}$ & $\begin{array}{c}-0.034 * * * \\
(0.000)\end{array}$ & $\begin{array}{c}-0.023 * * * \\
(0.001)\end{array}$ & $\begin{array}{c}-0.023 * * * \\
(0.000)\end{array}$ & $\begin{array}{c}-0.040 * * * \\
(0.000)\end{array}$ & $\begin{array}{c}-0.040 * * \\
(0.026)\end{array}$ & $\begin{array}{c}16,403.018 \\
(0.268)\end{array}$ & $\begin{array}{c}1.335 \\
(0.267)\end{array}$ \\
\hline $\operatorname{Return}_{i, t-1}$ & $\begin{array}{c}0.071 * * * \\
(0.000)\end{array}$ & $\begin{array}{c}0.032 * * * \\
(0.000)\end{array}$ & $\begin{array}{c}0.025 * * * \\
(0.000)\end{array}$ & $\begin{array}{c}0.011 \\
(0.254)\end{array}$ & $\begin{array}{c}0.002 \\
(0.864)\end{array}$ & $\begin{array}{c}0.013 \\
(0.205)\end{array}$ & $\begin{array}{c}0.632 * * * \\
(0.000)\end{array}$ & $\begin{array}{c}0.640 * * * \\
(0.001)\end{array}$ \\
\hline Constant & $\begin{array}{c}-0.049 * * * \\
(0.000)\end{array}$ & $\begin{array}{c}-0.084 * * * \\
(0.000)\end{array}$ & $\begin{array}{c}-0.046 * \\
(0.078)\end{array}$ & $\begin{array}{c}-0.048 * * * \\
(0.001)\end{array}$ & $\begin{array}{l}-0.058 * \\
(0.059)\end{array}$ & $\begin{array}{l}-0.066 \\
(0.287)\end{array}$ & $\begin{array}{c}-3,393.385 \\
(0.461)\end{array}$ & $\begin{array}{l}-0.327 \\
(0.358)\end{array}$ \\
\hline $\begin{array}{l}\text { Year fixed effect } \\
\text { Number of obs. } \\
\text { Adjusted } \mathrm{R}^{2}\end{array}$ & $\begin{array}{c}\text { Yes } \\
56,968 \\
0.029\end{array}$ & $\begin{array}{c}\text { Yes } \\
56,963 \\
0.010\end{array}$ & $\begin{array}{c}\text { Yes } \\
56,824 \\
0.014\end{array}$ & $\begin{array}{c}\text { Yes } \\
25,723 \\
0.006\end{array}$ & $\begin{array}{c}\text { Yes } \\
25,673 \\
0.005\end{array}$ & $\begin{array}{c}\text { Yes } \\
24,962 \\
0.003\end{array}$ & $\begin{array}{c}\text { Yes } \\
56,830 \\
0.000\end{array}$ & $\begin{array}{c}\text { Yes } \\
56,830 \\
0.000\end{array}$ \\
\hline
\end{tabular}




\section{Table AVIII. A Placebo Test: Pseudo Superstition Index and Investment Performance of Individual Investors- Regression Analysis}

In this table we report the parameter estimates for the following panel regression:

Return $_{i, t}=\alpha+\beta_{1}$ SI $_{i, t-1}+\beta_{2}$ OrderSize $_{i, t-1}+\beta_{3}$ SubRatio $_{0 \text { and } 5, i, t-1}+\beta_{4} \operatorname{Ln}\left(N_{i, t-1}\right)+\beta_{5}$ Disposition $_{i, t-1}+\beta_{6}$ Return $_{i, t-1}+\varepsilon_{i, t}$

where Return $_{i, t}$ and Return $_{i, t-1}$ are the average mark-to-market returns or round-trip performance for investor $i$ in year $t$ and year $t-1$. $S I_{i, t-1}$ is investor $i$ 's pseudo superstition index in year $t-1$, calculated as the difference between limit order submission ratios at "7" and " 3 ." In each year, we calculate the investor's submission ratio at " 7 " as the number of limit orders submitted at prices ending with " 7 " divided by the total number of limit orders submitted at all prices within a year. The submission ratio at " 3 " is calculated in a similar fashion. OrderSize Ort- $_{-1}$ is the average number of contracts per limit order submitted by investor $i$ in year $t$-1. SubRatio 0 and $5, i, t-1$ is the sum of investor $i$ 's submission ratios at prices ending with " 0 " and " 5 " in year $t-1 . \operatorname{Ln}\left(N_{i, t-1}\right)$ is the $\log$ of number of limit orders submitted by investor $i$ in the previous year. Disposition $_{i, t-1}$ is the difference between the durations of losing and winning round-trip trades of investor $i$ in year $t$ - 1 , divided by their average. Mark-to-market return of limit (market) orders is the return under the assumption that the initiating limit (market) orders are covered at the closing price of a trading day. The round-trip daily profit and daily index return are calculated as the average round-trip profit or index return divided by the average round-trip duration for each investor. Standard errors are adjusted for heteroskedasticity. To ensure a reasonable magnitude of the superstition index, we require that investors submit at least 10 limit orders in each of two consecutive years. *, **, and $* * *$ indicate significance levels of $0.1,0.05$, and 0.01 , respectively. 


\begin{tabular}{|c|c|c|c|c|c|c|c|c|}
\hline \multirow{2}{*}{$\begin{array}{l}\text { Independent } \\
\text { Variable }\end{array}$} & \multicolumn{3}{|c|}{$\begin{array}{c}\text { Mark-to-market Return of Limit } \\
\text { Orders }(\%)\end{array}$} & \multicolumn{3}{|c|}{$\begin{array}{c}\text { Mark-to-market Return of Market } \\
\text { Orders }(\%)\end{array}$} & \multicolumn{2}{|c|}{ Round-trip Performance } \\
\hline & Intraday & 1-day & 5-day & Intraday & 1-day & 5-day & $\begin{array}{l}\text { Daily profit } \\
\text { (TWD) }\end{array}$ & $\begin{array}{c}\text { Daily index return } \\
(\%)\end{array}$ \\
\hline \multirow[t]{2}{*}{$S I_{i, t-1}$} & -0.015 & 0.034 & 0.176 & -0.060 & 0.113 & 0.067 & $4,739.201$ & 0.237 \\
\hline & $(0.580)$ & $(0.542)$ & $(0.130)$ & $(0.397)$ & $(0.413)$ & $(0.819)$ & $(0.258)$ & $(0.478)$ \\
\hline \multirow{2}{*}{$\operatorname{OrderSize}_{i, t-1}$} & $0.002 * * *$ & -0.001 & $-0.004 * *$ & 0.002 & 0.003 & -0.003 & $-1,029.776$ & -0.055 \\
\hline & $(0.000)$ & $(0.521)$ & $(0.039)$ & $(0.174)$ & $(0.149)$ & $(0.591)$ & $(0.123)$ & $(0.231)$ \\
\hline \multirow{2}{*}{ SubRatio $_{0}$ and $5, i, t-1$} & $-0.039 * * *$ & $-0.083 * * *$ & $-0.163 * * *$ & $-0.044 * * *$ & $-0.118 * * *$ & $-0.204 * * *$ & -752.143 & -0.066 \\
\hline & $(0.000)$ & $(0.000)$ & $(0.000)$ & $(0.001)$ & $(0.000)$ & $(0.001)$ & $(0.433)$ & $(0.358)$ \\
\hline \multirow[t]{2}{*}{$\operatorname{Ln}\left(N_{i, t-1}\right)$} & $0.011 * * *$ & $0.017 * * *$ & $0.017 * * *$ & $0.011 * * *$ & $0.022 * * *$ & $0.025 * *$ & $966.223 * *$ & $0.078 * * *$ \\
\hline & $(0.000)$ & $(0.000)$ & $(0.000)$ & $(0.000)$ & $(0.000)$ & $(0.021)$ & $(0.016)$ & (0.008) \\
\hline \multirow{2}{*}{ Disposition $_{i, t-1}$} & $-0.019 * * *$ & $-0.048 * * *$ & $-0.139 * * *$ & $-0.019 * * *$ & $-0.058 * * *$ & $-0.145 * * *$ & $-4,654.303 * * *$ & $-0.384 * * *$ \\
\hline & $(0.000)$ & $(0.000)$ & $(0.000)$ & $(0.000)$ & $(0.000)$ & $(0.000)$ & $(0.000)$ & $(0.000)$ \\
\hline \multirow[t]{2}{*}{$\operatorname{Return}_{i, t-1}$} & $0.091 * * *$ & $0.027 * * *$ & $0.026 * * *$ & $0.019 *$ & 0.007 & 0.008 & $0.550 * * *$ & $0.540 * * *$ \\
\hline & $(0.000)$ & $(0.002)$ & $(0.001)$ & $(0.092)$ & $(0.527)$ & $(0.483)$ & $(0.002)$ & $(0.004)$ \\
\hline \multirow[t]{2}{*}{ Constant } & $-0.061 * * *$ & $-0.097 * * *$ & -0.045 & $-0.047 * * *$ & $-0.073 * *$ & -0.074 & -638.298 & -0.103 \\
\hline & $(0.000)$ & $(0.000)$ & $(0.105)$ & $(0.004)$ & $(0.036)$ & $(0.286)$ & $(0.774)$ & $(0.485)$ \\
\hline Year fixed effect & Yes & Yes & Yes & Yes & Yes & Yes & Yes & Yes \\
\hline Number of obs. & 46,741 & 46,737 & 46,648 & 21,323 & 21,280 & 20,685 & 46,815 & 46,815 \\
\hline Adjusted $\mathrm{R}^{2}$ & 0.032 & 0.014 & 0.024 & 0.005 & 0.006 & 0.006 & 0.084 & 0.089 \\
\hline
\end{tabular}




\section{Table AIX. Individual Investors' Superstition Index and Investment Performance - Lucky vs. Unlucky Side}

In this table we report the parameter estimates for the following panel regression:

$\operatorname{Return}_{i, t}=\alpha+\beta_{1}$ SI $_{i, t-1}+\beta_{2}$ OrderSize $_{i, t-1}+\beta_{3}$ SubRatio $_{0 \text { and } 5, i, t-1}+\beta_{4} \operatorname{Ln}\left(N_{i, t-1}\right)+\beta_{5}$ Disposition $_{i, t-1}+\beta_{6}$ Return $_{i, t-1}+\varepsilon_{i, t}$

where Return $_{i, t}$ and $\operatorname{Return}_{i, t-1}$ are the average mark-to-market returns or round-trip performance for investor $i$ in year $t$ and year $t-1 . S I_{i, t-1}$ is the lucky or unlucky part of investor $i$ 's superstition index in year $t-1$. In Panel A, we consider the lucky part of superstition index by calculating $S I_{i, t-1}$ as the difference between limit order submission ratios at " 8 " and " 3 " for investor $i$ in year $t-1$. In Panel B, we consider the unlucky part of superstition index by calculating $S I_{i, t-1}$ as the difference between limit order submission ratios at " 3 " and " 4 " for investor $i$ in year $t-1$. The submission ratio at " 8 " of an investor is calculated as the number of limit orders submitted at prices ending with " 8 " divided by the total number of limit orders submitted at all prices within a year. The submission ratios at " 3 " and" 4 " are calculated in a similar fashion. OrderSize $i, t-1$ is the average number of contracts per limit order submitted by investor $i$ in year $t-1$. SubRatio ${ }_{0}$ and $5, i, t-1$ is the sum of investor $i$ 's submission ratios at prices ending with " 0 " and " 5 " in year $t-1 . \operatorname{Ln}\left(N_{i, t-1}\right)$ is the log of number of limit orders submitted by investor $i$ in the previous year. Disposition $_{i, t-1}$ is the difference between the durations of losing and winning round-trip trades of investor $i$ in year $t$ - 1 , divided by their average. Mark-to-market return of limit (market) orders is the return under the assumption that the initiating limit (market) orders are covered at the closing price of a trading day. The round-trip daily profit and daily index return are calculated as the average round-trip profit or index return divided by the average round-trip duration for each investor. Standard errors are adjusted for heteroskedasticity. To ensure a reasonable magnitude of the superstition index, we require that investors submit at least 10 limit orders in each of two consecutive years. *, **, and $* * *$ indicate significance levels of $0.1,0.05$, and 0.01 , respectively. 
Panel A: Lucky Part of the Superstition Index

\begin{tabular}{|c|c|c|c|c|c|c|c|c|}
\hline \multirow{2}{*}{$\begin{array}{l}\text { Independent } \\
\text { Variable }\end{array}$} & \multicolumn{3}{|c|}{$\begin{array}{c}\text { Mark-to-market Return of Limit } \\
\text { Orders }(\%)\end{array}$} & \multicolumn{3}{|c|}{$\begin{array}{c}\text { Mark-to-market Return of Market } \\
\text { Orders }(\%)\end{array}$} & \multicolumn{2}{|c|}{ Round-trip Performance } \\
\hline & Intraday & 1-day & 5-day & Intraday & 1-day & 5-day & $\begin{array}{l}\text { Daily profit } \\
\text { (TWD) }\end{array}$ & $\begin{array}{l}\text { Daily index return } \\
(\%)\end{array}$ \\
\hline \multicolumn{9}{|l|}{ SubRatio $_{8, i, t-1}$} \\
\hline- SubRatio $_{3, i, t-1}$ & $\begin{array}{c}-0.063 * * * \\
(0.000)\end{array}$ & $\begin{array}{l}-0.061 * \\
(0.075)\end{array}$ & $\begin{array}{c}-0.180 * * \\
(0.011)\end{array}$ & $\begin{array}{l}-0.040 \\
(0.356)\end{array}$ & $\begin{array}{l}-0.092 \\
(0.293)\end{array}$ & $\begin{array}{l}-0.272 \\
(0.139)\end{array}$ & $\begin{array}{l}-39,311.340 \\
\quad(0.306)\end{array}$ & $\begin{array}{l}-3.264 \\
(0.293)\end{array}$ \\
\hline OrderSize $_{i, t-1}$ & $\begin{array}{c}0.002 * * * \\
(0.000)\end{array}$ & $\begin{array}{c}0.001 \\
(0.539)\end{array}$ & $\begin{array}{l}-0.001 \\
(0.557)\end{array}$ & $\begin{array}{c}0.001 \\
(0.249)\end{array}$ & $\begin{array}{c}0.002 \\
(0.445)\end{array}$ & $\begin{array}{l}-0.003 \\
(0.555)\end{array}$ & $\begin{array}{l}-1,643.621 \\
\quad(0.205)\end{array}$ & $\begin{array}{l}-0.114 \\
(0.258)\end{array}$ \\
\hline SubRatio $_{0}$ and $5, i, t-1$ & $\begin{array}{c}-0.046 * * * \\
(0.000)\end{array}$ & $\begin{array}{c}-0.083 * * * \\
(0.000)\end{array}$ & $\begin{array}{c}-0.172 * * * \\
(0.000)\end{array}$ & $\begin{array}{c}-0.049 * * * \\
(0.000)\end{array}$ & $\begin{array}{c}-0.127 * * * \\
(0.000)\end{array}$ & $\begin{array}{c}-0.178 * * * \\
(0.002)\end{array}$ & $\begin{array}{c}48,620.242 \\
(0.326)\end{array}$ & $\begin{array}{c}3.956 \\
(0.324)\end{array}$ \\
\hline $\operatorname{Ln}\left(N_{i, t-1}\right)$ & $\begin{array}{c}0.011 * * * \\
(0.000)\end{array}$ & $\begin{array}{c}0.015 * * * \\
(0.000)\end{array}$ & $\begin{array}{c}0.011 * * \\
(0.013)\end{array}$ & $\begin{array}{c}0.013 * * * \\
(0.000)\end{array}$ & $\begin{array}{c}0.019 * * * \\
(0.000)\end{array}$ & $\begin{array}{c}0.017 \\
(0.108)\end{array}$ & $\begin{array}{c}2,999.263 \\
(0.286)\end{array}$ & $\begin{array}{c}0.246 \\
(0.276)\end{array}$ \\
\hline Disposition $_{i, t-1}$ & $\begin{array}{c}-0.023 * * * \\
(0.000)\end{array}$ & $\begin{array}{c}-0.033 * * * \\
(0.000)\end{array}$ & $\begin{array}{c}-0.028 * * * \\
(0.000)\end{array}$ & $\begin{array}{c}-0.024 * * * \\
(0.000)\end{array}$ & $\begin{array}{c}-0.042 * * * \\
(0.000)\end{array}$ & $\begin{array}{c}-0.038 * * \\
(0.048)\end{array}$ & $\begin{array}{c}18,960.959 \\
(0.268)\end{array}$ & $\begin{array}{c}1.539 \\
(0.268)\end{array}$ \\
\hline $\operatorname{Return}_{i, t-1}$ & $\begin{array}{c}0.082 * * * \\
(0.000)\end{array}$ & $\begin{array}{c}0.031 * * * \\
(0.000)\end{array}$ & $\begin{array}{c}0.028 * * * \\
(0.000)\end{array}$ & $\begin{array}{c}0.015 \\
(0.146)\end{array}$ & $\begin{array}{c}0.002 \\
(0.883)\end{array}$ & $\begin{array}{c}0.011 \\
(0.308)\end{array}$ & $\begin{array}{c}0.660 * * * \\
(0.000)\end{array}$ & $\begin{array}{c}0.667 * * * \\
(0.001)\end{array}$ \\
\hline Constant & $\begin{array}{c}-0.052 * * * \\
(0.000)\end{array}$ & $\begin{array}{c}-0.091 * * * \\
(0.000)\end{array}$ & $\begin{array}{c}-0.054 * \\
(0.053)\end{array}$ & $\begin{array}{c}-0.047 * * * \\
(0.002)\end{array}$ & $\begin{array}{l}-0.053 \\
(0.105)\end{array}$ & $\begin{array}{c}-0.070 \\
(0.294)\end{array}$ & $\begin{array}{c}-1,638.501 \\
(0.580)\end{array}$ & $\begin{array}{l}-0.186 \\
(0.385)\end{array}$ \\
\hline Year fixed effect & Yes & Yes & Yes & Yes & Yes & Yes & Yes & Yes \\
\hline Number of obs. & 51,836 & 51,832 & 51,709 & 23,349 & 23,303 & 22,646 & 51,756 & 51,756 \\
\hline Adjusted $\mathrm{R}^{2}$ & 0.030 & 0.010 & 0.014 & 0.006 & 0.004 & 0.003 & 0.000 & 0.000 \\
\hline
\end{tabular}


Panel B: Unlucky Part of the Superstition Index

\begin{tabular}{|c|c|c|c|c|c|c|c|c|}
\hline \multirow{2}{*}{$\begin{array}{l}\text { Independent } \\
\text { Variable }\end{array}$} & \multicolumn{3}{|c|}{$\begin{array}{c}\text { Mark-to-market Return of Limit } \\
\text { Orders }(\%)\end{array}$} & \multicolumn{3}{|c|}{$\begin{array}{c}\text { Mark-to-market Return of Market } \\
\text { Orders }(\%)\end{array}$} & \multicolumn{2}{|c|}{ Round-trip Performance } \\
\hline & Intraday & 1-day & 5-day & Intraday & 1-day & 5-day & $\begin{array}{l}\text { Daily profit } \\
\text { (TWD) }\end{array}$ & $\begin{array}{l}\text { Daily index return } \\
(\%)\end{array}$ \\
\hline \multirow{3}{*}{$\begin{array}{l}\text { SubRatio }_{3, i, t-1} \\
- \text { SubRatio }_{4, i, t-1}\end{array}$} & & & & & & & & \\
\hline & -0.013 & $-0.084 *$ & $-0.248 * *$ & -0.024 & -0.033 & -0.034 & $-5,608.824$ & -0.374 \\
\hline & $(0.562)$ & $(0.075)$ & $(0.014)$ & $(0.684)$ & $(0.802)$ & $(0.900)$ & $(0.136)$ & $(0.151)$ \\
\hline \multirow[t]{2}{*}{ OrderSize $_{i, t-1}$} & $0.002 * * *$ & -0.000 & -0.003 & 0.002 & 0.003 & -0.002 & -883.853 & -0.046 \\
\hline & $(0.000)$ & $(0.792)$ & $(0.107)$ & $(0.128)$ & $(0.166)$ & $(0.709)$ & $(0.183)$ & $(0.314)$ \\
\hline \multirow{2}{*}{ SubRatio $_{0}$ and $5, i, t-1$} & $-0.040 * * *$ & $-0.078 * * *$ & $-0.160 * * *$ & $-0.047 * * *$ & $-0.119 * * *$ & $-0.150 * * *$ & -528.127 & -0.054 \\
\hline & $(0.000)$ & $(0.000)$ & $(0.000)$ & $(0.000)$ & $(0.000)$ & $(0.008)$ & $(0.559)$ & $(0.410)$ \\
\hline \multirow[t]{2}{*}{$\operatorname{Ln}\left(N_{i, t-1}\right)$} & $0.011 * * *$ & $0.015^{* * *}$ & $0.017 * * *$ & $0.011 * * *$ & $0.019 * * *$ & $0.018 *$ & $831.421 * *$ & $0.068 * *$ \\
\hline & $(0.000)$ & $(0.000)$ & $(0.000)$ & $(0.000)$ & $(0.000)$ & $(0.078)$ & $(0.023)$ & $(0.011)$ \\
\hline \multirow{2}{*}{ Disposition $_{i, t-1}$} & $-0.020 * * *$ & $-0.047 * * *$ & $-0.136 * * *$ & $-0.018 * * *$ & $-0.054 * * *$ & $-0.147 * * *$ & $-4,539.066 * * *$ & $-0.375 * * *$ \\
\hline & $(0.000)$ & $(0.000)$ & $(0.000)$ & $(0.000)$ & $(0.000)$ & $(0.000)$ & $(0.000)$ & $(0.000)$ \\
\hline \multirow[t]{2}{*}{ Return $_{i, t-1}$} & $0.081 * * *$ & $0.025 * * *$ & $0.020 * * *$ & $0.017 *$ & 0.005 & 0.010 & $0.531 * * *$ & $0.522 * * *$ \\
\hline & $(0.000)$ & $(0.001)$ & $(0.004)$ & $(0.083)$ & $(0.673)$ & $(0.364)$ & $(0.001)$ & $(0.004)$ \\
\hline \multirow[t]{2}{*}{ Constant } & $-0.056 * * *$ & $-0.088 * * *$ & $-0.048 *$ & $-0.043 * * *$ & $-0.057 *$ & -0.065 & -212.111 & -0.062 \\
\hline & $(0.000)$ & $(0.000)$ & $(0.073)$ & $(0.005)$ & $(0.087)$ & $(0.330)$ & $(0.918)$ & $(0.652)$ \\
\hline Year fixed effect & Yes & Yes & Yes & Yes & Yes & Yes & Yes & Yes \\
\hline Number of obs. & 50,763 & 50,759 & 50,657 & 23,177 & 23,132 & 22,489 & 50,843 & 50,843 \\
\hline Adjusted $\mathrm{R}^{2}$ & 0.031 & 0.014 & 0.023 & 0.005 & 0.006 & 0.006 & 0.081 & 0.085 \\
\hline
\end{tabular}




\section{Table AX. Individual Investors' Pseudo-Superstition Index, Market Return, and the Buy Ratio and Buy-sell Ratio - Quintile Analysis}

In this table we report the Buy Ratio and Buy-sell Ratio for individual investors with various pseudo-superstition indices and under different market returns. We first sort individual investors into quintiles by the pseudo superstition index in one year. Investors in quintile 5 (Q5) of the pseudo-superstitious index are the most pseudo superstitious. We then sort the trading days of the next year into quintiles based on the daily market returns. Market returns on trading days in Quintile-5 (M5) are the highest. We then compute the average Buy Ratio and average Buy-Sell Ratio of each product (MXF or TXF orders that expire in one month, two months, three months, six months, nine months, or one year) for the investors in each pseudo superstitious quintile and market return quintile. We define $S I_{i, t-1}$ as the difference between limit order submission ratios at " 7 " and " 3 " for investor $i$ in year $t-1$. We calculate the investor's submission ratio at " 7 " as the number of limit orders submitted at prices ending with "7" divided by the total number of limit orders submitted at all prices within a year. The submission ratio at "3" is calculated in a similar fashion. The Buy Ratio is calculated as the number of buy contracts (taking long positions) scaled by total number of executed contracts. We calculate the Buy-sell Ratio as the difference between the numbers of buy and sell contracts, divided by their average. Both limit and market orders are included in the calculation of Buy Ratio and Buy-sell Ratio. Standard errors are adjusted for heteroskedasticity. To ensure a reasonable magnitude of the superstition index, we require that investors submit at least 10 limit orders in each of two consecutive years. The Satterthwaite $p$ value assumes unequal variances of investor performance in quintiles 1 and $5 . *, * *$, and $* * *$ indicate significance levels of $0.1,0.05$, and 0.01 , respectively.

Panel A: Buy Ratio

\begin{tabular}{|c|c|c|c|c|c|c|c|}
\hline \multirow{2}{*}{$\begin{array}{l}\text { Quintile Ranks of } \\
\text { Market Returns }\end{array}$} & \multicolumn{5}{|c|}{ Quintile Ranks of Pseudo $S I_{i, t-1}$} & \multirow[b]{2}{*}{ Diff (Q5-Q1) } & \multirow[b]{2}{*}{ p-value } \\
\hline & Q1 & Q2 & Q3 & $\mathrm{Q} 4$ & Q5 & & \\
\hline M1 & 0.705 & 0.679 & 0.673 & 0.668 & 0.698 & -0.007 & 0.369 \\
\hline M2 & 0.628 & 0.613 & 0.616 & 0.608 & 0.626 & -0.002 & 0.261 \\
\hline M3 & 0.587 & 0.578 & 0.579 & 0.573 & 0.579 & -0.008 & 0.352 \\
\hline M4 & 0.552 & 0.553 & 0.553 & 0.548 & 0.546 & -0.007 & 0.256 \\
\hline M5 & 0.529 & 0.537 & 0.544 & 0.535 & 0.526 & -0.003 & 0.165 \\
\hline Diff (M5-M1) & $-0.176 * * *$ & $-0.142 * * *$ & $-0.129 * * *$ & $-0.133 * * *$ & $-0.172 * * *$ & & \\
\hline $\mathrm{p}$-value & 0.000 & 0.000 & 0.000 & 0.000 & 0.000 & & \\
\hline
\end{tabular}


Panel B: Buy-Sell Ratio

\begin{tabular}{|c|c|c|c|c|c|c|c|}
\hline \multirow{2}{*}{$\begin{array}{l}\text { Quintile Ranks of } \\
\text { Market Returns }\end{array}$} & \multicolumn{5}{|c|}{ Quintile Ranks of Pseudo $S I_{i, t-1}$} & \multirow[b]{2}{*}{ Diff (Q5-Q1) } & \multirow[b]{2}{*}{ p-value } \\
\hline & Q1 & Q2 & Q3 & Q4 & Q5 & & \\
\hline M1 & 0.820 & 0.717 & 0.691 & 0.670 & 0.792 & -0.028 & 0.103 \\
\hline M2 & 0.513 & 0.452 & 0.463 & 0.430 & 0.504 & -0.009 & 0.261 \\
\hline M3 & 0.347 & 0.312 & 0.318 & 0.292 & 0.315 & -0.033 & 0.105 \\
\hline M4 & 0.209 & 0.212 & 0.214 & 0.193 & 0.182 & -0.027 & 0.101 \\
\hline M5 & 0.117 & 0.149 & 0.176 & 0.138 & 0.106 & -0.012 & 0.165 \\
\hline Diff (M5-M1) & $-0.702 * * *$ & $-0.568 * * *$ & $-0.515 * * *$ & $-0.532 * * *$ & $-0.686 * * *$ & & \\
\hline p-value & 0.000 & 0.000 & 0.000 & 0.000 & 0.000 & & \\
\hline
\end{tabular}




\section{o-Table AXI. Individual Investors’'Time-to-Execution/Time-to-Cancellation and Investment Performance}

In this table we report the parameter estimates for the following panel regression:

Return $_{i, t}=\alpha+\beta_{1}$ TimeToExecution $_{i, t}$ (or TimeToCancellation $\left._{i, t}\right)+\beta_{2}$ OrderSize $_{i, t-1}+\beta_{3}$ SubRatio $\left._{0 \text { and } 5, i, t-1}+\beta_{4} \operatorname{Ln}_{\left(N_{i, t-1}\right.}\right)+\beta_{5}$ Disposition $_{i, t-1}+$ $\beta_{6} \operatorname{Return}_{i, t-1}+\varepsilon_{i, t}$

where Return $_{i, t}$ and $\operatorname{Return}_{i, t-1}$ are the average mark-to-market returns or round-trip performance for investor $i$ in year $t$ and year $t$ - 1 . TimeToExecution $_{i, t}$ is the interval from order submission to execution for executed limit orders for investor $i$ in year $t$. TimeToCancellation $i, t$ is the interval from submission to cancellation for orders that are submitted and then deleted by investor $i$ in year $t$. OrderSize $e_{i, t-1}$ is the average number of contracts per limit order submitted by investor $i$ in year $t-1$. SubRatio $0_{0}$ and $5, i, t-1$ is the sum of investor $i$ 's submission ratios at prices ending with " 0 " and " 5 " in year $t-1 . \operatorname{Ln}\left(N_{i, t-1}\right)$ is the $\log$ of number of limit orders submitted by investor $i$ in the previous year. Disposition $_{i, t-1}$ is the difference between the durations of losing and winning round-trip trades of investor $i$ in year $t-1$, divided by their average. Mark-to-market return of limit (market) orders is the return under the assumption that the initiating limit (market) orders are covered at the closing price of a trading day. The round-trip daily profit and daily index return are calculated as the average round-trip profit or index return divided by the average round-trip duration for each investor. Standard errors are adjusted for heteroskedasticity. To ensure a reasonable magnitude of the superstition index, we require that investors submit at least 10 limit orders in each of two consecutive years. *, **, and *** indicate significance levels of $0.1,0.05$, and 0.01 , respectively. 
Panel A. Time-to-Execution

\begin{tabular}{|c|c|c|c|c|c|c|c|c|}
\hline \multirow{2}{*}{$\begin{array}{l}\text { Independent } \\
\text { Variable }\end{array}$} & \multicolumn{3}{|c|}{$\begin{array}{c}\text { Mark-to-market Return of Limit } \\
\text { Orders }(\%)\end{array}$} & \multicolumn{3}{|c|}{$\begin{array}{c}\text { Mark-to-market Return of Market } \\
\text { Orders }(\%)\end{array}$} & \multicolumn{2}{|c|}{ Round-trip Performance } \\
\hline & Intraday & 1-day & 5-day & Intraday & 1-day & 5-day & $\begin{array}{l}\text { Daily profit } \\
\text { (TWD) }\end{array}$ & $\begin{array}{l}\text { Daily index return } \\
(\%)\end{array}$ \\
\hline TimeToExecution $_{i, t}$ & $\begin{array}{c}-0.029 * * * \\
(0.000)\end{array}$ & $\begin{array}{c}-0.038 * * * \\
(0.000)\end{array}$ & $\begin{array}{l}-0.043 * * * \\
(0.000)\end{array}$ & $\begin{array}{c}-0.019 * * * \\
(0.000)\end{array}$ & $\begin{array}{c}-0.021 * * \\
(0.015)\end{array}$ & $\begin{array}{l}-0.006 \\
(0.716)\end{array}$ & $\begin{array}{l}-17,251.539 \\
\quad(0.307)\end{array}$ & $\begin{array}{l}-1.390 \\
(0.310)\end{array}$ \\
\hline OrderSize $_{i, t-1}$ & $\begin{array}{c}0.001 * * \\
(0.011)\end{array}$ & $\begin{array}{c}0.000 \\
(0.665)\end{array}$ & $\begin{array}{l}-0.002 \\
(0.477)\end{array}$ & $\begin{array}{c}0.002 \\
(0.125)\end{array}$ & $\begin{array}{c}0.002 \\
(0.338)\end{array}$ & $\begin{array}{l}-0.001 \\
(0.790)\end{array}$ & $\begin{array}{l}-1,711.001 \\
\quad(0.190)\end{array}$ & $\begin{array}{l}-0.119 \\
(0.244)\end{array}$ \\
\hline SubRatio $_{0}$ and $5, i, t-1$ & $\begin{array}{c}-0.020 * * * \\
(0.000)\end{array}$ & $\begin{array}{c}-0.052 * * * \\
(0.000)\end{array}$ & $\begin{array}{c}-0.134 * * * \\
(0.000)\end{array}$ & $\begin{array}{c}-0.033 * * * \\
(0.006)\end{array}$ & $\begin{array}{c}-0.092 * * * \\
(0.000)\end{array}$ & $\begin{array}{c}-0.125^{* *} \\
(0.018)\end{array}$ & $\begin{array}{c}48,778.242 \\
(0.324)\end{array}$ & $\begin{array}{c}3.970 \\
(0.322)\end{array}$ \\
\hline $\operatorname{Ln}\left(N_{i, t-1}\right)$ & $\begin{array}{c}0.010 * * * \\
(0.000)\end{array}$ & $\begin{array}{c}0.013 * * * \\
(0.000)\end{array}$ & $\begin{array}{l}0.007 * \\
(0.086)\end{array}$ & $\begin{array}{c}0.012 * * * \\
(0.000)\end{array}$ & $\begin{array}{c}0.017 * * * \\
(0.001)\end{array}$ & $\begin{array}{c}0.010 \\
(0.286)\end{array}$ & $\begin{array}{c}3,507.781 \\
(0.296)\end{array}$ & $\begin{array}{c}0.286 \\
(0.289)\end{array}$ \\
\hline Disposition $_{i,-1}$ & $\begin{array}{c}-0.021 * * * \\
(0.000)\end{array}$ & $\begin{array}{c}-0.030 * * * \\
(0.000)\end{array}$ & $\begin{array}{c}-0.018 * * \\
(0.012)\end{array}$ & $\begin{array}{c}-0.021 * * * \\
(0.000)\end{array}$ & $\begin{array}{c}-0.038 * * * \\
(0.000)\end{array}$ & $\begin{array}{c}-0.040 * * \\
(0.027)\end{array}$ & $\begin{array}{c}18,288.088 \\
\quad(0.272)\end{array}$ & $\begin{array}{c}1.487 \\
(0.272)\end{array}$ \\
\hline $\operatorname{Return}_{i, t-1}$ & $\begin{array}{c}0.064 * * * \\
(0.000)\end{array}$ & $\begin{array}{c}0.030 * * * \\
(0.000)\end{array}$ & $\begin{array}{c}0.025 * * * \\
(0.000)\end{array}$ & $\begin{array}{c}0.010 \\
(0.258)\end{array}$ & $\begin{array}{c}0.002 \\
(0.860)\end{array}$ & $\begin{array}{c}0.012 \\
(0.210)\end{array}$ & $\begin{array}{c}0.636 * * * \\
(0.000)\end{array}$ & $\begin{array}{c}0.644 * * * \\
(0.001)\end{array}$ \\
\hline Constant & $\begin{array}{c}-0.045 * * * \\
(0.000)\end{array}$ & $\begin{array}{c}-0.078 * * * \\
(0.000)\end{array}$ & $\begin{array}{l}-0.039 \\
(0.136)\end{array}$ & $\begin{array}{c}-0.044 * * * \\
(0.002)\end{array}$ & $\begin{array}{l}-0.053 * \\
(0.082)\end{array}$ & $\begin{array}{l}-0.065 \\
(0.293)\end{array}$ & $\begin{array}{c}-124.241 \\
(0.957)\end{array}$ & $\begin{array}{l}-0.064 \\
(0.686)\end{array}$ \\
\hline $\begin{array}{l}\text { Year fixed effect } \\
\text { Number of obs. } \\
\text { Adjusted } \mathrm{R}^{2}\end{array}$ & $\begin{array}{c}\text { Yes } \\
56,952 \\
0.034\end{array}$ & $\begin{array}{c}\text { Yes } \\
56,947 \\
0.012\end{array}$ & $\begin{array}{c}\text { Yes } \\
56,808 \\
0.015\end{array}$ & $\begin{array}{c}\text { Yes } \\
25,735 \\
0.007\end{array}$ & $\begin{array}{c}\text { Yes } \\
25,685 \\
0.005\end{array}$ & $\begin{array}{c}\text { Yes } \\
24,974 \\
0.003\end{array}$ & $\begin{array}{c}\text { Yes } \\
56,843 \\
0.000\end{array}$ & $\begin{array}{c}\text { Yes } \\
56,843 \\
0.000\end{array}$ \\
\hline
\end{tabular}


Panel B. Time-to-Cancellation

\begin{tabular}{|c|c|c|c|c|c|c|c|c|}
\hline \multirow{2}{*}{$\begin{array}{l}\text { Independent } \\
\text { Variable }\end{array}$} & \multicolumn{3}{|c|}{$\begin{array}{c}\text { Mark-to-market Return of Limit } \\
\text { Orders }(\%)\end{array}$} & \multicolumn{3}{|c|}{$\begin{array}{c}\text { Mark-to-market Return of Market } \\
\text { Orders }(\%)\end{array}$} & \multicolumn{2}{|c|}{ Round-trip Performance } \\
\hline & Intraday & 1-day & 5-day & Intraday & 1-day & 5-day & $\begin{array}{l}\text { Daily profit } \\
\text { (TWD) }\end{array}$ & $\begin{array}{l}\text { Daily index return } \\
(\%)\end{array}$ \\
\hline TimeToCancellation $_{i, t}$ & $\begin{array}{c}-0.008 * * * \\
(0.000)\end{array}$ & $\begin{array}{c}-0.011 * * * \\
(0.000)\end{array}$ & $\begin{array}{c}-0.011 * * * \\
(0.001)\end{array}$ & $\begin{array}{c}-0.006 * * * \\
(0.000)\end{array}$ & $\begin{array}{c}-0.013 * * * \\
(0.000)\end{array}$ & $\begin{array}{c}-0.024 * * * \\
(0.001)\end{array}$ & $\begin{array}{l}38.063 \\
(0.847)\end{array}$ & $\begin{array}{c}0.006 \\
(0.706)\end{array}$ \\
\hline OrderSize $_{i, t-1}$ & $\begin{array}{c}0.001 * * \\
(0.017)\end{array}$ & $\begin{array}{c}0.000 \\
(0.718)\end{array}$ & $\begin{array}{l}-0.001 \\
(0.523)\end{array}$ & $\begin{array}{l}0.002 * \\
(0.079)\end{array}$ & $\begin{array}{c}0.002 \\
(0.304)\end{array}$ & $\begin{array}{l}-0.001 \\
(0.837)\end{array}$ & $\begin{array}{c}-772.719 \\
(0.287)\end{array}$ & $\begin{array}{l}-0.039 \\
(0.445)\end{array}$ \\
\hline SubRatio $_{0}$ and $5, i, t-1$ & $\begin{array}{c}-0.032 * * * \\
(0.000)\end{array}$ & $\begin{array}{c}-0.066 * * * \\
(0.000)\end{array}$ & $\begin{array}{c}-0.148 * * * \\
(0.000)\end{array}$ & $\begin{array}{c}-0.037 * * * \\
(0.002)\end{array}$ & $\begin{array}{c}-0.082 * * * \\
(0.002)\end{array}$ & $\begin{array}{l}-0.079 \\
(0.139)\end{array}$ & $\begin{array}{c}-1,430.179 \\
(0.168)\end{array}$ & $\begin{array}{c}-0.095 \\
(0.203)\end{array}$ \\
\hline $\operatorname{Ln}\left(N_{i, t-1}\right)$ & $\begin{array}{c}0.009 * * * \\
(0.000)\end{array}$ & $\begin{array}{c}0.011 * * * \\
(0.000)\end{array}$ & $\begin{array}{c}0.004 \\
(0.358)\end{array}$ & $\begin{array}{c}0.010 * * * \\
(0.000)\end{array}$ & $\begin{array}{c}0.013 * * * \\
(0.007)\end{array}$ & $\begin{array}{c}0.004 \\
(0.644)\end{array}$ & $\begin{array}{c}161.475 \\
(0.683)\end{array}$ & $\begin{array}{c}0.016 \\
(0.611)\end{array}$ \\
\hline Disposition $_{i, t-1}$ & $\begin{array}{c}-0.022 * * * \\
(0.000)\end{array}$ & $\begin{array}{c}-0.031 * * * \\
(0.000)\end{array}$ & $\begin{array}{c}-0.020 * * * \\
(0.008)\end{array}$ & $\begin{array}{c}-0.020 * * * \\
(0.000)\end{array}$ & $\begin{array}{c}-0.034 * * * \\
(0.000)\end{array}$ & $\begin{array}{c}-0.030 * \\
(0.097)\end{array}$ & $\begin{array}{c}1,363.819 * \\
(0.068)\end{array}$ & $\begin{array}{l}0.118 * \\
(0.078)\end{array}$ \\
\hline $\operatorname{Return}_{i, t-1}$ & $\begin{array}{c}0.066^{* * * *} \\
(0.000)\end{array}$ & $\begin{array}{c}0.029 * * * \\
(0.000)\end{array}$ & $\begin{array}{c}0.023 * * * \\
(0.000)\end{array}$ & $\begin{array}{c}0.009 \\
(0.315)\end{array}$ & $\begin{array}{c}0.001 \\
(0.957)\end{array}$ & $\begin{array}{c}0.009 \\
(0.373)\end{array}$ & $\begin{array}{c}0.562 * * * \\
(0.001)\end{array}$ & $\begin{array}{c}0.575^{* * * *} \\
(0.003)\end{array}$ \\
\hline Constant & $\begin{array}{c}-0.036 * * * \\
(0.000)\end{array}$ & $\begin{array}{c}-0.062 * * * \\
(0.000)\end{array}$ & $\begin{array}{l}-0.019 \\
(0.485)\end{array}$ & $\begin{array}{c}-0.031 * * \\
(0.033)\end{array}$ & $\begin{array}{l}-0.028 \\
(0.371)\end{array}$ & $\begin{array}{l}-0.022 \\
(0.733)\end{array}$ & $\begin{array}{c}1,322.681 \\
(0.526)\end{array}$ & $\begin{array}{c}0.041 \\
(0.771)\end{array}$ \\
\hline Year fixed effect & Yes & Yes & Yes & Yes & Yes & Yes & Yes & Yes \\
\hline Number of obs. & 55,372 & 55,367 & 55,234 & 25,271 & 25,223 & 24,521 & 55,312 & 55,312 \\
\hline Adjusted $\mathrm{R}^{2}$ & 0.032 & 0.011 & 0.014 & 0.006 & 0.004 & 0.003 & 0.071 & 0.078 \\
\hline
\end{tabular}




\section{Appendix Table AXII. Investors' Learning and Superstition}

In this table we report the parameter estimates from the following regression for individual investors:

$$
\begin{aligned}
& S I_{i, t}-S I_{i, t-1}=\alpha+\beta_{1} \operatorname{Ln}\left(N_{i, t-k}\right)+\beta_{2} \text { Return }_{8, i, t-1}+\beta_{3} \text { Return }_{4, i, t-1}+\beta_{4} \text { Return }_{\text {other }, i, t-1} \\
& +\beta_{5} \text { Return }_{\text {market }, i, t-1}+\beta_{6} \text { SI }_{i, t-1}+\beta_{7} \text { OrderSize }_{i, t-1}+\beta_{8} \text { SubRatio }_{0 \text { and } 5, i, t-1} \\
& +\beta_{9} \text { Disposition }_{i, t-1}+\varepsilon_{i, t}
\end{aligned}
$$

where $S I_{i, t}$ and $S I_{i, t-1}$ are the superstition indices for investor $i$ in years $t$ and $t-1$, and are calculated as the difference between limit order submission ratios at " 8 " and " 4 " in each year. We calculate the investor's submission ratio at " 8 " as the number of limit orders submitted at prices ending with " 8 " divided by the total number of limit orders submitted at all prices within a year. The submission ratio at " 4 " is calculated in a similar fashion. $\operatorname{Ln}\left(N_{i, t-k}\right)$ is the log of the number of limit orders submitted by investor $i$ in year $t-k$ ( $k$ is an integer that ranges from 1 to 3 ). Return $_{8, i, t-1}$ is the mark-to-market intraday return of limit orders submitted by investor $i$ at prices ending with " 8 " in year $t-1$. Return $n_{4, i, t-1}$ is the mark-to-market intraday return of limit orders submitted by investor $i$ at prices ending with "4" in year $t-1$. Return $_{\text {others }, i, t-1}$ is the mark-to-market intraday return of limit orders submitted by investor $i$ at prices ending with other numbers in year $t$-1. Return market $, i, t-1_{1}$ is the mark-to-market intraday return of market orders submitted by investor $i$ in year $t-1$. OrderSize $_{i, t-1}$ is the average number of contracts per limit order submitted by investor $i$ in year $t-1$. SubRatio S and $5, i, t-1_{1}$ is the sum of investor $i$ 's submission ratios at prices ending with " 0 " and " 5 " in year $t-1$. Disposition ${ }_{i, t-1}$ is the disposition effect, which is calculated as the difference between the durations of losing and winning round-trip trades of investor $i$ in year $t-1$, divided by their average. We express the superstition index in percentage. In models 1 and 4 , we require that investors submit at least 10 limit orders in each of the two consecutive years. Standard errors are adjusted for heteroskedasticity. In models 2 and 5, we require that investors must submit at least 10 limit orders in each of three consecutive years. In models 3 and 6, we require that investors submit at least 10 limit orders in each of four consecutive years. *,**, and *** indicate significance levels of $0.1,0.05$, and 0.01 , respectively. 


\begin{tabular}{|c|c|c|c|c|c|c|}
\hline \multirow{2}{*}{$\begin{array}{l}\text { Independent } \\
\text { Variables }\end{array}$} & \multicolumn{6}{|c|}{$S I_{i, t}-S I_{i, t-1}(\%)$} \\
\hline & Model 1 & Model 2 & Model 3 & Model 4 & Model 5 & Model 6 \\
\hline $\operatorname{Ln}\left(N_{i, t-1}\right)$ & $\begin{array}{c}-0.096 * * * \\
(0.000)\end{array}$ & & & $\begin{array}{c}-0.188 * * * \\
(0.000)\end{array}$ & & \\
\hline $\operatorname{Ln}\left(N_{i, t-2}\right)$ & & $\begin{array}{c}-0.075^{* * * *} \\
(0.003)\end{array}$ & & & $\begin{array}{c}-0.093 * * * \\
(0.009)\end{array}$ & \\
\hline $\operatorname{Ln}\left(N_{i, t-3}\right)$ & & & $\begin{array}{c}0.001 \\
(0.976)\end{array}$ & & & $\begin{array}{l}-0.082 \\
(0.127)\end{array}$ \\
\hline $\operatorname{Return}_{8, i, t-1}(\%)$ & & & & $\begin{array}{l}-0.103 \\
(0.343)\end{array}$ & $\begin{array}{l}-0.111 \\
(0.306)\end{array}$ & $\begin{array}{l}-0.133 \\
(0.478)\end{array}$ \\
\hline $\operatorname{Return}_{4, i, t-1}(\%)$ & & & & $\begin{array}{l}-0.052 \\
(0.602)\end{array}$ & $\begin{array}{l}-0.055 \\
(0.577)\end{array}$ & $\begin{array}{l}-0.002 \\
(0.989)\end{array}$ \\
\hline Return $_{\text {other }, i, t-1}(\%)$ & & & & $\begin{array}{c}-0.767 * * \\
(0.018)\end{array}$ & $\begin{array}{c}-0.858 * * * \\
(0.008)\end{array}$ & $\begin{array}{l}-0.692 \\
(0.185)\end{array}$ \\
\hline Return $_{\text {market }, i, t-1}(\%)$ & & & & $\begin{array}{c}0.032 \\
(0.772)\end{array}$ & $\begin{array}{c}0.020 \\
(0.856)\end{array}$ & $\begin{array}{c}0.075 \\
(0.683)\end{array}$ \\
\hline$S I_{i, t-1}(\%)$ & $\begin{array}{c}-0.434 * * * \\
(0.000)\end{array}$ & $\begin{array}{c}-0.434 * * * \\
(0.000)\end{array}$ & $\begin{array}{c}-0.391 * * * \\
(0.000)\end{array}$ & $\begin{array}{c}-0.333 * * * \\
(0.000)\end{array}$ & $\begin{array}{c}-0.333 * * * \\
(0.000)\end{array}$ & $\begin{array}{c}-0.270 * * * \\
(0.000)\end{array}$ \\
\hline OrderSize $_{i, t-1}$ & $\begin{array}{c}-0.047 * * * \\
(0.000)\end{array}$ & $\begin{array}{c}-0.049 * * * \\
(0.000)\end{array}$ & $\begin{array}{c}-0.035^{* *} \\
(0.031)\end{array}$ & $\begin{array}{l}-0.013 \\
(0.293)\end{array}$ & $\begin{array}{l}-0.019 \\
(0.125)\end{array}$ & $\begin{array}{l}-0.023 \\
(0.173)\end{array}$ \\
\hline SubRatio $_{0}$ and $5, i, t-1$ & $\begin{array}{c}-0.932 * * * \\
(0.000)\end{array}$ & $\begin{array}{c}-0.884 * * * \\
(0.000)\end{array}$ & $\begin{array}{c}-1.512 * * * \\
(0.000)\end{array}$ & $\begin{array}{l}-0.017 \\
(0.940)\end{array}$ & $\begin{array}{c}0.044 \\
(0.844)\end{array}$ & $\begin{array}{c}-0.832 * * \\
(0.011)\end{array}$ \\
\hline Disposition $_{i, t-1}$ & $\begin{array}{c}0.279 * * * \\
(0.000)\end{array}$ & $\begin{array}{c}0.276 * * * \\
(0.000)\end{array}$ & $\begin{array}{c}0.340 * * * \\
(0.000)\end{array}$ & $\begin{array}{c}0.207 * * * \\
(0.003)\end{array}$ & $\begin{array}{c}0.196 * * * \\
(0.005)\end{array}$ & $\begin{array}{l}0.204^{*} \\
(0.060)\end{array}$ \\
\hline Constant & $\begin{array}{c}2.785 * * * \\
(0.000)\end{array}$ & $\begin{array}{c}2.634 * * * \\
(0.000)\end{array}$ & $\begin{array}{c}2.392 * * * \\
(0.000)\end{array}$ & $\begin{array}{c}2.274 * * * \\
(0.000)\end{array}$ & $\begin{array}{c}1.677 * * * \\
(0.000)\end{array}$ & $\begin{array}{c}2.050 * * * \\
(0.000)\end{array}$ \\
\hline Year fixed effect & Yes & Yes & Yes & Yes & Yes & Yes \\
\hline Observations & 56,260 & 56,260 & 24,388 & 22,298 & 22,298 & 9,404 \\
\hline r2_a & 0.168 & 0.168 & 0.153 & 0.090 & 0.089 & 0.069 \\
\hline
\end{tabular}




\section{Figure A1. Limit Order Submission Ratios on Various Days of the Month}

In this figure, we report the proportion of limit orders submitted by investors on various dates in the month. The submission ratio is calculated as the number of limit orders submitted on each date of the month divided by the total number of limit orders submitted in the month. We report the figures separately for individual investors, domestic institutions, and Qualified Foreign Institutional Investors (QFIIs.)

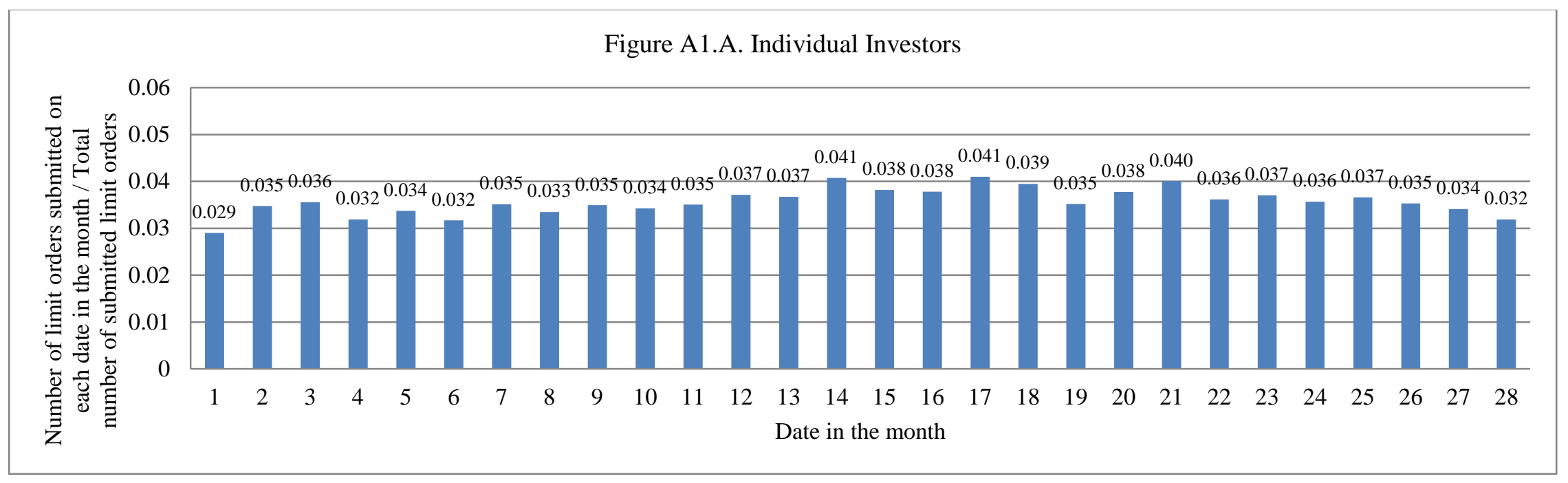



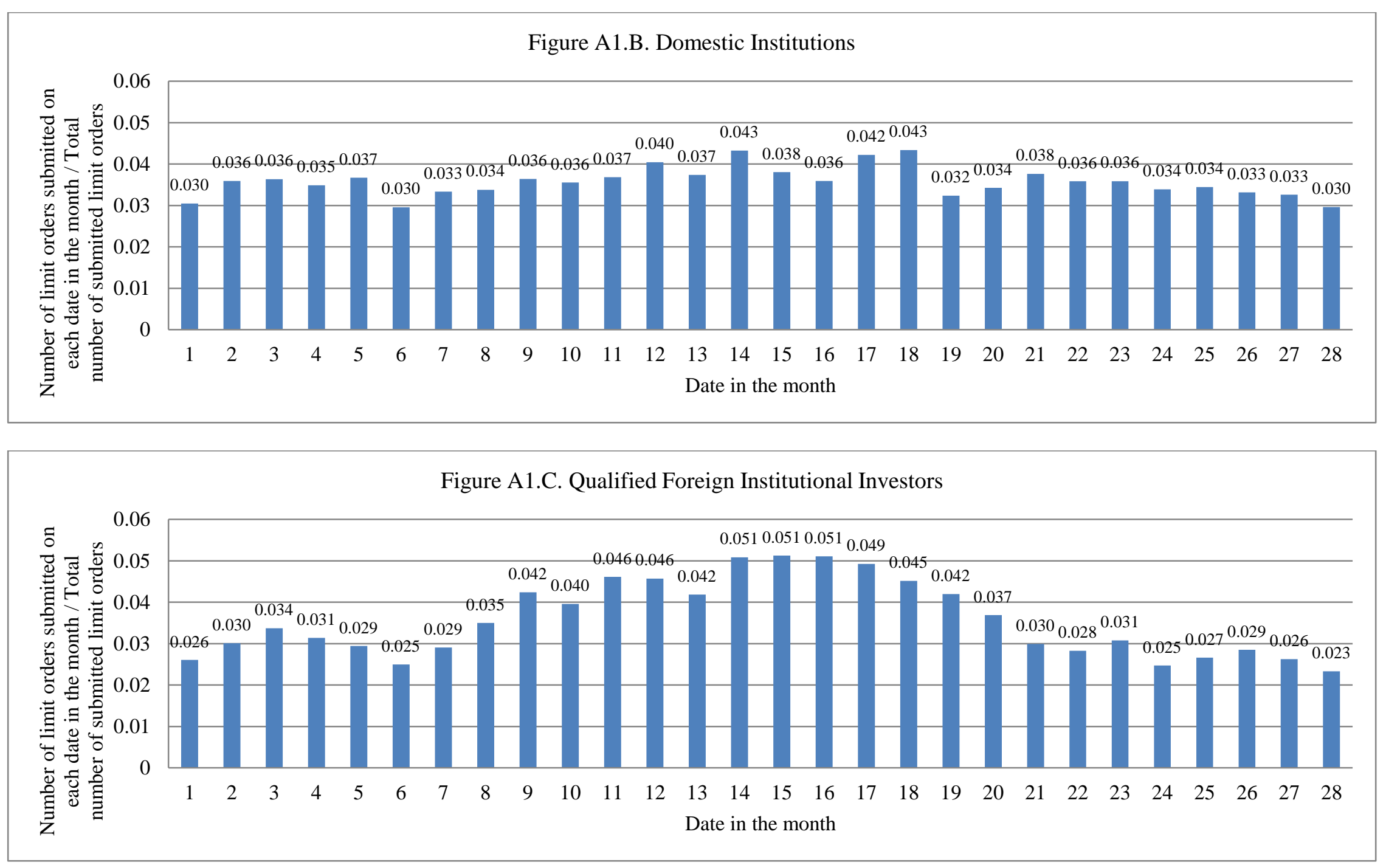


\section{Figure A2. Limit Order Submission Ratios at Various Prices for Limit Buy Orders}

In this figure, we report the proportion of limit buy orders submitted by investors at prices ending with " $\mathrm{X}$ " ( $\mathrm{X}$ is an integer ranging from 0 to 9). The submission ratio is calculated as the number of limit buy orders submitted at " $\mathrm{X}$ " divided by the total number of submitted limit buy orders. We report the figures separately for individual investors, domestic institutions, and Qualified Foreign Institutional Investors (QFIIs.)

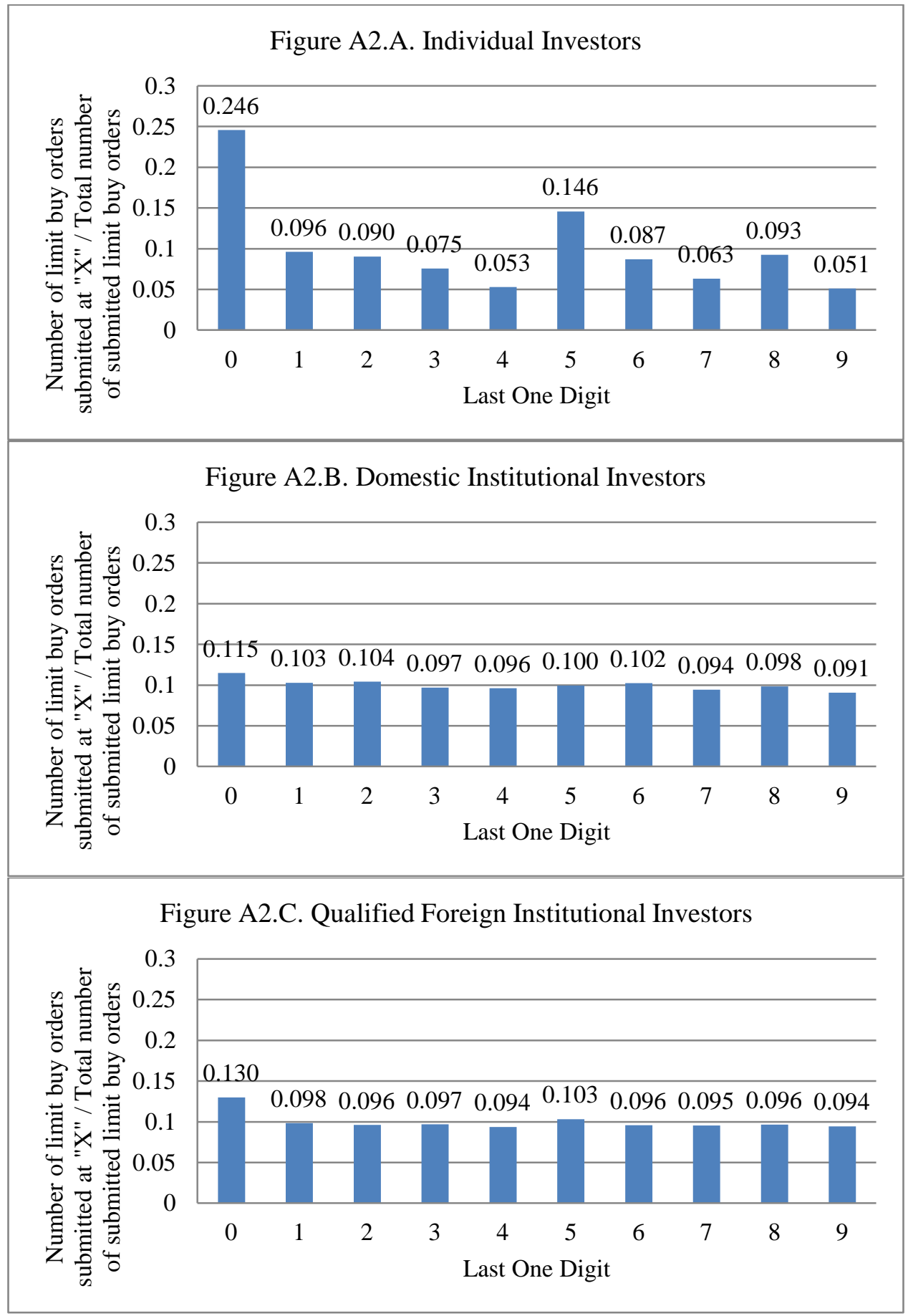




\section{Figure A3. Limit Order Submission Ratios at Various Prices for Limit Sell Orders}

In this figure, we report the proportion of limit sell orders submitted by investors at prices ending with " $\mathrm{X}$ " ( $\mathrm{X}$ is an integer ranging from 0 to 9 ). The submission ratio is calculated as the number of limit sell orders submitted at " $\mathrm{X}$ " divided by the total number of submitted limit sell orders. We report the figures separately for individual investors, domestic institutions, and Qualified Foreign Institutional Investors (QFIIs.)

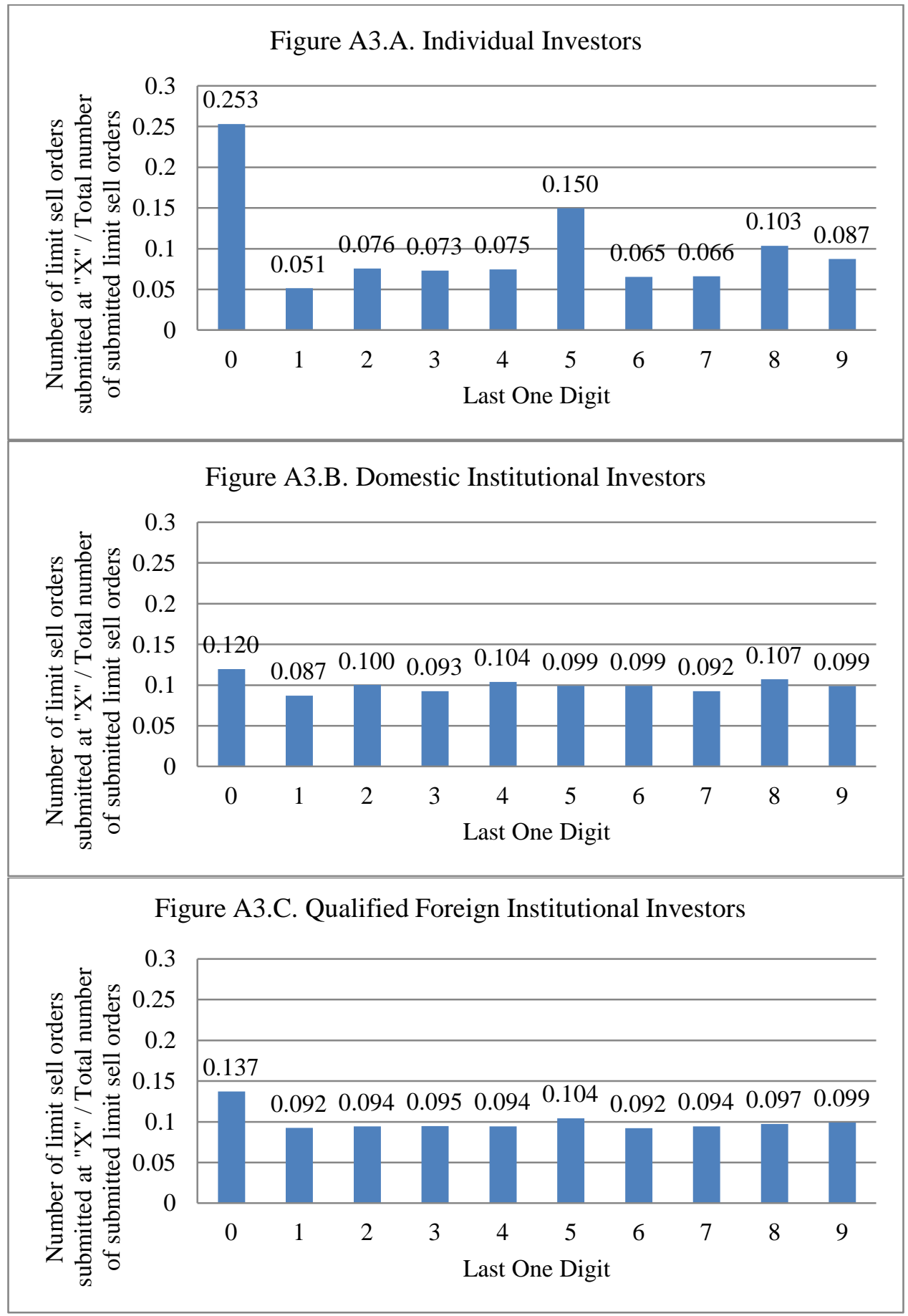




\section{Figure A4. Superstition and Intraday Returns of Limit Orders Submitted at "X"}

In this figure, we sort investors into quintiles by the superstition index in one year, and plot the mark-tomarket return of limit orders submitted at prices ending with " $\mathrm{X}$ " in the subsequent year ( $\mathrm{X}$ is an integer ranging from 0 to 9). Quintile-5 (Q5) investors are more superstitious. In each year, we calculate the superstition index for each investor as the difference between limit order submission ratios at "8" and "4." The submission ratio at " 8 " of an investor is calculated as the number of limit orders submitted at prices ending with " 8 " divided by the total number of limit orders submitted at all prices within a year. The submission ratio at "4" is calculated in a similar fashion. Mark-to-market intraday return is the difference between the trade price and the daily closing price divided by the trade price. Results for individual investors, domestic institutions, and Qualified Foreign Institutional Investors (QFIIs) are reported separately.
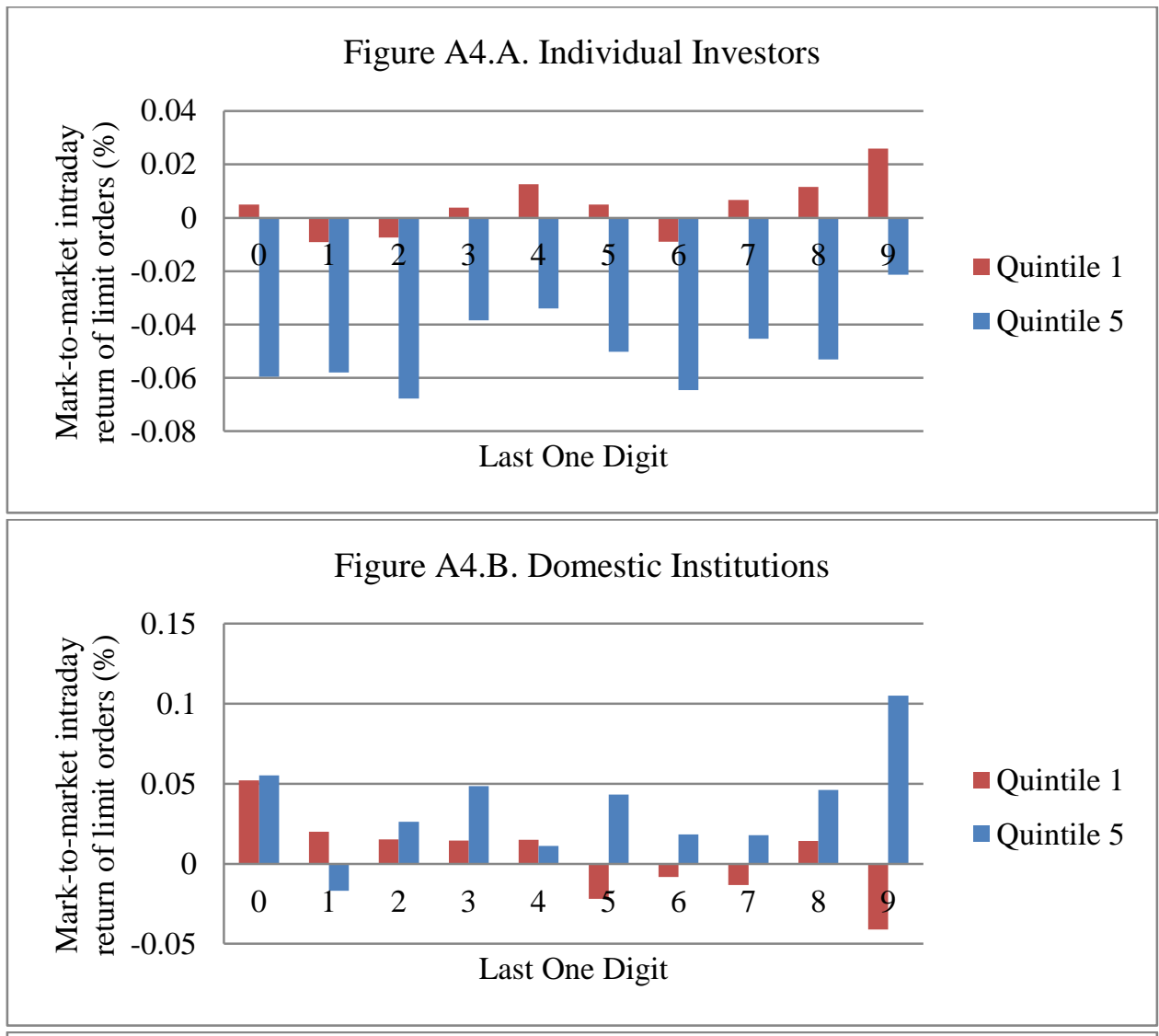

Figure A4.C. Qualified Foreign Institutional Investors

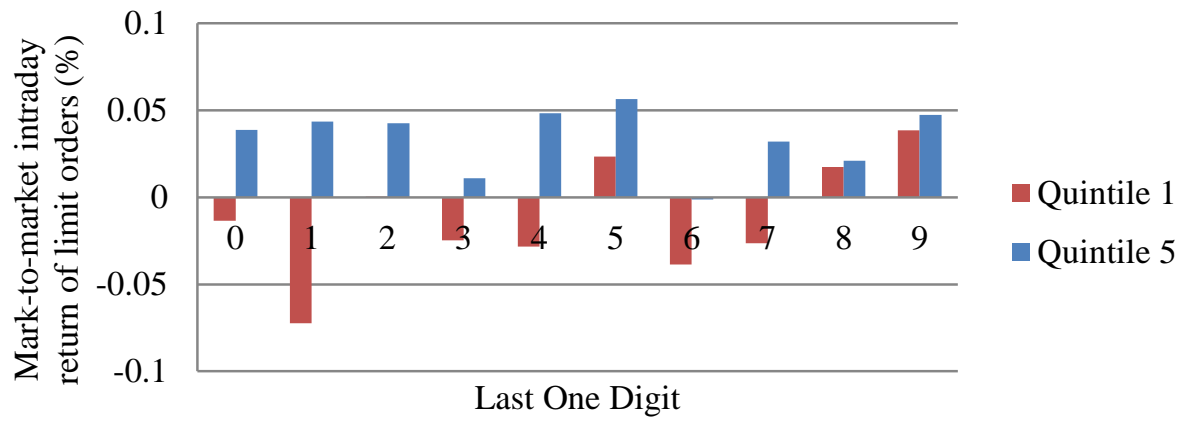




\section{Figure A5. Intraday Returns of Institutional Investors When They Pick Up Limit Orders Submitted by Individual Investors at " $X$ "}

In this figure, we plot the returns of institutional investors when they pick up the limit orders submitted by individual investors. We first sort individual investors into quintiles by the superstition index in one year, and group their limit orders in the subsequent year into ten groups according to the last digit of limit order prices. The Quintile-5 individual investors are the most superstitious. We then identify the individual limit orders that are picked up by institutional investors. The intraday mark-to-market returns of institutional investors are calculated separately for those orders that have picked up the limit orders submitted by the Quintile-5 and Quintile-1 individual investors, and for each of the last one digit. In each year, we calculate the superstition index for each investor as the difference between limit order submission ratios at " 8 " and "4." The submission ratio at " 8 " of an investor is calculated as the number of limit orders submitted at prices ending with " 8 " divided by the total number of limit orders submitted at all prices within a year. The submission ratio at " 4 " is calculated in a similar fashion. Mark-to-market intraday return of institutional investors is the difference between the trade price and the daily closing price divided by the trade price. Results for domestic institutions and Qualified Foreign Institutional Investors (QFIIs) are shown in figures A5.A and A5.B, respectively.
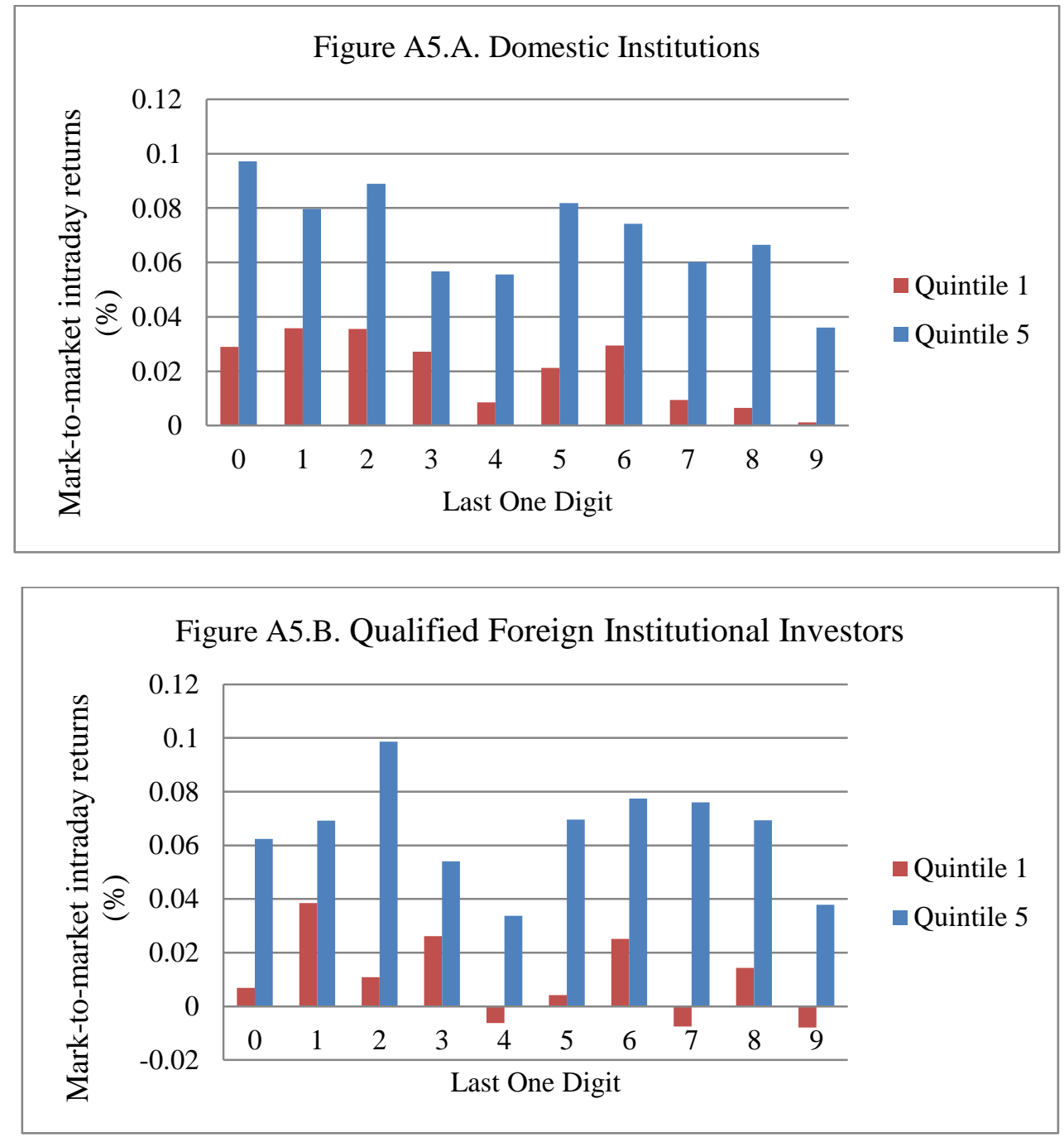